\title{
Risk factors for mortality of coronavirus disease 2019 (COVID-19) patients during the early outbreak of COVID-19: a systematic review and meta-analysis
}

\author{
Yanyan $\mathrm{Wu}^{1,2 \#}$, Hongyu Li ${ }^{1,2 \#}$, Zhongheng Zhang ${ }^{3}$, Wenhua Liang ${ }^{4}$, Tiansong Zhang ${ }^{5}$, Zhenhua Tong ${ }^{6}$, \\ Xiaozhong Guo ${ }^{1,2}$, Xingshun $\mathbf{Q i}^{1,2}$
}

${ }^{1}$ Liver Cirrhosis Study Group, Department of Gastroenterology, General Hospital of Northern Theater Command (formerly called General Hospital of Shenyang Military Area), Shenyang, China; ${ }^{2}$ Postgraduate College, Jinzhou Medical University, Jinzhou, China; ${ }^{3}$ Department of Emergency Medicine, Sir Run Run Shaw Hospital, Zhejiang University School of Medicine, Hangzhou, China; ${ }^{4}$ Department of Thoracic Oncology and Surgery, China State Key Laboratory of Respiratory Disease \& National Clinical Research Center for Respiratory Disease, the First Affiliated Hospital of Guangzhou Medical University, Guangzhou, China; ${ }^{5}$ Department of Traditional Chinese Medicine, Jing'an District Central Hospital, Shanghai, China; 'Section of Medical Service, General Hospital of Northern Command (formerly General Hospital of Shenyang Military Area), Shenyang, China

Contributions: (I) Conception and design: X Qi; (II) Administrative support: X Qi; (III) Provision of study materials or patients: Y Wu, H Li; (IV) Collection and assembly of data: Y Wu, H Li, X Guo, X Qi; (V) Data analysis and interpretation: Y Wu, H Li, Z Zhang, T Zhang, X Qi; (VI) Manuscript writing: All Authors; (VII) Final approval of manuscript: All Authors.

\#These authors contributed equally to this work.

Correspondence to: Dr. Xingshun Qi, MD. Department of Gastroenterology, General Hospital of Northern Theater Command (formerly called General Hospital of Shenyang Military Area), No. 83 Wenhua Road, Shenyang 110840, China. Email: xingshunqi@126.com.

Background: Identification of risk factors for poor prognosis of patients with coronavirus disease 2019 (COVID-19) is necessary to enable the risk stratification and modify the patient's management. Thus, we performed a systematic review and meta-analysis to evaluate the in-hospital mortality and risk factors of death in COVID-19 patients.

Methods: All studies were searched via the PubMed, Embase, Cochrane Library, China National Knowledge Infrastructure (CNKI), VIP, and Wanfang databases. The in-hospital mortality of COVID-19 patients was pooled. Odds ratios (ORs) or mean difference (MD) with 95\% confidence intervals (CIs) were calculated for evaluation of risk factors.

Results: A total of 80 studies were included with a pooled in-hospital mortality of 14\% (95\% CI: 12.215.9\%). Older age ( $\mathrm{MD}=13.32,95 \% \mathrm{CI}: 10.87-15.77 ; \mathrm{P}<0.00001)$, male (OR =1.66, 95\% CI: 1.37-2.01; $\mathrm{P}<0.00001$ ), hypertension ( $\mathrm{OR}=2.67,95 \% \mathrm{CI}: 2.08-3.43 ; \mathrm{P}<0.00001$ ), diabetes $(\mathrm{OR}=2.14,95 \% \mathrm{CI}$ : 1.76-2.6; $\mathrm{P}<0.00001)$, chronic respiratory disease (OR =3.55, 95\% CI: 2.65-4.76; $\mathrm{P}<0.00001)$, chronic heart disease/cardiovascular disease ( $\mathrm{OR}=3.15,95 \% \mathrm{CI}: 2.43-4.09 ; \mathrm{P}<0.00001)$, elevated levels of high-sensitive cardiac troponin I (MD =66.65, 95\% CI: 16.94-116.36; P=0.009), D-dimer (MD =4.33, 95\% CI: 2.97-5.68; $\mathrm{P}<0.00001)$, C-reactive protein $(\mathrm{MD}=48.03$, 95\% CI: 27.79-68.27; $\mathrm{P}<0.00001)$, and a decreased level of albumin at admission ( $\mathrm{MD}=-3.98,95 \% \mathrm{CI}:-5.75$ to $-2.22 ; \mathrm{P}<0.0001$ ) are associated with higher risk of death. Patients who developed acute respiratory distress syndrome (OR =62.85, 95\% CI: 29.45-134.15; $\mathrm{P}<0.00001$ ), acute cardiac injury ( $\mathrm{OR}=25.16,95 \% \mathrm{CI}$ : 6.56-96.44; $\mathrm{P}<0.00001)$, acute kidney injury (OR $=22.86$, 95\% CI: 4.60-113.66; $\mathrm{P}=0.0001)$, and septic shock $(\mathrm{OR}=24.09$, 95\% CI: 4.26-136.35; $\mathrm{P}=0.0003)$ might have a higher in-hospital mortality.

Conclusions: Advanced age, male, comorbidities, increased levels of acute inflammation or organ damage indicators, and complications are associated with the risk of mortality in COVID-19 patients, and should be integrated into the risk stratification system.

Keywords: Coronavirus disease 2019 (COVID-19); severe acute respiratory syndrome coronavirus 2 (SARS- 
$\mathrm{CoV}-2)$; meta-analysis; mortality; risk factors

Submitted Dec 22, 2020. Accepted for publication Mar 12, 2021.

doi: 10.21037/apm-20-2557

View this article at: http://dx.doi.org/10.21037/apm-20-2557

\section{Introduction}

According to the World Health Organization, a novel pneumonia caused by severe acute respiratory syndrome coronavirus 2 (SARS-CoV-2, previously known as $2019-\mathrm{nCoV})$ is designated as coronavirus disease 2019 (COVID-19) (1). SARS-CoV-2 belongs to the coronavirus family together with SARS-CoV and Middle East respiratory syndrome coronavirus (MERS-CoV), but has more rapid transmission than SARS-CoV and MERS$\mathrm{CoV}(2-4)$, which leads to a dramatic increase in the number of confirmed cases during a short period, thereby posing a serious threat for health systems worldwide. Till August 4, 2020, a cumulative total of 18,142,718 confirmed COVID-19 cases and 691,013 deaths have been reported in 216 countries (5).

Fever and cough are main clinical manifestations of COVID-19 patients (6). Most of COVID-19 patients have a favorable outcome, but a minority of them may develop severe pneumonia, dyspnea and hypoxemia, and progress into respiratory or multi-organ failure and even death (7). Based on 55,924 laboratory confirmed cases in China, the overall national mortality rate is $3.8 \%$, but the fatality rate of patients over 80 years old is up to $22 \%$ (8). Besides, male, pre-existing comorbidities, elevated inflammatory markers, and complications [i.e., acute respiratory distress syndrome (ARDS), acute cardiac injury, acute kidney injury and sepsis] were associated with an increased risk of death (9-15).

In the early stages of COVID-19 outbreak, because effective vaccines and antiviral drugs for SARS-CoV-2 are lacking, the management of critically ill patients is often challenging. Thus, it is very essential to identify the risk factors associated with poor outcome of COVID-19 patients and perform early interventions for high-risk patients. The present study aimed to systematically review the evidence on the in-hospital mortality of COVID-19 patients and elucidate the risk factors of mortality in COVID-19 patients.

\section{Methods}

This meta-analysis was conducted based on Meta-analysis Of Observational Studies in Epidemiology (MOOSE) guidelines and results were reported according to the Preferred Reporting Items for Systematic Reviews and Meta-Analyses (PRISMA) statement (available at http:// dx.doi.org/10.21037/apm-20-2557).

\section{Registration}

This study was registered at PROSPERO (registration number: CRD42020169921).

\section{Search strategy}

All relevant studies regarding mortality of COVID-19 patients were retrieved via the PubMed, Embase, Cochrane Library, China National Knowledge Infrastructure (CNKI), VIP, and Wanfang databases. The search terms were ("2019-nCoV” OR "SARS-CoV-2" OR "COVID-19" OR "new coronary pneumonia" OR "corona virus" OR "novel coronavirus" OR " $\mathrm{nCoV}$ " OR "severe acute respiratory syndrome coronavirus 2") AND ("death" OR "died" OR "die" OR "mortality" OR "survival" OR "survivor" OR "fatal" OR "outcome" OR "decease" OR "deadly" OR "lethal" OR "fatality"). The last search was performed on May 26, 2020.

\section{Study selection}

There was neither publication language nor publication status restriction. All eligible studies should report the mortality and/or risk factors for death in COVID-19 patients. Exclusion criteria were as follows: (I) duplicates; (II) case reports, reviews or meta-analyses, guidelines, consensus, experimental or animal studies, comments, notes, and correspondences; (III) irrelevant papers; (IV) data regarding the mortality and/or risk factors cannot 
be extracted; and (V) duplicate study population. As for duplicate studies, we selected only one original study with more comprehensive clinical and laboratory data. Casecontrol studies were excluded from the proportion metaanalyses regarding mortality of COVID-19 patients due to their potential patient selection bias.

\section{Data extraction}

The following data were extracted from the included studies: the first author, publication year, region, source of cases, enrollment period, follow-up periods, number of COVID-19 patients, number of COVID-19 patients with severe disease, number of non-survivors and survivors, age, gender, and other potential risk factors for death.

\section{Study quality}

The Newcastle-Ottawa Scale (NOS) was used to assess the quality of included studies. It includes study selection (four items), comparability (two items), and exposure/outcome (three items). The highest NOS score was 9, and studies with a NOS score of $>6$ were considered as high quality.

\section{Statistical analysis}

All meta-analyses were performed using STATA version 12.0 (Stata Corp., College Station, Texas, USA) and Review Manager software version 5.4 (Cochrane collaboration, the Nordic Cochrane Centre, Copenhagen, Denmark). The meta-analyses were conducted by using a random-effect model. We pooled the in-hospital mortality in COVID-19 patients, and then calculated the pooled proportion with 95\% confidence interval (CI). We collected the risk factors for death in COVID-19 patients, and then calculated the odds ratios (ORs) or mean difference (MD) with $95 \%$ CIs. The heterogeneity among studies was evaluated by Cochrane Q test and the $\mathrm{I}^{2}$ statistics, and $\mathrm{I}^{2}>50 \%$ and/ or $\mathrm{P}<0.1$ were considered to have statistically significant heterogeneity. Publication bias was assessed with Egger test. $\mathrm{P}<0.1$ was considered as a statistically significant publication bias. Subgroup analyses, meta-regression analyses, and sensitivity analyses would be performed to explore the sources of heterogeneity among studies. Subgroup analyses were conducted according to the sample size $(>100$ versus $\leq 100$ ), source of cases (single-center versus multiplecenter), NOS ( $>6$ versus $\leq 6$ ), region (Asia versus Europe versus North America), study design (retrospective versus prospective), longest follow-up duration ( $>30$ days versus $\leq 30$ days), and proportion of patients with severe disease ( $>50 \%$ versus $\leq 50 \%$ ). Meta-regression analyses were also grouped in terms of the variables mentioned above. Scattered plots were drawn to show the trend in overall inhospital mortality according to the proportion of severe COVID-19 patients included. The correlation between them was evaluated using Spearman correlation analysis in the IBM SPSS 22.0 (IBM Corp, Armonk, NY, USA). Coefficients were calculated. A two-sided $\mathrm{P}<0.05$ indicates a statistical significance.

\section{Results}

\section{Study selection}

A total of 7,003 studies were identified via the 6 databases, and 6 studies were identified via a manual search. Finally, 80 studies with 25,385 COVID-19 patients were included (Figure 1). All included studies are listed in the Appendix.

\section{Study characteristics}

Characteristics of the included studies were listed in Table 1. Forty-three studies were published as full texts, 32 was published in press (i.e., available online ahead of print), and 5 studies were preprinted. The sample size ranged from 8 to 2,964. Sixty-one studies were performed in Asia, 11 in Europe, and 8 in North America; 72 of them were retrospective and 8 were prospective; 56 and 24 studies were single-center and multi-center studies, respectively.

\section{Study quality}

The NOS score ranged between 3 and 8. Twenty-two studies were considered to be of high quality and 3 were of low quality (Table S1).

\section{Mortality}

The results of the meta-analyses regarding in-hospital mortality of COVID-19 patients are summarized in Table 2.

\section{Overall analyses}

Eighty studies reported the in-hospital mortality of COVID-19 patients, and the pooled in-hospital mortality of COVID-19 patients was 14\% (95\% CI: $12.2-15.9 \%$ ). The heterogeneity was statistically significant $\left(\mathrm{I}^{2}=97.8 \%\right.$; 


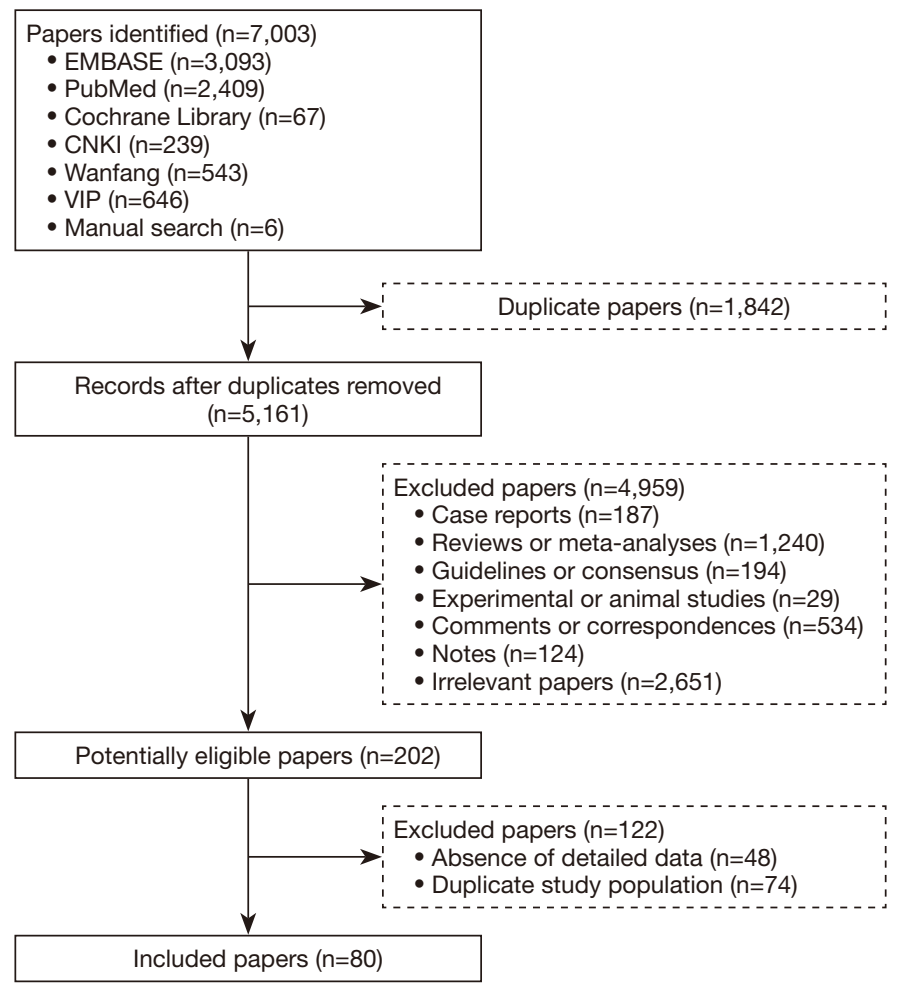

Figure 1 Flow chart of study selection.

$\mathrm{P}<0.001)$. Fifty studies reported the number of severe COVID-19 patients, and the pooled incidence of severe COVID-19 patients was 49.6\% (95\% CI: 43.6-55.6\%). The heterogeneity was statistically significant $\left(\mathrm{I}^{2}=99.9 \%\right.$; $\mathrm{P}<0.001)$.

\section{Subgroup analyses}

The pooled in-hospital mortality of COVID-19 patients was $10.1 \%, 23.7 \%$, and $25.4 \%$ in Asia, Europe, and North America, respectively. The pooled in-hospital mortality of COVID-19 patients was $13.7 \%$ and $15.2 \%$ in studies with a sample size of $>100$ and $\leq 100$, respectively. The pooled in-hospital mortality of COVID-19 patients was $14.2 \%$ and $13.6 \%$ in single-center and multiple-center studies, respectively. The pooled in-hospital mortality of COVID-19 patients was $13.6 \%$ and $18 \%$ in retrospective and prospective studies, respectively. The pooled inhospital mortality of COVID-19 patients was the same between the studies with NOS $>6$ and NOS $\leq 6$ (both 14\%). The pooled in-hospital mortality of COVID-19 patients was $15.1 \%$ and $17.3 \%$ in studies with the longest followup duration of $>30$ days and $\leq 30$ days, respectively. The pooled in-hospital mortality of COVID-19 patients was $22.5 \%$ and $7.7 \%$ in studies with the proportion of patients with severe disease of $>50 \%$ and $\leq 50 \%$, respectively. The heterogeneity was statistically significant in all subgroup analyses.

\section{Meta-regression analyses}

The results of meta-regression analyses are shown in Table S2. Meta-regression analyses indicated that region (Asia versus Europe versus North America) ( $\mathrm{P}=0.0001$ ), proportion of patients with severe disease $(>50 \%$ versus $\leq 50 \%)(\mathrm{P}<0.001)$, rather than sample size $(>100$ versus $\leq 100)(\mathrm{P}=0.456)$, source of cases (single-center versus multiple-center) $(\mathrm{P}=0.756)$, NOS $(>6$ versus $\leq 6)(\mathrm{P}=0.956)$, study design (retrospective versus prospective) $(\mathrm{P}=0.403)$, and longest follow-up duration ( $>30$ versus $\leq 30$ days) $(\mathrm{P}=0.624)$, might be related to the heterogeneity.

\section{Sensitivity analyses}

The sensitivity analysis showed that none of these included studies could significantly influence the results of the metaanalysis. 


\begin{tabular}{|c|c|c|c|c|c|c|c|c|c|c|c|c|}
\hline \multirow{2}{*}{ First author (year) } & \multirow{2}{*}{ Country } & \multirow{2}{*}{ Source of cases } & \multirow{2}{*}{ Enrollment period } & \multirow{2}{*}{$\begin{array}{l}\text { Longest follow-up } \\
\text { periods }\end{array}$} & \multirow{2}{*}{$\begin{array}{l}\text { No. of severe } \\
\text { patients (\%) }\end{array}$} & \multirow{2}{*}{$\begin{array}{c}\text { Sample } \\
\text { size }\end{array}$} & \multicolumn{3}{|c|}{ Non-survivors } & \multicolumn{3}{|c|}{ Survivors } \\
\hline & & & & & & & $\mathrm{N}(\%)$ & Age, years ${ }^{a}$ & Male (\%) & $\mathrm{N}(\%)$ & Age, years ${ }^{a}$ & Male (\%) \\
\hline Aggarwal S [2020] & United States & UnityPoint Clinic & 2020.03.01-2020.04.04 & NA & NA & 16 & $3(18.8)$ & NA & NA & $13(81.3)$ & NA & NA \\
\hline Barrasa $\mathrm{H}[2020]$ & Spain & University Hospital Araba & 2020.03.04-2020.03.31 & 33 days & $48(100.0)$ & 48 & $14(29.2)$ & NA & NA & $34(70.8)$ & NA & NA \\
\hline Benussi A [2020] & Italy & ASST Spedali Civili di Brescia Hospital & 2020.02.21-2020.04.05 & NA & NA & 56 & $21(37.5)$ & NA & NA & $35(62.5)$ & NA & NA \\
\hline Bhatraju PK [2020] & United States & Nine hospital in the Seattle & 2020.02.24-2020.03.09 & 28 days & $24(100.0)$ & 24 & $12(50.0)$ & NA & NA & $12(50.0)$ & NA & NA \\
\hline Bianchetti A [2020] & Italy & Acute Hospital in Brescia Province, Northern Italy & NA & NA & NA & 627 & $194(30.9)$ & NA & NA & $433(69.1)$ & NA & NA \\
\hline Borghesi A [2020] & Italy & Radiological Sciences and Public Health, University of Brescia & 2020.03.04-2020.03.24 & NA & NA & 302 & $65(21.5)$ & 77 [70.5-81] & $50(76.9)$ & $237(78.5)$ & 64 [54-73.3] & $144(60.8)$ \\
\hline Buckner FS [2020] & United States & Three University of Washington affiliated hospitals & 2020.03.02-2020.03.26 & 67 days & $51(48.6)$ & 105 & $35(33.3)$ & NA & NA & $70(66.7)$ & NA & NA \\
\hline Cai Q [2020] & China & Third People's Hospital of Shenzhen & 2020.01.11-2020.02.06 & 55 days & $58(19.5)$ & 298 & $3(1.0)$ & NA & NA & $295(99.0)$ & NA & NA \\
\hline Cecconi M [2020] & Italy & Humanitas Research Hospital & 2020.02.22-2020.03.22 & 32 days & $27(11.3)$ & 239 & $36(15.1)$ & NA & NA & $203(84.9)$ & NA & NA \\
\hline Chen R [2020] & China & 575 hospitals in China & As of January 31,2020 & NA & NA & 1590 & $50(3.1)$ & 68 [51-86] & $39 / 50(78.0)$ & $1,540(96.9)$ & $48[1-94]$ & $865 / 1,528(56.6)$ \\
\hline Andrea C [2020] & Italy & San Raffaele Hospital & 2020.02.27-2020.03.17 & 42 days & NA & 191 & $42(22.0)$ & $75.3 \pm 12.9$ & $31(73.8)$ & $149(78.0)$ & $60.4 \pm 13.7$ & $100(67.1)$ \\
\hline Cummings MJ [2020] & United States & Milstein Hospital and Allen Hospital & 2020.03.02-2020.04.01 & 57 days & $257(100.0)$ & 257 & $101(39.3)$ & NA & NA & $156(60.7)$ & NA & NA \\
\hline Deng Y [2020] & China & Hankou and Caidian branch of Tongji Hospital, and Hankou branch of Central Hospital of Wuhan & 2020.01.01-2020.02.21 & NA & $104(10.8)$ & 964 & $109(11.3)$ & $69[62-74]$ & $73(67.0)$ & $855(88.7)$ & NA & NA \\
\hline Dong XC [2020] & China & Designated hospitals in Tianjin & NA & NA & $62(45.9)$ & 135 & $3(2.2)$ & NA & NA & $132(97.8)$ & NA & NA \\
\hline Du RH [2020] & China & Wuhan Pulmonary Hospital & 2019.12.25-2020.02.07 & 90 days & NA & 179 & $21(11.7)$ & $70.2 \pm 7.7$ & $10(47.6)$ & $158(88.3)$ & $56.0 \pm 13.5$ & $87(55.1)$ \\
\hline Gao L [2020] & China & Hubei General Hospital & NA & 15 days & $54(100.0)$ & 54 & $18(33.3)$ & NA & NA & $36(66.7)$ & NA & NA \\
\hline Guo T [2020] & China & Seventh Hospital of Wuhan & 2020.01.23-2020.02.23 & 33 days & NA & 187 & $43(23.0)$ & NA & NA & $144(77)$ & NA & NA \\
\hline Hong KS [2020] & South Korea & Yeungnam University Medical Center & As of March 29, 2020 & NA & NA & 98 & $5(5.1)$ & NA & NA & $93(94.9)$ & NA & NA \\
\hline Hou W [2020] & China & Beijing YouAn Hospital & 2020.01.21-2020.03.09 & NA & $22(21.8)$ & 101 & $5(5.0)$ & NA & NA & $96(95.0)$ & NA & NA \\
\hline Hu H [2020] & China & Renmin Hospital of Wuhan University (Sichuan Medical Team) & 2020.02.07-2020.03.07 & NA & $105(100.0)$ & 105 & $19(18.1)$ & $75.05 \pm 12.94$ & $14(73.7)$ & $86(81.9)$ & $57.71 \pm 15.34$ & $48(55.8)$ \\
\hline Hu L [2020] & China & Tianyou Hospital in Wuhan & 2020.01.08-2020.02.20 & 62 days & $172(53.3)$ & 323 & $35(10.8)$ & NA & NA & $288(89.2)$ & NA & NA \\
\hline Huang J [2020] & China & Third People's Hospital of Yichang & 2020.01.25-2020.03.24 & NA & NA & 299 & $16(5.4)$ & $69.2 \pm 9.7$ & $11(68.8)$ & $283(94.6)$ & $52.5 \pm 16.6$ & $149(52.7)$ \\
\hline Inciardi RM [2020] & Italy & Civil Hospitals of Brescia & 2020.03.04-2020.03.25 & 14 days & NA & 99 & $26(26.3)$ & NA & NA & $73(73.7)$ & NA & NA \\
\hline Israelsen SB [2020] & Denmark & Hvidoure Hospital & 2020.03.10-2020.04.23 & 41 days & NA & 175 & $43(24.6)$ & NA & NA & $132(75.4)$ & NA & NA \\
\hline Itelman E [2020] & Israel & Sheba Medical Center & 2020.02.01-2020.04.10 & NA & $26(16.0)$ & 162 & $5(3.1)$ & NA & NA & $157(96.9)$ & NA & NA \\
\hline Javanian M [2020] & Iran & Ayatollah Rohani, Shahid Beheshti and Yahyanejad hospitals & 2020.02.25-2020.03.12 & 21 days & NA & 100 & $19(19.0)$ & $69.26 \pm 11.10$ & $12(63.2)$ & $81(81.0)$ & $57.74 \pm 13.58$ & $39(48.1)$ \\
\hline Ji D [2020] & China & Fuyang Second People's Hospital and Fifth Medical Center of Chinese PLA General Hospital & 2020.01.20-2020.02.22 & 58 days & $0(0)$ & 208 & $2(1.0)$ & NA & NA & $206(99.0)$ & NA & NA \\
\hline Klang E cohort1 [2020] & United States & $\begin{array}{l}\text { Mount Sinai Hospital, Mount Sinai Brooklyn, Mount Sinai Queens, Mount Sinai Morningside and } \\
\text { Mount Sinai West }\end{array}$ & 2020.03.01-2020.05.17 & NA & NA & 572 & $60(10.5)$ & 46.5 [42.8-49] & $45(75.0)$ & $512(89.5)$ & 40 [34-46] & $352(68.8)$ \\
\hline Klang E cohort2 [2020] & United States & $\begin{array}{l}\text { Mount Sinai Hospital, Mount Sinai Brooklyn, Mount Sinai Queens, Mount Sinai Morningside and } \\
\text { Mount Sinai West }\end{array}$ & 2020.03.01-2020.05.17 & NA & NA & 2,834 & $1,076(38.0)$ & 76 [67-84] & $615(57.2)$ & $1,758(62.0)$ & $68[60-77]$ & $949(54.0)$ \\
\hline Li J [2020] & China & Central Hospital of Wuhan & 2020.01.15-2020.03.15 & NA & $173(47.8)$ & 362 & $77(21.3)$ & 72 [64.5-82] & $50(64.9)$ & $285(78.7)$ & $65[57.5-71]$ & $139(48.7)$ \\
\hline Li R [2020] & China & Hanchuan City People's Hospital & 2020.01.20-2020.02.14 & 40 days & $37(16.4)$ & 225 & $2(0.9)$ & NA & NA & $223(99.1)$ & NA & NA \\
\hline LiX [2020] & China & Designated hospitals in Guizhou & 2020.01.20-2020.02.12 & NA & NA & 135 & $1(0.7)$ & NA & NA & $134(99.3)$ & NA & NA \\
\hline
\end{tabular}

Table 1 (continued) 
Table $\mathbf{1}$ (continued)

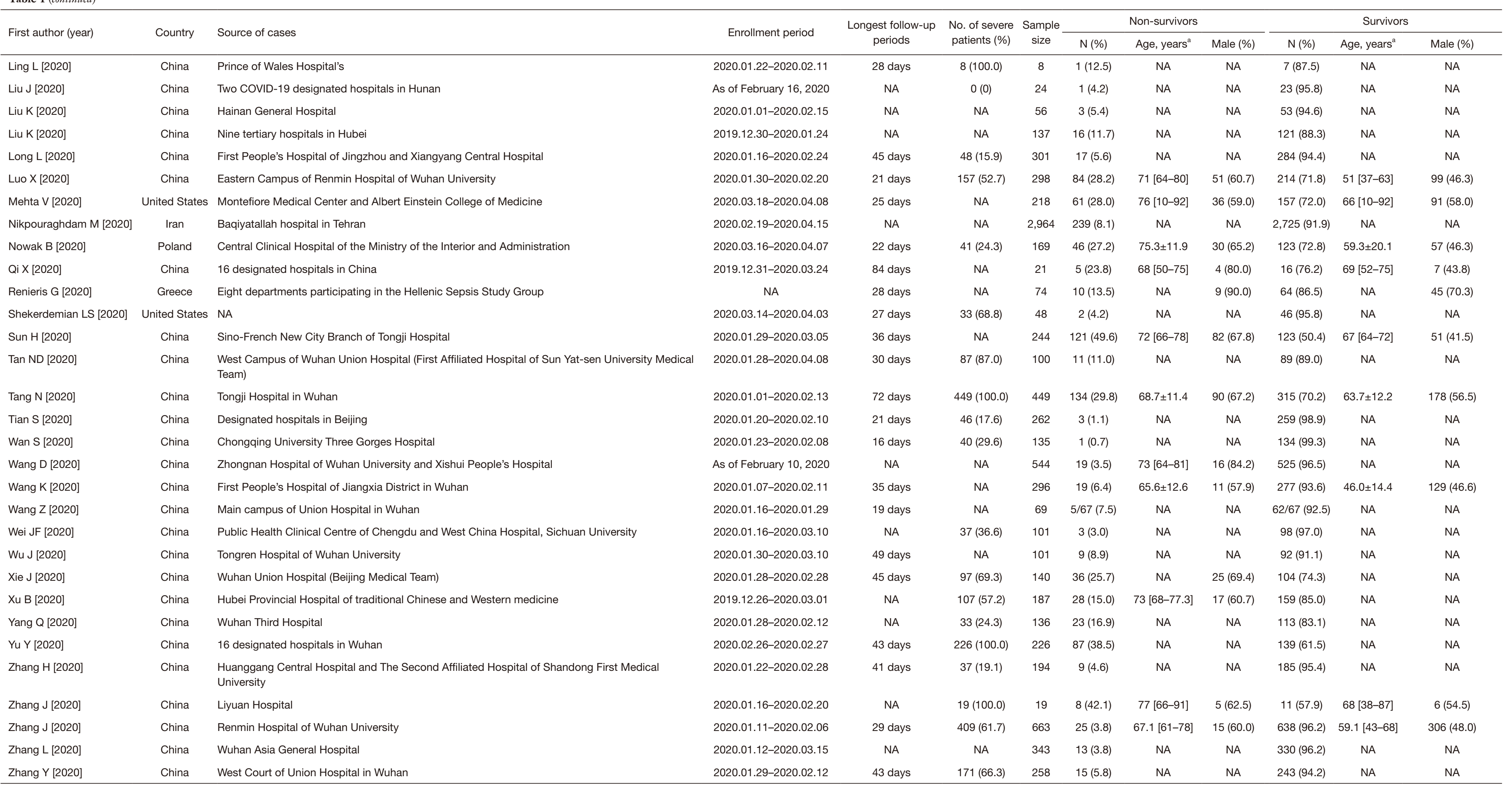




\begin{tabular}{|c|c|c|c|c|c|c|c|c|c|c|c|c|}
\hline \multirow{2}{*}{ First author (year) } & \multirow{2}{*}{ Country } & \multirow{2}{*}{ Source of cases } & \multirow{2}{*}{ Enrollment period } & \multirow{2}{*}{$\begin{array}{l}\text { Longest follow-up } \\
\text { periods }\end{array}$} & \multirow{2}{*}{$\begin{array}{l}\text { No. of severe } \\
\text { patients (\%) }\end{array}$} & \multirow{2}{*}{$\begin{array}{c}\text { Sample } \\
\text { size }\end{array}$} & \multicolumn{3}{|c|}{ Non-survivors } & \multicolumn{3}{|c|}{ Survivors } \\
\hline & & & & & & & $\mathrm{N}(\%)$ & Age, years ${ }^{a}$ & Male (\%) & $N(\%)$ & Age, years ${ }^{\mathrm{a}}$ & Male (\%) \\
\hline Zhang YT [2020] & China & Designated hospitals in Guangdong & 2020.01.15-2020.03.04 & 69 days & $222(16.4)$ & 1,350 & $8(0.6)$ & NA & NA & $1,342(99.4)$ & NA & NA \\
\hline Zhao XY [2020] & China & Jingzhou Central Hospital & 2020.01.16-2020.02.10 & 25 days & $30(33.0)$ & 91 & $2(2.2)$ & NA & NA & $89(97.8)$ & NA & NA \\
\hline Zhou F [2020] & China & Jinyintan Hospital and Wuhan Pulmonary Hospital & 2019.12.29-2020.01.31 & 33 days & $119(62.3)$ & 191 & $54(28.3)$ & $69[63-76]$ & $38(70.4)$ & $137(71.7)$ & $52[45-58]$ & $81(59.1)$ \\
\hline Zhou X [2020] & China & Wuhan Fourth Hospital & 2020.01.25-2020.02.20 & NA & NA & 110 & $9(8.2)$ & NA & NA & $101(91.8)$ & NA & NA \\
\hline An W [2020] & China & Hubei No. 3 People's Hospital & 2020.01.24-2020.02.19 & NA & $15(13.6)$ & 110 & $11(10.0)$ & $72.4 \pm 7.1$ & $6(54.5)$ & $99(90.0)$ & $54.6 \pm 15.6$ & $38(38.4)$ \\
\hline Chang Z [2020] & China & Wuhan Puren Hospital & 2020.01-2020.02 & NA & $57(38.0)$ & 150 & $20(13.3)$ & NA & NA & $130(86.7)$ & NA & NA \\
\hline Foy BH [2020] & United States & $\begin{array}{l}\text { Massachusetts General Hospital, Brigham and Women's Hospital, North Shore Medical Center and } \\
\text { Newton-Wellesley Hospital }\end{array}$ & 2020.03.04-2020.04.28 & 55 days & NA & 1,198 & 155 (12.9) & $75 \pm 13.2$ & $98(63.2)$ & $1,043(87.1)$ & $59.6 \pm 17.5$ & $563(54.0)$ \\
\hline Guo F [2020] & China & First Affiliated Hospital of Bengbu Medical College & 2020.01.22-2020.03.08 & NA & $31(39.2)$ & 79 & $5(6.3)$ & NA & NA & $72(91.1)$ & NA & NA \\
\hline Li JW [2020] & China & Wuhan Red Cross Hospital in Wuhan & 2020.01.21-2020.02.14 & 24 days & NA & 161 & $65(40.4)$ & $67[31-87]$ & $42(64.6)$ & $96(59.6)$ & 46 [22-87] & $38(39.6)$ \\
\hline Luo M [2020] & China & Wuhan Tongren Hospital of Wuhan University (Wuhan Third Hospital) & 2020.01.17-2020.02.25 & NA & $152(11.6)$ & 1,305 & $69(5.3)$ & NA & $46(66.7)$ & $1,236(94.7)$ & NA & NA \\
\hline Fang XW [2020] & China & Infectious Hospital of Anhui Provincial Hospital & 2020.01.22-2020.02.18 & 27 days & $24(30.4)$ & 79 & $1(1.3)$ & NA & NA & $78(98.7)$ & NA & NA \\
\hline Yang $\mathrm{H}[2020]$ & China & Sino-French Eco-City section of Tongji Hospital (Peking University Supporting Medical Team) & 2020.01.29-2020.03.10 & 68 days & $19(20.2)$ & 94 & $13(13.8)$ & 77 [67.5-83] & $8(61.5)$ & $81(86.2)$ & $66[59.0-72.5]$ & $37(45.7)$ \\
\hline Yang JK [2020] & China & Wuhan Union Hospital (Beijing Tongren Hospital Medical Team) & 2020.01.29-2020.03.20 & 55 days & $46(66.7)$ & 69 & $16(23.2)$ & 64 [57-68] & $13(81.3)$ & $53(76.8)$ & $60[51-67]$ & $21(39.6)$ \\
\hline Zhang CS [2020] & China & Dabieshan Medical Center & 2020.01.30-2020.02.14 & NA & $32(100.0)$ & 32 & $6(18.8)$ & $59.3 \pm 11.1$ & $3(50.0)$ & $26(81.3)$ & $57.9 \pm 12.4$ & $17(65.4)$ \\
\hline Zhang F [2020] & China & Wuhan No.1 Hospital & 2019.12.25-2020.01.15 & NA & $22(45.8)$ & 48 & 17 (35.4) & $78.65 \pm 8.31$ & $12(70.6)$ & 31 (64.6) & $66.16 \pm 13.66$ & $21(67.7)$ \\
\hline Zhang JG [2020] & China & $\begin{array}{l}\text { The First People's Hospital of Jiangxia District (The Affiliated Hospital of Jiangsu University Medical } \\
\text { Team) }\end{array}$ & 2020.02.01-2020.03.15 & NA & $30(22.2)$ & 135 & $18(13.3)$ & $65[56.8-76.8]$ & $9(50.0)$ & $117(86.7)$ & NA & NA \\
\hline
\end{tabular}

, age data presented as median (interquartile range), mean (standard deviation) or median (range). 
Table 2 Mortality of COVID-19 patients: results of meta-analyses

\begin{tabular}{|c|c|c|c|c|c|c|}
\hline \multirow{2}{*}{ Groups } & \multirow{2}{*}{ No. studies } & \multirow{2}{*}{ Range } & \multirow{2}{*}{$\begin{array}{l}\text { Pooled proportion using random- } \\
\text { effects model }\end{array}$} & \multicolumn{2}{|c|}{ Heterogeneity } & \multirow{2}{*}{$\begin{array}{c}\text { Publication bias: } 95 \% \mathrm{Cl} \text {; } \\
\mathrm{P}_{\text {egger: bias }}\end{array}$} \\
\hline & & & & $\mathrm{I}^{2}$ & $\mathrm{P}$ & \\
\hline Overall mortality & 79 & $0.6-50 \%$ & 0.140 (95\% Cl: 0.122-0.159) & $97.80 \%$ & $<0.001$ & $3.896-7.253 ;<0.001$ \\
\hline \multicolumn{7}{|l|}{ Sample size } \\
\hline$>100$ & 54 & $0.6-40.4 \%$ & 0.137 (95\% Cl: 0.115-0.158) & $98.40 \%$ & $<0.001$ & $5.011-9.934 ;<0.001$ \\
\hline \multicolumn{7}{|l|}{ Region } \\
\hline Asia & 61 & $0.6-50 \%$ & 0.101 (95\% Cl: 0.086-0.115) & $95.60 \%$ & $<0.001$ & $3.477-5.847 ;<0.001$ \\
\hline Europe & 11 & $13.5-37.5 \%$ & 0.237 (95\% Cl: 0.197-0.276) & $77.80 \%$ & $<0.001$ & -4.227 to $4.729 ; 0.902$ \\
\hline North America & 7 & $4.2-39.3 \%$ & 0.254 (95\% Cl: 0.150-0.359) & $98.60 \%$ & $<0.001$ & -15.421 to $14.102 ; 0.917$ \\
\hline Multiple-center & 24 & $0.6-50 \%$ & 0.136 (95\% Cl: 0.099-0.173) & $98.90 \%$ & $<0.001$ & $2.029-11.399 ; 0.007$ \\
\hline \multicolumn{7}{|l|}{ Study quality } \\
\hline NOS $>6$ & 21 & $0.7-35.4 \%$ & 0.140 (95\% Cl: 0.106-0.174) & $93.70 \%$ & $<0.001$ & $2.264-6.298 ;<0.001$ \\
\hline NOS $\leq 6$ & 58 & $0.6-50 \%$ & 0.140 (95\% Cl: 0.118-0.162) & $98.30 \%$ & $<0.001$ & $3.866-8.353 ;<0.001$ \\
\hline \multicolumn{7}{|l|}{ Study design } \\
\hline Retrospective & 71 & $0.6-50 \%$ & 0.136 (95\% Cl: 0.117-0.156) & $97.90 \%$ & $<0.001$ & $3.594-7.186 ;<0.001$ \\
\hline Prospective & 8 & $0.7-39.3 \%$ & 0.180 (95\% Cl: 0.093-0.267) & $97.80 \%$ & $<0.001$ & $3.937-15.797 ; 0.007$ \\
\hline \multicolumn{7}{|l|}{ Longest follow-up } \\
\hline
\end{tabular}

NOS, Newcastle-Ottawa scale.

\section{Risk factors}

A total of 31 studies reported the detailed data regarding the association of demographic and clinical characteristics, laboratory data, imaging features, and complications with mortality of COVID-19 patients, of which 25 performed both univariate and multivariate analyses (Table S3).

The detailed results of meta-analyses are presented in Table 3 and forest plots in the Supplementary Materials.

\section{Demographics}

Meta-analyses indicated that male $(\mathrm{OR}=1.66,95 \% \mathrm{CI}$ : $1.37-2.01 ; \mathrm{P}<0.00001)$ and older age $(\mathrm{MD}=13.32,95 \% \mathrm{CI}$ :
10.87-15.77; $\mathrm{P}<0.00001)$ were significant risk factors for death of COVID-19 patients.

\section{Comorbidities}

Meta-analyses indicated that hypertension $(\mathrm{OR}=2.67$, 95\% CI: 2.08-3.43; $\mathrm{P}<0.00001)$, diabetes ( $\mathrm{OR}=2.14$, 95\% CI: 1.76-2.6; $\mathrm{P}<0.00001)$, chronic respiratory disease (OR $=3.55,95 \%$ CI: 2.65-4.76; $\mathrm{P}<0.00001)$, chronic heart disease/cardiovascular disease (OR $=3.15$, 95\% CI: $2.43-$ 4.09; $\mathrm{P}<0.00001)$, cerebrovascular disease $(\mathrm{OR}=5.92,95 \%$ CI: 4.16-8.42; $\mathrm{P}<0.00001)$, chronic kidney disease (OR $=3.04,95 \%$ CI: 2.12-4.36; $\mathrm{P}<0.00001)$, cancer $(\mathrm{OR}=3.05$, 
Table 3 Comparison of demographic characteristics, comorbidities, clinical symptoms, laboratory data, imaging features, and complications between non-survivors and survivors of COVID-19

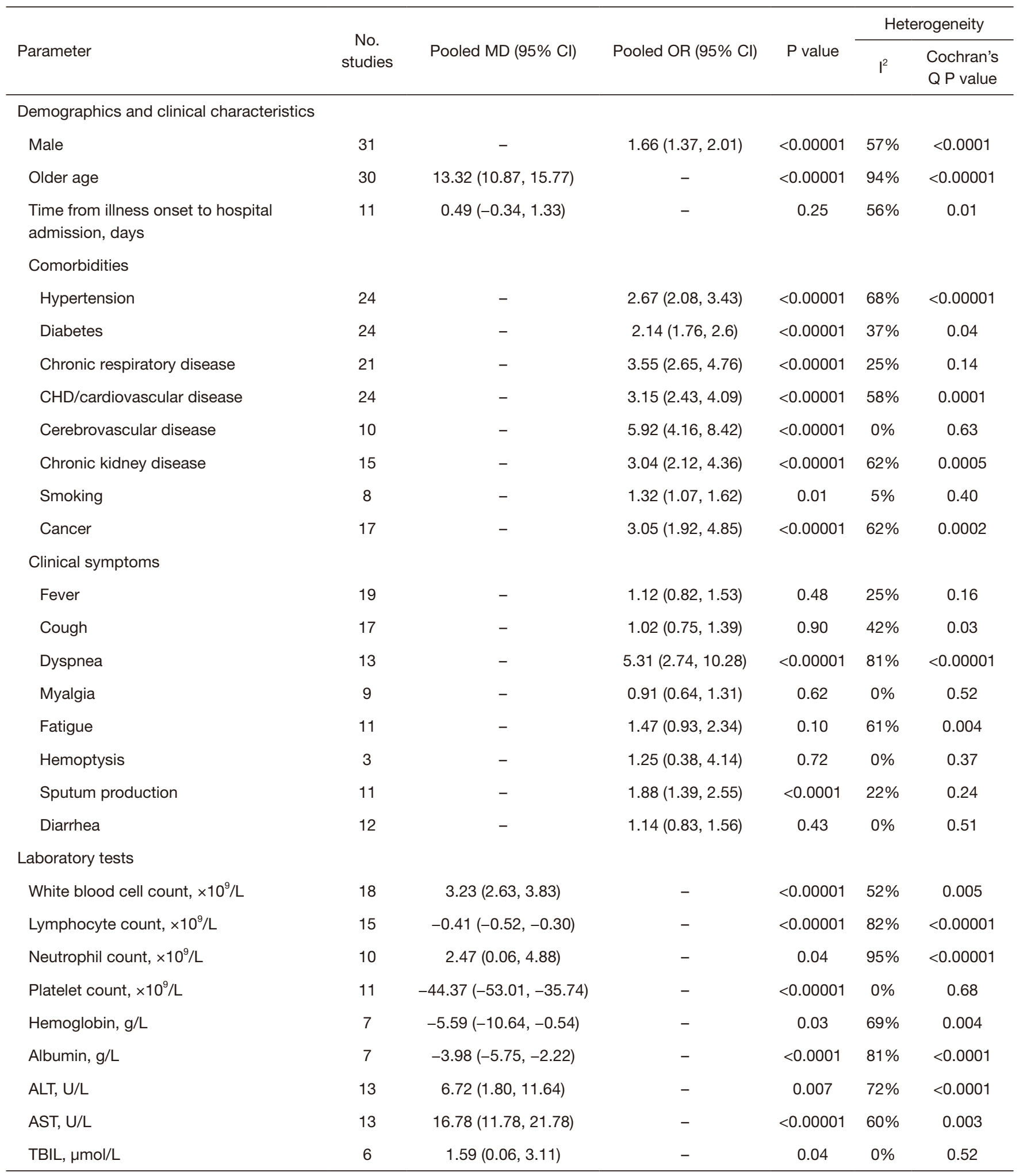

Table 3 (continued) 
Table 3 (continued)

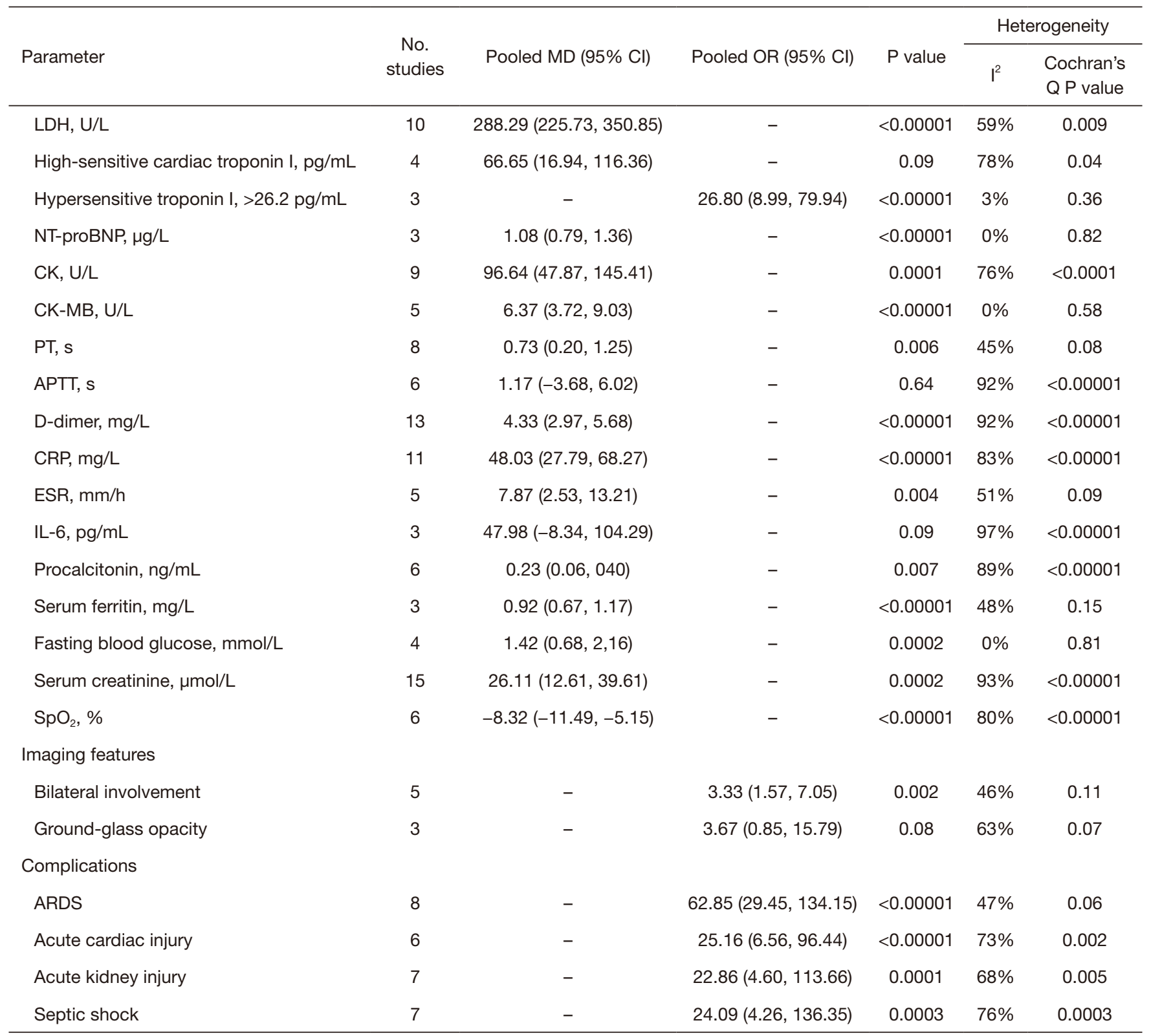

OR, odds ratio; WMD, weighted mean difference; COPD, chronic obstructive pulmonary disease; CHD, chronic heart disease; ALT, alanine aminotransferase; AST, aspartate transaminase; LDH, lactate dehydrogenase; NT-proBNP, amino-terminal pro-brain natriuretic peptide; $\mathrm{CK}$, creatine kinase; CK-MB, creatine kinase-MB; PT, prothrombin time; APTT, activated partial thromboplastin time; ESR, erythrocyte sedimentation rate; CRP, C-reactive protein; $\mathrm{SpO}_{2}$, peripheral oxygen saturation; ARDS, acute respiratory distress syndrome.

95\% CI: $1.92-4.85 ; \mathrm{P}<0.00001)$, and smoking $(\mathrm{OR}=1.32$, $95 \%$ CI: $1.07-1.62 ; \mathrm{P}=0.01)$ were significant risk factors for death of COVID-19 patients.

\section{Clinical symptoms}

Meta-analysis indicated that dyspnea $(\mathrm{OR}=5.31,95 \% \mathrm{CI}$ :
2.74-10.28; $\mathrm{P}<0.00001)$ and expectoration ( $\mathrm{OR}=1.88,95 \%$ CI: $1.39-2.55 ; \mathrm{P}<0.0001)$ at admission were significant risk factor for death of COVID-19 patients, but fever (OR $=1.12$, 95\% CI: $0.82-1.53 ; \mathrm{P}=0.48)$, cough $(\mathrm{OR}=1.02$, 95\% CI: $0.75-1.39 ; \mathrm{P}=0.90)$, myalgia $(\mathrm{OR}=0.91,95 \% \mathrm{CI}$ : $0.64-1.31 ; \mathrm{P}=0.62)$, fatigue $(\mathrm{OR}=1.47,95 \% \mathrm{CI}: 0.93-2.34$; 

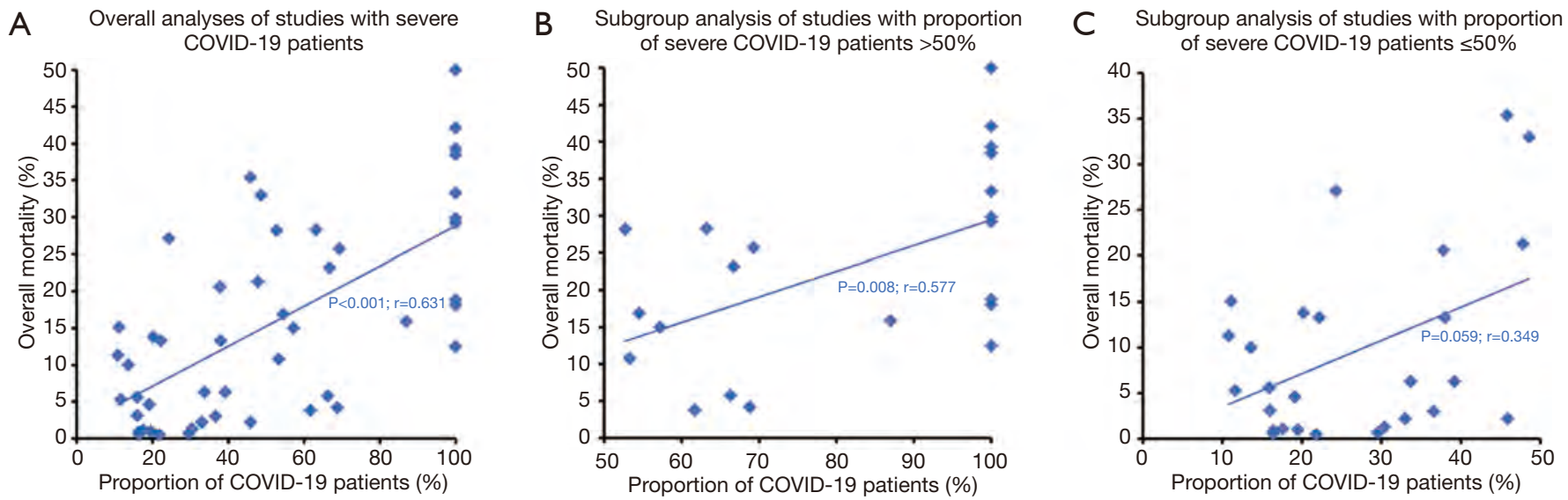

Figure 2 Scattered plots of association of mortality with the proportion of severe COVID-19 patients. (A) Scattered plots showing an increased trend of overall mortality with the proportion of severe COVID-19 patients included. (B) In studies with the proportion of severe patients $>50 \%$, an increased trend of mortality with the proportion of severe COVID-19 patients included. (C) In studies with the proportion of severe patients $>50 \%$, an increased trend of mortality with the proportion of severe COVID-19 patients included.

$\mathrm{P}=0.10)$, hemoptysis $(\mathrm{OR}=1.25,95 \% \mathrm{CI}: 0.38-4.14$; $\mathrm{P}=0.72$ ), and diarrhea ( $\mathrm{OR}=1.14$, 95\% CI: $0.83-1.56$; $\mathrm{P}=0.43)$ at admission were not significantly associated with mortality.

\section{Laboratory tests}

Meta-analysis indicated that increased levels of white blood cells (WBC) ( $\mathrm{MD}=3.23$, 95\% CI: 2.63-3.83; $\mathrm{P}<0.00001)$, alanine aminotransferase (ALT) $(\mathrm{MD}=6.72,95 \% \mathrm{CI}$ : 1.80-11.64; $\mathrm{P}=0.007$ ), aspartate aminotransferase (AST) $(\mathrm{MD}=16.78,95 \% \mathrm{CI}: 11.78-21.78 ; \mathrm{P}<0.00001)$, total bilirubin (TBIL) ( $\mathrm{MD}=1.59,95 \% \mathrm{CI}: 0.06-3.11 ; \mathrm{P}=0.04)$, lactate dehydrogenase $(\mathrm{LDH})(\mathrm{MD}=288.29,95 \% \mathrm{CI}$ : 225.73-350.85; $\mathrm{P}<0.00001)$, high-sensitive cardiac troponin I (hs-cTnI) (MD =66.65, 95\% CI: 16.94-116.36; $\mathrm{P}=0.009)$, $\mathrm{D}$-dimer $(\mathrm{MD}=4.33,95 \% \mathrm{CI}: 2.97-5.68 ; \mathrm{P}<0.00001)$, C-reactive protein $(\mathrm{MD}=48.03$, 95\% CI: 27.79-68.27; $\mathrm{P}<0.00001)$, and serum creatinine $(\mathrm{MD}=26.11,95 \% \mathrm{CI}$ : 12.61-39.61; $\mathrm{P}=0.0002)$ at admission were significant risk factors for death of COVID-19 patients; and decreased levels of albumin ( $\mathrm{MD}=-3.98,95 \% \mathrm{CI}:-5.75$ to -2.22 ; $\mathrm{P}<0.0001$ ), lymphocytes ( $\mathrm{MD}=-0.41,95 \% \mathrm{CI}:-0.52$ to $-0.30 ; \mathrm{P}<0.00001)$, hemoglobin $(\mathrm{MD}=-5.59,95 \% \mathrm{CI}$ : -10.64 to $-0.54 ; \mathrm{P}=0.03)$, platelet $(\mathrm{MD}=-44.37,95 \%$ CI: -53.01 to $-37.74 ; \mathrm{P}<0.00001)$, and peripheral oxygen saturation $\left(\mathrm{SpO}_{2}\right)(\mathrm{MD}=-8.32,95 \% \mathrm{CI}:-11.49$ to -5.15 ; $\mathrm{P}<0.00001)$ at admission were significant risk factors for death of COVID-19 patients. Additionally, hs-cTnI $>26.2 \mathrm{pg} / \mathrm{mL}$ as a categorical variable $(\mathrm{OR}=26.80,95 \%$
CI: 8.99-79.94; $\mathrm{P}<0.00001)$ at admission was significantly associated with an increased risk of COVID-19 mortality.

\section{Imaging features}

Meta-analysis indicated that bilateral involvement was a significant risk factor for death of COVID-19 patients ( $\mathrm{OR}=3.33$, 95\% CI: $1.57-7.05 ; \mathrm{P}=0.002)$, but ground-glass opacity was not significantly associated with mortality (OR $=3.67$, 95\% CI: 0.85-15.79; $\mathrm{P}=0.08$ ).

\section{Complications}

Meta-analysis indicated that ARDS (OR $=62.85,95 \%$ CI: 29.45-134.15; $\mathrm{P}<0.00001)$, acute cardiac injury $(\mathrm{OR}=25.16$, 95\% CI: 6.56-96.44; $\mathrm{P}<0.00001)$, acute kidney injury (OR $=22.86,95 \%$ CI: 4.60-113.66; $\mathrm{P}=0.0001)$, and septic shock $(\mathrm{OR}=24.09,95 \% \mathrm{CI}$ : 4.26-136.35; $\mathrm{P}=0.0003)$ were significant risk factors for death of COVID-19 patients.

Scattered plots demonstrated an increased trend of overall mortality with the proportion of severe COVID-19 patients included $(\mathrm{P}<0.001, \mathrm{r}=0.631)$ (Figure $2 A)$. In studies with the proportion of severe patients $>50 \%$, the trend remained statistically significant $(\mathrm{P}=0.008 ; \mathrm{r}=0.577)$ (Figure $2 B$ ). In studies with the proportion of severe patients $\leq 50 \%$, the trend remained not statistically significant $(\mathrm{P}=0.059, \mathrm{r}=0.349)$ (Figure 2C).

\section{Discussion}

The present meta-analysis suggested that the pooled in- 
hospital mortality of COVID-19 patients was $14 \%$. By comparison, previous meta-analyses reported that the mortality of COVID-19 patients was relatively lower [i.e., $3.2 \%$ in the Hu' meta-analysis (16) or $7.7 \%$ in our previous meta-analysis (6)]. This discrepancy can be explained by the difference in the severity of COVID-19 patients included among them. Indeed, the proportion of severe COVID-19 patients was higher in the present meta-analysis than the previous meta-analysis [49.6\% versus 18\% (16)], which might overestimate the overall mortality.

Severe disease status was an independent risk factor for death in COVID-19 patients $(17,18)$. Our subgroup analyses also found that the in-hospital mortality of COVID-19 patients in studies with the proportion of patients with severe disease of $>50 \%$ was higher than those $\leq 50 \%$ (22.5\% versus $7.7 \%)$. Severe patients had more prominent laboratory abnormalities [i.e., leukopenia, lymphopenia, elevated levels of C-reactive protein and interleukin 6 (IL6)] as compared to non-severe patients. Increased levels of C-reactive protein and inflammatory cytokines, such as IL-6, may induce "cytokines storm", thereby aggravating systemic inflammatory response syndrome in patients with severe disease, which may be a driving factor of acute lung injury and ARDS and even death (19-21). The mortality in COVID-19 patients with ARDS was up to $39 \%$ (22). We also confirmed that ARDS was associated with a 62.85 -fold increase in the risk of death in COVID-19 patients.

The mortality of COVID-19 patients greatly varies among regions. It seems to be the lowest in China (3.1\%) and the highest in the United Kingdom (20.8\%) and New York State (20.99\%) (23). Our subgroup analysis also demonstrated that the in-hospital mortality of COVID-19 patients in Europe and North America were higher than Asia $(23.7 \%$ and $25.4 \%$ versus $10.1 \%)$. This might be explained by the aging of patients in Europe and North America. It has been reported that $37.6 \%$ of COVID-19 patients are beyond 70 years old in Italy, but only $11.9 \%$ in China (24). As shown by our meta-analysis and others (23), age is a significant risk factor of death in COVID-19 patients. In other words, a higher proportion of elderly patients is often in parallel with an increased mortality. This phenomenon could be attributed to the relationship of aging with immune response impairment and chronic inflammation (25) and a high prevalence of comorbidities, such as hypertension, diabetes, and cardiovascular disease, in elderly patients. Obesity is common in Western countries with an increasing prevalence of obesity, and associated with poor prognosis of COVID-19 patients
$(26,27)$. Angiotensin-converting enzyme 2 (ACE2) is the receptor of SARS-CoV-2 infection target cells, and ACE2 expression level in adipocytes is higher than that in lung tissue. Obese people have more adipose tissue and therefore higher ACE2 levels. Among the obese population, the renin-angiotensin-aldosterone system is overactive, increasing the production of angiotensin II (26). Elevated angiotensin II levels in COVID-19 patients are related to the severity of lung injury (28), which will increase the risk of death. Additionally, it has been confirmed that obesity increases the risk of cardiovascular disease and its mortality (29). Besides, the difference in public prevention and control strategies of COVID-19 among countries is another major explanation for this variation (30).

Pre-existing comorbidities correlated with an increased risk of mortality in COVID-19 patients, probably because patients with hypertension and diabetes have higher circulating ACE2 levels $(31,32)$. A wider distribution of ACE2 in cardiac epithelial cells as well as respiratory, kidney, and liver is associated with organ failure in patients with SARS (33-35). Therefore, it is postulated that patients with cardiovascular disease are more prone to use angiotensin-converting enzyme inhibitors (ACEIs) or angiotensin-receptor blockers (ARBs), thereby elevating the ACE2 expression and then increasing the risk of SARS$\mathrm{CoV}-2$ infection and disease progression (36).

Acute cardiac injury was also associated with poor outcomes in COVID-19 patients. Similarly, previous studies suggested that COVID-19 patients with abnormal troponin I, which is a marker of acute myocardial injury, had worse prognosis $(37,38)$. Underlying mechanisms for explaining this phenomenon are as follows. First, the release of proinflammatory cytokines, endothelial dysfunction, and increased oxidative stress can lead to a hypercoagulable state, which is prone to coronary arterial thrombosis and triggers acute coronary syndrome (25). Second, SARS$\mathrm{CoV}-2$ binds to ACE2 receptor, which is widely expressed in cardiomyocytes, thereby attacking cardiac epithelial cells and inducing cardiac injury (39-41).

Lung pathology of critically ill patients showed occlusion and micro-thrombosis in pulmonary vessels (42). Additionally, severe COVID-19 patients, especially those with sepsis, are often at a hypercoagulable state $(20,43)$. Our study confirmed that D-dimer level, a convenient biomarker of thrombotic events (44), was associated with the mortality of COVID-19 patients.

Of note, non-survival group had a significantly higher 
proportion of male than survival group. This may be attributed to the difference in the levels and types of sex hormones between males and females. Estrogen can modulate the responses of adaptive and innate immunity, which can reduce the susceptibility of females to viral infections (45). On the contrary, males are more susceptible to SARS-CoV-2 infection (46).

Major limitations of the present work should be that all studies included in this meta-analysis were observational with different patient characteristics and follow-up periods, a majority of studies were retrospective, and some of them were of low quality, which might produce the potential selection bias and recall bias. Additionally, the heterogeneity in most of meta-analyses was significant. Although we performed subgroup, meta-regression, and sensitivity analyses, the source of heterogeneity was not clearly identified.

In conclusion, based on the systematic review and meta-analysis, the in-hospital mortality of COVID-19 patients was up to $14 \%$. Older age, male, comorbidities (i.e., hypertension, diabetes, cardiovascular diseases, and respiratory diseases), clinical presentations with dyspnea and expectoration, and laboratory abnormalities (i.e., WBC, AST, ALT, serum creatinine, C-reactive protein, LDH, hscTnI, and D-dimer), should be important predictors for mortality of COVID-19 patients. Moreover, patients who develop ARDS, acute cardiac injury, acute kidney injury, and septic shock are at higher risk of death.

\section{Acknowledgments}

Funding: None.

\section{Footnote}

Reporting Checklist: The authors have completed the MOOSE and PRISMA reporting checklists. Available at http://dx.doi.org/10.21037/apm-20-2557

Peer Review File: Available at http://dx.doi.org/10.21037/ apm-20-2557

Conflicts of Interest: All authors have completed the ICMJE uniform disclosure form (available at http://dx.doi. org/10.21037/apm-20-2557). The authors have no conflicts of interest to declare.

Ethical Statement: The authors are accountable for all aspects of the work in ensuring that questions related to the accuracy or integrity of any part of the work are appropriately investigated and resolved.

Open Access Statement: This is an Open Access article distributed in accordance with the Creative Commons Attribution-NonCommercial-NoDerivs 4.0 International License (CC BY-NC-ND 4.0), which permits the noncommercial replication and distribution of the article with the strict proviso that no changes or edits are made and the original work is properly cited (including links to both the formal publication through the relevant DOI and the license). See: https://creativecommons.org/licenses/by-nc-nd/4.0/.

\section{References}

1. WHO. Situation Report - 22 2020. Available online: https://www.who.int/docs/default-source/ coronaviruse/situation-reports/20200211-sitrep-22-ncov. pdf?sfvrsn=fb6d49b1_2. Accessed on August 4, 2020.

2. Li Q, Guan X, Wu P, et al. Early Transmission Dynamics in Wuhan, China, of Novel Coronavirus-Infected Pneumonia. N Engl J Med 2020;382:1199-207.

3. Zhou P, Yang XL, Wang XG, et al. A pneumonia outbreak associated with a new coronavirus of probable bat origin. Nature 2020;579:270-3.

4. Xu Z, Shi L, Wang Y, et al. Pathological findings of COVID-19 associated with acute respiratory distress syndrome. Lancet Respir Med 2020;8:420-2.

5. WHO. Coronavirus disease 2019 (COVID-19) Situation Report. Available online: https://www.who.int/ emergencies/diseases/novel-coronavirus-2019. Accessed on August 4, 2020.

6. Wu YY, Li HY, Xu XB, et al. Clinical features and outcome of treatment for novel coronavirus pneumonia: a metaanalysis. Zhonghua Gan Zang Bing Za Zhi 2020;28:240-6.

7. Chen N, Zhou M, Dong X, et al. Epidemiological and clinical characteristics of 99 cases of 2019 novel coronavirus pneumonia in Wuhan, China: a descriptive study. Lancet 2020;395:507-13.

8. WHO. Report of the WHO-China Joint Mission on Coronavirus Disease 2019 (COVID-19). WHO. 2020. Available online: https://www.who.int/docs/default-source/ coronaviruse/who-china-joint-mission-on-covid-19--final-report-1100hr-28feb2020-11 mar-update.pdf?sfvrsn= 1a13fda0_2\&download=true. Accessed on August 4, 2020.

9. Wang D, Hu B, Hu C, et al. Clinical Characteristics of 138 Hospitalized Patients With 2019 Novel Coronavirus- 
Infected Pneumonia in Wuhan, China. JAMA 2020;323:1061-9.

10. Guan WJ, Ni ZY, Hu Y, et al. Clinical Characteristics of Coronavirus Disease 2019 in China. N Engl J Med 2020;382:1708-20.

11. Wang X, Fang X, Cai Z, et al. Comorbid Chronic Diseases and Acute Organ Injuries Are Strongly Correlated with Disease Severity and Mortality among COVID-19 Patients: A Systemic Review and Meta-Analysis. Research (Wash D C) 2020;2020:2402961.

12. Martins-Filho PR, Tavares CSS, Santos VS. Factors associated with mortality in patients with COVID-19. A quantitative evidence synthesis of clinical and laboratory data. Eur J Intern Med 2020;76:97-9.

13. Parohan M, Yaghoubi S, Seraji A, et al. Risk factors for mortality in patients with Coronavirus disease 2019 (COVID-19) infection: a systematic review and meta-analysis of observational studies. Aging Male 2020;23:1416-24.

14. Tian $W$, Jiang $W$, Yao J, et al. Predictors of mortality in hospitalized COVID-19 patients: A systematic review and meta-analysis. J Med Virol 2020;92:1875-83.

15. Lippi G, Wong J, Henry BM. Hypertension in patients with coronavirus disease 2019 (COVID-19): a pooled analysis. Pol Arch Intern Med 2020;130:304-9.

16. Hu Y, Sun J, Dai Z, et al. Prevalence and severity of corona virus disease 2019 (COVID-19): A systematic review and meta-analysis. J Clin Virol 2020;127:104371.

17. Sun DW, Zhang D, Tian RH, et al. The underlying changes and predicting role of peripheral blood inflammatory cells in severe COVID-19 patients: A sentinel? Clin Chim Acta 2020;508:122-9.

18. Luo M, Jiang B, Xu HJ, et al. Analysis of influencing factors of death in patients with COVID-19. Chinese Traditional and Herbal Drugs 2020;51:1450-4.

19. Mehta P, McAuley DF, Brown M, et al. COVID-19: consider cytokine storm syndromes and immunosuppression. Lancet 2020;395:1033-4.

20. Lin L, Lu L, Cao W, et al. Hypothesis for potential pathogenesis of SARS-CoV-2 infection-a review of immune changes in patients with viral pneumonia. Emerg Microbes Infect 2020;9:727-32.

21. Ulhaq ZS, Soraya GV. Interleukin-6 as a potential biomarker of COVID-19 progression. Med Mal Infect 2020;50:382-3.

22. Hasan SS, Capstick T, Ahmed R, et al. Mortality in COVID-19 patients with acute respiratory distress syndrome and corticosteroids use: a systematic review and meta-analysis. Expert Rev Respir Med 2020;14:1149-63.

23. Bonanad C, Garcia-Blas S, Tarazona-Santabalbina F, et al. The Effect of Age on Mortality in Patients With COVID-19: A Meta-Analysis With 611,583 Subjects. J Am Med Dir Assoc 2020;21:915-8.

24. Onder G, Rezza G, Brusaferro S. Case-Fatality Rate and Characteristics of Patients Dying in Relation to COVID-19 in Italy. JAMA 2020;323:1775-6.

25. Libby P. Inflammation in atherosclerosis. Nature 2002;420:868-74.

26. Sanchis-Gomar F, Lavie CJ, Mehra MR, et al. Obesity and Outcomes in COVID-19: When an Epidemic and Pandemic Collide. Mayo Clin Proc 2020;95:1445-53.

27. Sharma A, Garg A, Rout A, et al. Association of Obesity With More Critical Illness in COVID-19. Mayo Clin Proc 2020;95:2040-2.

28. Liu Y, Yang Y, Zhang C, et al. Clinical and biochemical indexes from 2019-nCoV infected patients linked to viral loads and lung injury. Sci China Life Sci 2020;63:364-74.

29. Pranata R, Huang I, Lim MA, et al. Impact of cerebrovascular and cardiovascular diseases on mortality and severity of COVID-19-systematic review, metaanalysis, and meta-regression. J Stroke Cerebrovasc Dis 2020;29:104949.

30. Hradsky O, Komarek A. Demographic and public health characteristics explain large part of variability in COVID-19 mortality across countries. Eur J Public Health 2021;31:12-6.

31. Patel SK, Velkoska E, Freeman M, et al. From gene to protein-experimental and clinical studies of ACE2 in blood pressure control and arterial hypertension. Front Physiol 2014;5:227.

32. Soro-Paavonen A, Gordin D, Forsblom C, et al. Circulating ACE2 activity is increased in patients with type 1 diabetes and vascular complications. J Hypertens 2012;30:375-83.

33. Yang JK, Feng Y, Yuan MY, et al. Plasma glucose levels and diabetes are independent predictors for mortality and morbidity in patients with SARS. Diabet Med 2006;23:623-8.

34. Li R, Qiao S, Zhang G. Analysis of angiotensin-converting enzyme 2 (ACE2) from different species sheds some light on cross-species receptor usage of a novel coronavirus 2019-nCoV. J Infect 2020;80:469-96.

35. Yang JK, Lin SS, Ji XJ, et al. Binding of SARS coronavirus to its receptor damages islets and causes acute diabetes. Acta Diabetol 2010;47:193-9.

36. Fang L, Karakiulakis G, Roth M. Are patients with 
hypertension and diabetes mellitus at increased risk for COVID-19 infection? Lancet Respir Med 2020;8:e21.

37. Lippi G, Lavie CJ, Sanchis-Gomar F. Cardiac troponin I in patients with coronavirus disease 2019 (COVID-19): Evidence from a meta-analysis. Prog Cardiovasc Dis 2020;63:390-1.

38. Vrsalovic M, Vrsalovic Presecki A. Cardiac troponins predict mortality in patients with COVID-19: A meta-analysis of adjusted risk estimates. J Infect 2020;81:e99-100.

39. Chen Y, Guo Y, Pan Y, et al. Structure analysis of the receptor binding of 2019-nCoV. Biochem Biophys Res Commun 2020;525:135-40.

40. Lu R, Zhao X, Li J, et al. Genomic characterisation and epidemiology of 2019 novel coronavirus: implications for virus origins and receptor binding. Lancet 2020;395:565-74.

41. Turner AJ, Hiscox JA, Hooper NM. ACE2: from vasopeptidase to SARS virus receptor. Trends Pharmacol

Cite this article as: Wu Y, Li H, Zhang Z, Liang W, Zhang T, Tong Z, Guo X, Qi X. Risk factors for mortality of coronavirus disease 2019 (COVID-19) patients during the early outbreak of COVID-19: a systematic review and meta-analysis. Ann Palliat Med 2021;10(5):5069-5083. doi: 10.21037/apm-20-2557
Sci 2004;25:291-4.

42. Luo W, Yu H, Gou J, et al. Clinical Pathology of Critical Patient with Novel Coronavirus Pneumonia (COVID-19). Preprints 2020. Available online: https://wwwpreprintsorg/ manuscript/2020020407/v4. Accessed 13 Aug 2020.

43. Levi M, van der Poll T. Coagulation and sepsis. Thromb Res 2017;149:38-44.

44. Bikdeli B, Madhavan MV, Jimenez D, et al. COVID-19 and Thrombotic or Thromboembolic Disease: Implications for Prevention, Antithrombotic Therapy, and Follow-Up: JACC State-of-the-Art Review. J Am Coll Cardiol 2020;75:2950-73.

45. Jaillon S, Berthenet K, Garlanda C. Sexual Dimorphism in Innate Immunity. Clin Rev Allergy Immunol 2019;56:308-21.

46. Vahidy FS, Pan AP, Ahnstedt H, et al. Sex differences in susceptibility, severity, and outcomes of coronavirus disease 2019: Cross-sectional analysis from a diverse US metropolitan area. PLoS One 2021;16:e0245556. 


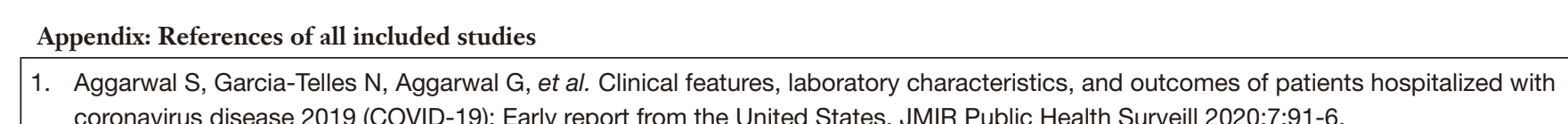

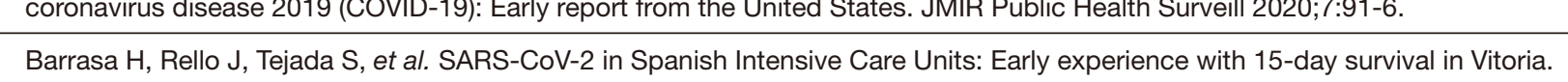

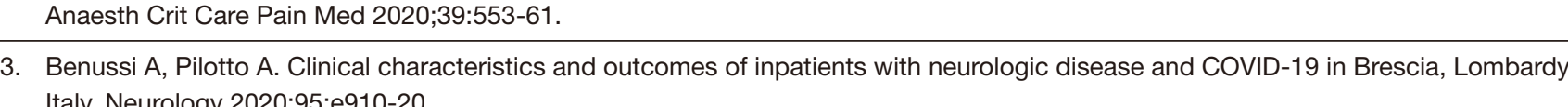

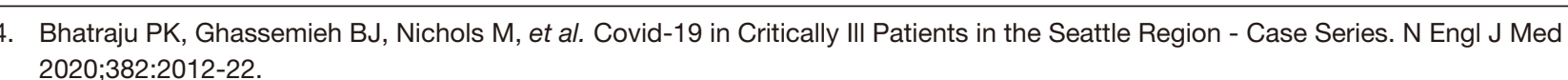

5. Bianchetti A, Rozzini R R, Guerini F, et all. Clinical Presentation of CoviD19 in Dementia Patients. J Nutr Heath Aging 2020;24:560-2.

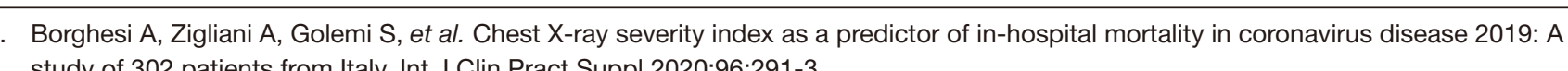

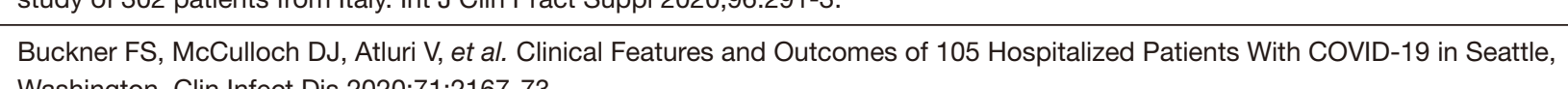

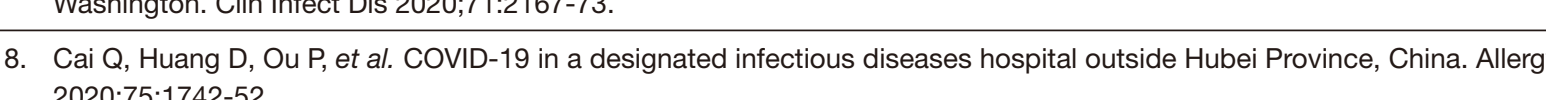

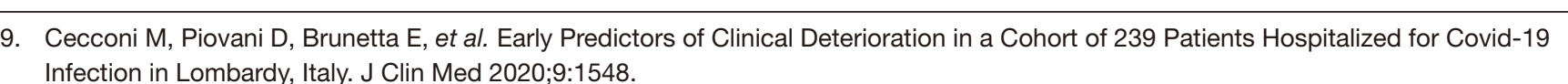

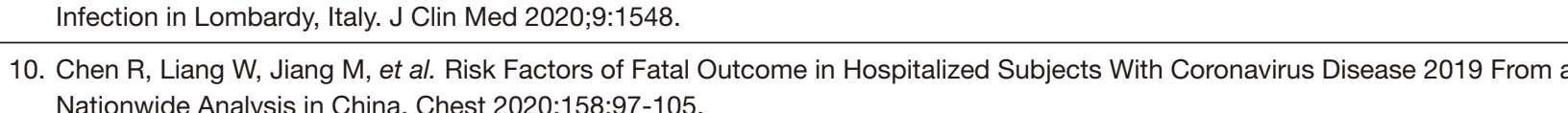

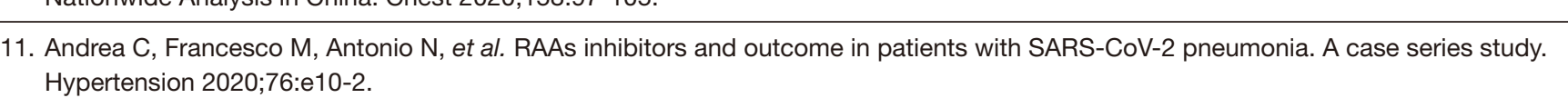

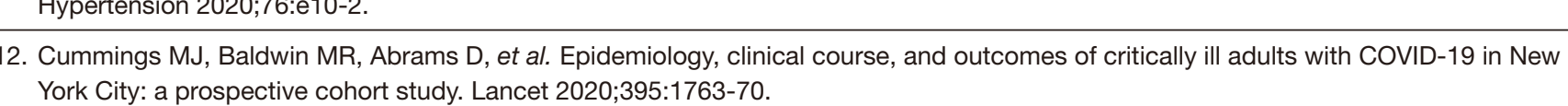

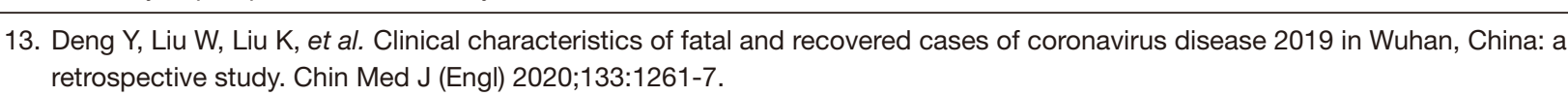

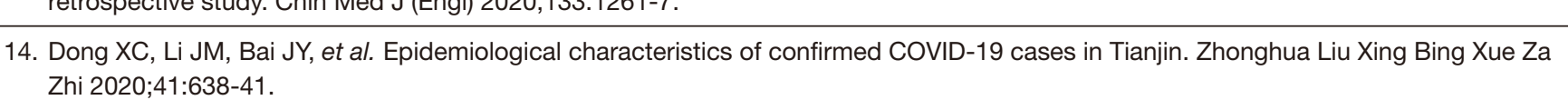

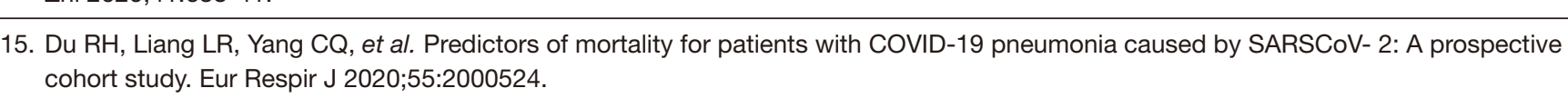
16. Gao L, Jiang D, Wen XS, etal. Prognostic value of NT-ProBNP in patients with severe COVID-19. Respir Res 2020;21:83.

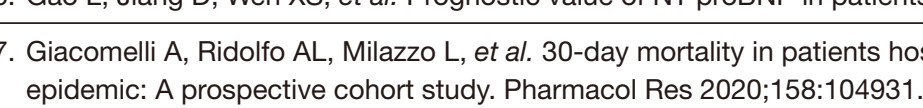

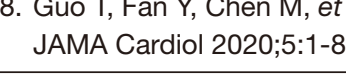

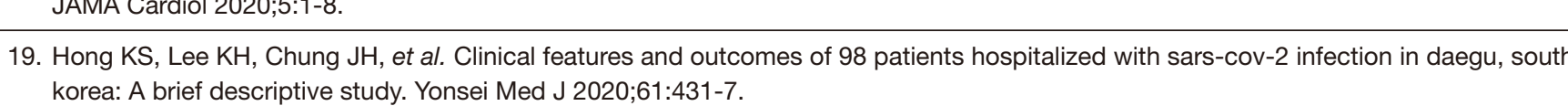

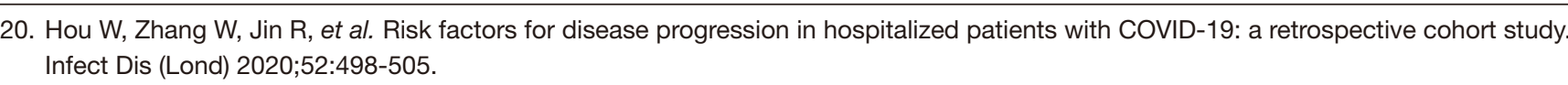

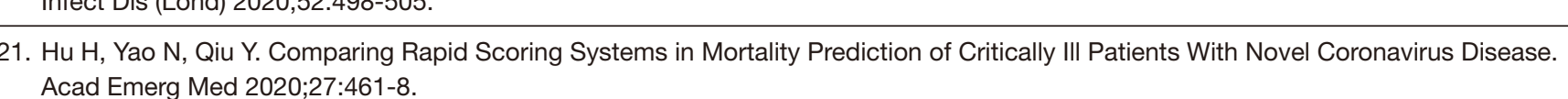

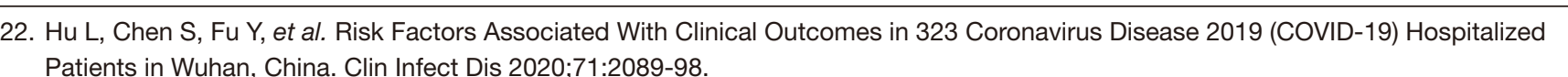

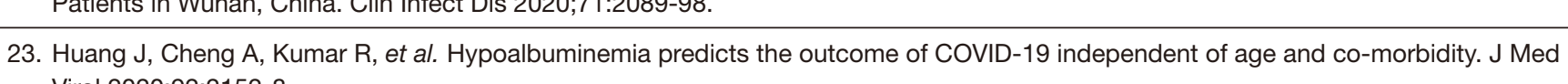

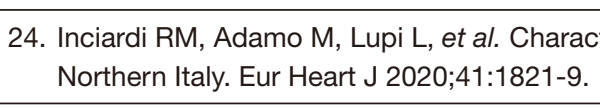

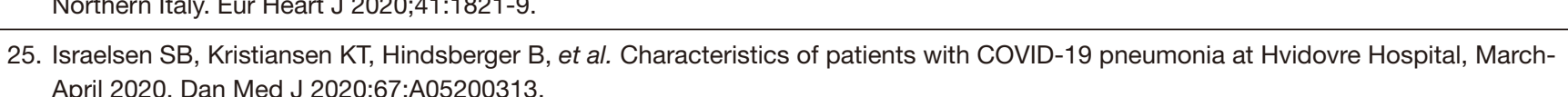

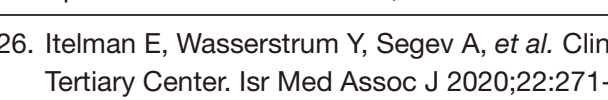
27. Javanian $\mathrm{M}$, Bayani $M$, Shokri M, etal. Clinical and laboratory findings from patients with Covi-19 pneumonia in Babol North of flan:

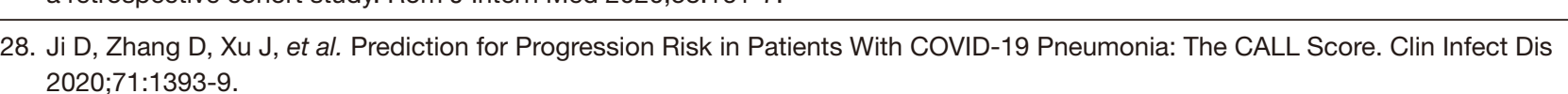

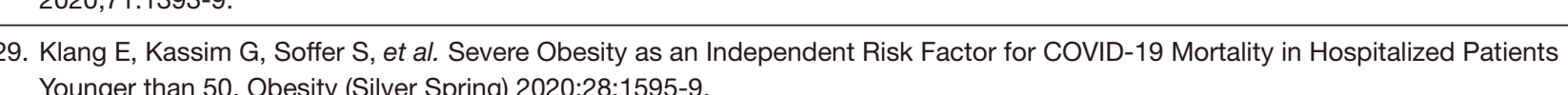

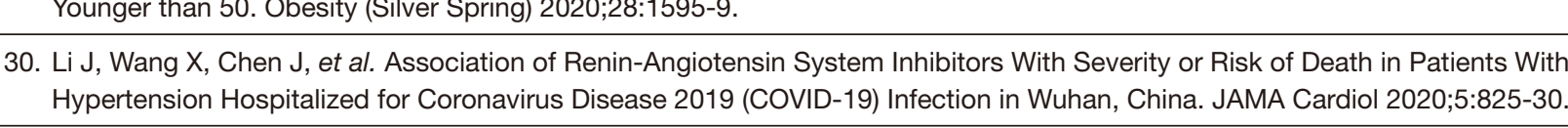

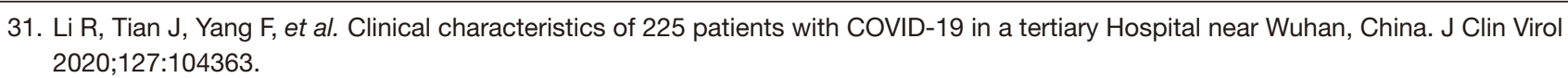

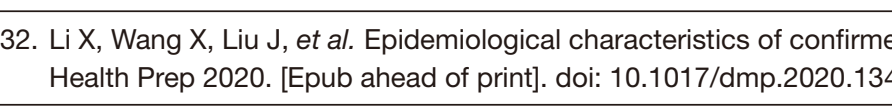

3. Ling L, So C, Shum HP, etal. Critically ill patients with COVID-19 in Hong Kong: a multicentre retrospective observational cohort study 34. LiuJ, Chen T, Yang H, etal. Cininical and radiological changes of hospitialised patients with COVID-19 pneumonia from disease onset to

35. LiuK, Chen $Y$, $2020: 08: 14$ : 36. Liu K, Fang YY, Deng Y, e tal. Clinical characterisitics of novel coronavirus cases in tertiary hospitals in Hubei Province. Chin Med J(Eno) 37. Long L Z Zeng $X$, Zhang $X$, etal. Short-term outcomes of CoviD-19 and risk factors for progression. Eur Respir J 2020;55:2000990.

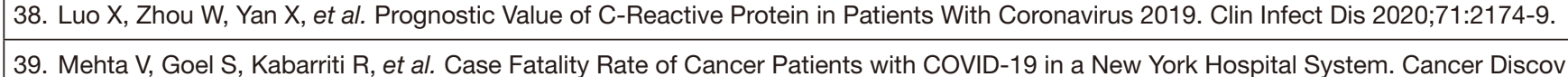

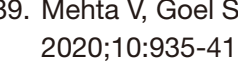

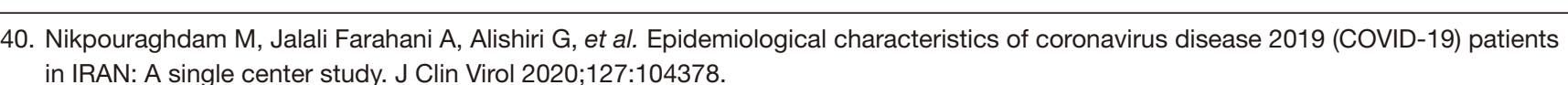

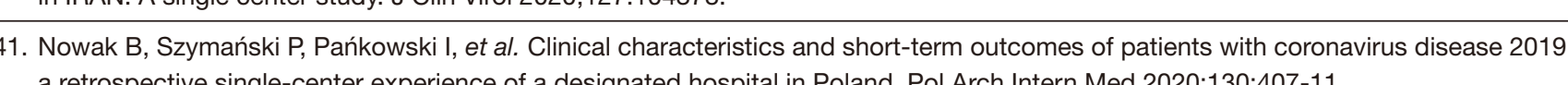

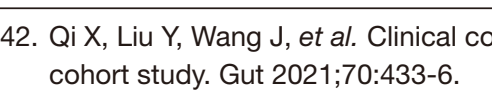
3. Renieris G, Katrini K, Damoulari C, etal. Serum Hydrogen Sulfide and Outcome Association in Pneumonia by the SARS-CON-2

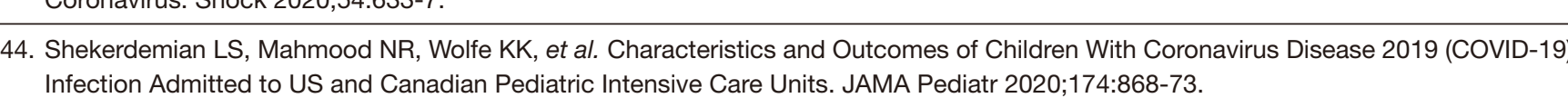
45. Sun H, Ning R, Tao Y, etal. Risk Factors for Mortally in 244 Older Adutts With COVID-19 in Wunan, China: A Retrospective Study. J Am

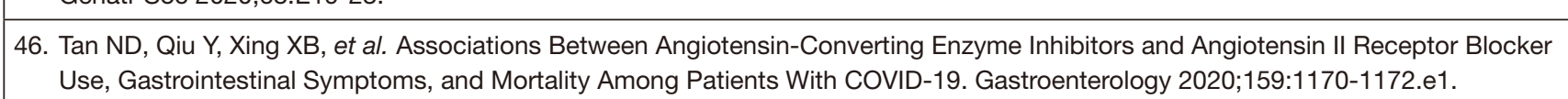

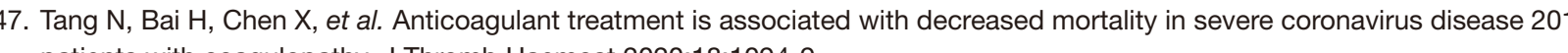

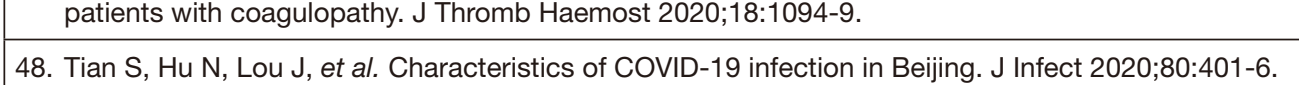

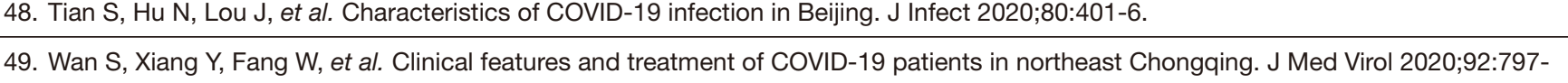
80 .

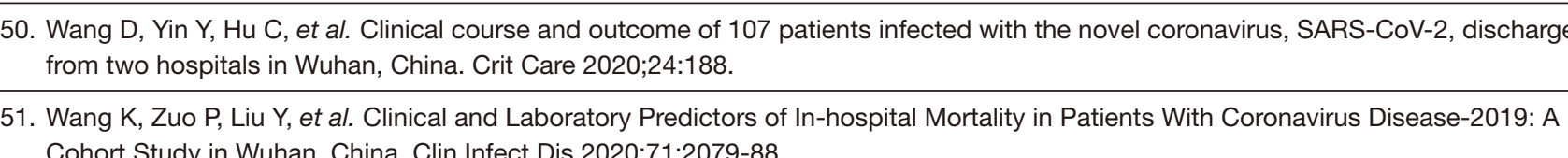

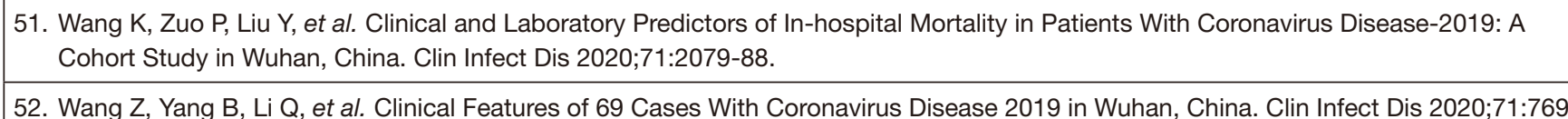
52. Wang Z, Yang B, Li Q e etal. Clinical Features of 69 Cases With Coronavirus Disease

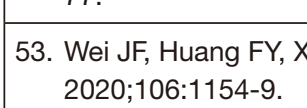

54. Wu J, LiJ, Z Zhu G, et tal. Clinical Features of Maintenance Hemodialysis Patients with 2019 Novel Coronavirus-Iniected Pneumonia in.

55. Xie J, Covassin N, Fan Z, etal. Association Between Hypoxemia and Mortality in Patients With CoviD-19. Mayo Clin Proc
2020:95:118-47.

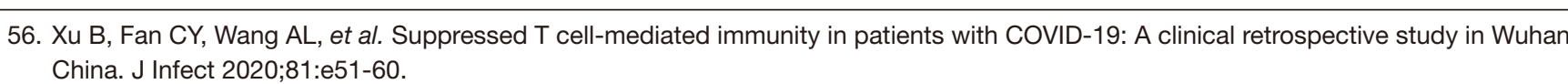

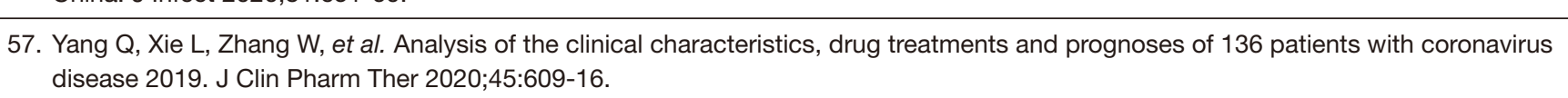
58. YuY, Xu D, Fu S, etal. Patients with COVID-19 in 19 ICUS in Wunan, China: a cross-sectional study. Crit Care 2020:24:219. 59. Zhang H, Shang W, Liu Q, etal. Clinical characteristicis of 194 cases of CoviD-19 in Huanggang and TTaian, China. Infection

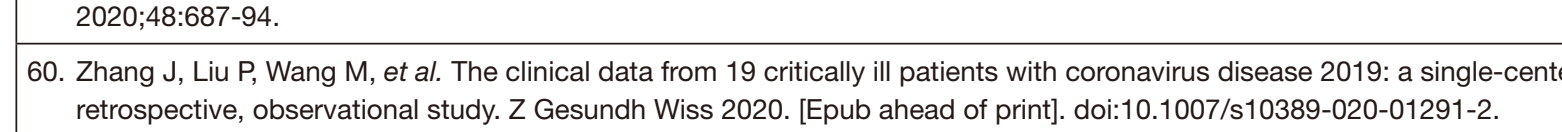

61. Zhang J, Wang $X$, Jia $X$, etal. Risk factors for disease severity, unimprovement, and mortallty in COVID-19 patients in Wuhan, China.

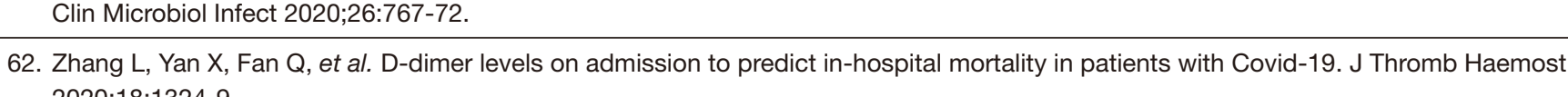

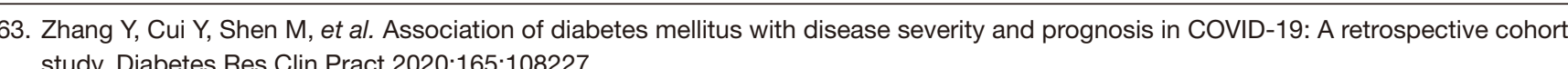
study. Diabetes Res Clin Pract 2020;165:108227.
64. Zhang YT, Deng AP. HU T, etal. Clinical outcomes of COVID-19 cases and influencing factors in Guangdong provinince. Zhonghua Liu

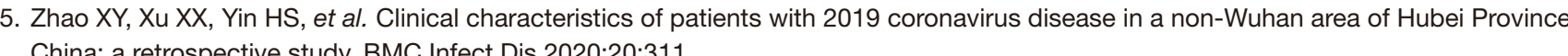

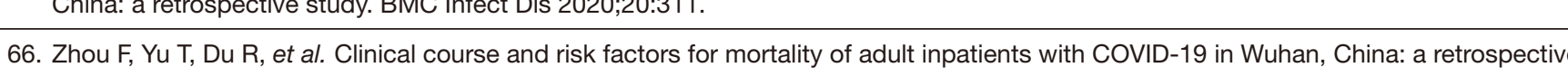

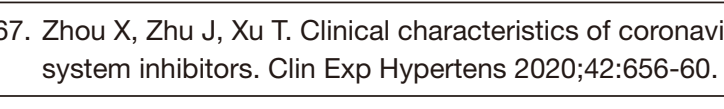

3. An $\mathrm{W}, \mathrm{X}$, Xa F, Chen $\mathrm{M}$, et al. Clinical features of 11 deaths

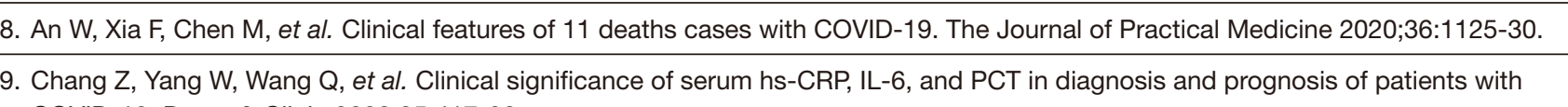
70. Foy BH, Carlson JCT, Reinertsen E, e, atal. Elevated RDW is Associated with Increased Motalality Risk in COVID-19. medRxiv preprint 2020. doi: https://doiorg//101101/2020050520091

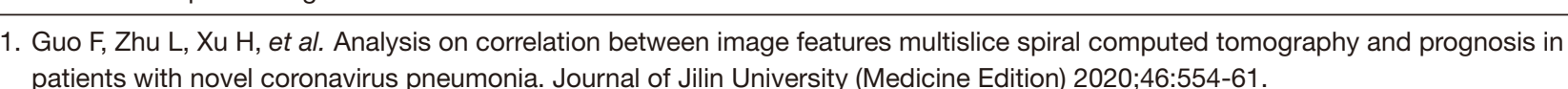

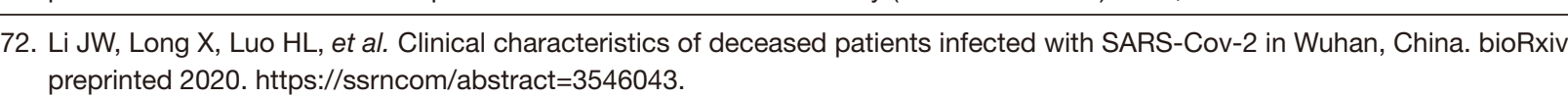

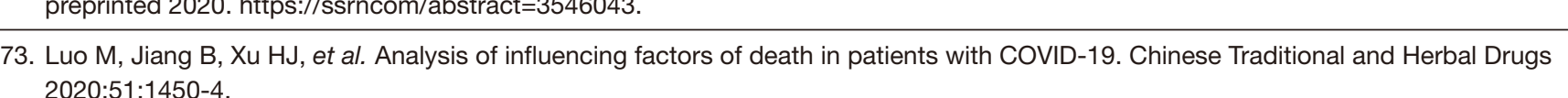

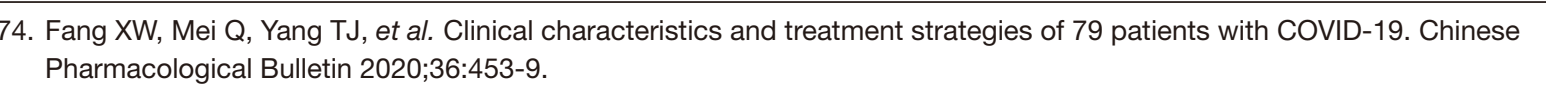

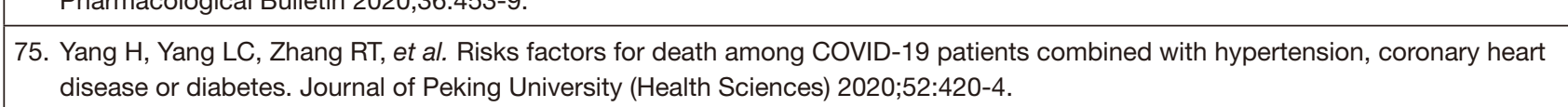

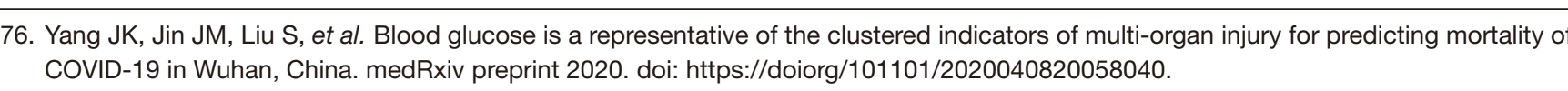

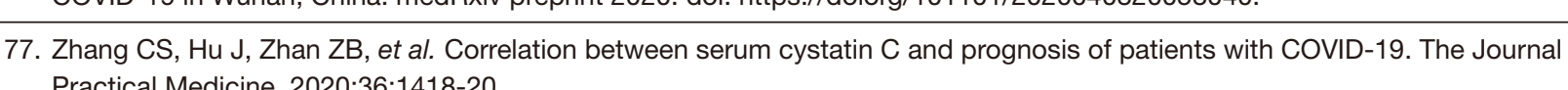

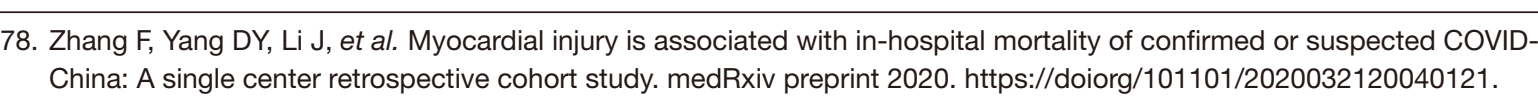

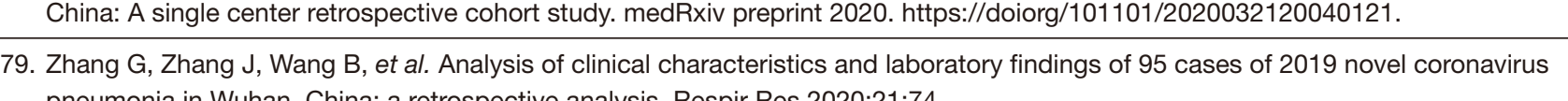

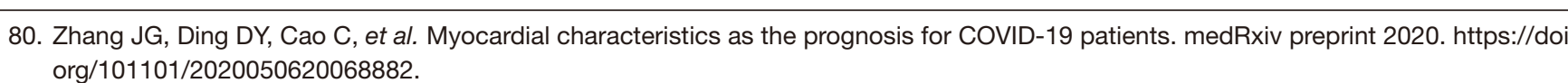


Table S1 Quality of included studies

\begin{tabular}{|c|c|c|c|c|c|c|c|c|c|c|}
\hline References & Quality Score & & ctior & 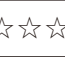 & & Com & 动动） & & me & \\
\hline Aggarwal S (2020) & 7 & 放 & is & is & 1 & 弥 & 放 & is & 1 & is \\
\hline Barrasa H (2020) & 6 & is & - & is & 动 & 1 & 1 & 虾 & is & is \\
\hline Benussi A (2020) & 5 & 虾 & 虾 & 动 & 1 & I & 虾 & 动 & I & I \\
\hline Bhatraju P (2020) & 5 & is & 1 & is & I & I & 1 & is & is & is \\
\hline Bianchetti A (2020) & 4 & is & 放 & के & I & I & 1 & is & I & I \\
\hline Borghesi A (2020) & 5 & is & is & is & 1 & I & I & is & I & I \\
\hline Buckner F (2020) & 6 & 虾 & is & is & 1 & I & 1 & is & is & is \\
\hline Cai Q (2020) & 6 & 虾 & 放 & 动 & 1 & 1 & 1 & 动 & 的 & 访 \\
\hline Cecconi M (2020) & 5 & 虾 & 1 & 动 & I & I & 1 & 㶦 & 动 & is \\
\hline Chen R (2020) & 6 & is & 虾 & is & I & I & 1 & is & w & is \\
\hline Andrea C (2020) & 6 & is & is & is & I & I & I & 弥 & is & के \\
\hline Cummings M (2020) & 6 & is & 1 & is & का & I & 1 & कर & is & is \\
\hline Deng Y (2020) & 4 & 虾 & is & 动 & I & I & 1 & is & I & I \\
\hline Dong X (2020) & 5 & is & 弥 & is & I & I & I & is & I & is \\
\hline Du R (2020) & 7 & is & is & is & के & I & I & is & is & is \\
\hline Gao L (2020) & 7 & is & is & is & I & I & is & is & 动 & is \\
\hline Giacomelli A (2020) & 7 & is & 战 & 出 & is & I & 1 & 动 & 动 & 蛇 \\
\hline Guo T (2020) & 4 & is & is & 论 & 1 & 1 & 1 & is & I & I \\
\hline Hong K (2020) & 7 & is & is & is & 1 & I & is & 动 & th & is \\
\hline Hou W (2020) & 5 & is & is & is & I & I & is & is & I & / \\
\hline Hu H (2020) & 4 & is & 放 & is & I & I & 1 & is & I & I \\
\hline Hu L (2020) & 7 & 虾 & 虾 & 动 & 1 & 动 & 1 & 动 & 的 & 动 \\
\hline Huang J (2020) & 4 & is & is & का & I & I & I & is & I & I \\
\hline Inciardi R (2020) & 7 & is & is & है & I & 弥 & I & 动 & के & के \\
\hline Israelsen S (2020) & 8 & 虾 & 动 & 动 & I & 弥 & 论 & is & is & 访 \\
\hline Itelman E (2020) & 4 & 虾 & 放 & is & 1 & 1 & 1 & 动 & I & I \\
\hline Javanian M (2020) & 6 & 虾 & is & is & 1 & I & 1 & के & 许 & 虾 \\
\hline Ji D (2020) & 6 & is & is & is & 1 & I & I & is & is & is \\
\hline Klang E cohort1 (2020) & 4 & is & is & 放 & I & I & 1 & is & I & I \\
\hline Klang E cohort2 (2020) & 4 & is & is & is & I & I & 1 & is & I & I \\
\hline Li J (2020) & 5 & is & is & is & I & is & 1 & is & I & I \\
\hline Li R (2020) & 5 & 虾 & 1 & is & 1 & I & I & is & is & is \\
\hline LiX (2020) & 3 & is & 1 & is & 1 & I & I & is & I & I \\
\hline Ling L (2020) & 5 & 虾 & 1 & क 5 & 1 & I & I & is & is & is \\
\hline Liu J (2020) & 5 & th & 1 & 动 & 1 & 1 & 1 & is & 邻 & 标 \\
\hline Liu K (2020) & 6 & is & is & is & I & 论 & is & is & I & I \\
\hline Liu K (2020) & 3 & is & 1 & is & I & I & I & is & I & I \\
\hline Long L (2020) & 7 & is & is & is & is & I & 1 & is & is & के \\
\hline Luo X (2020) & 6 & is & 访 & is & I & I & 1 & is & is & is \\
\hline Mehta V (2020) & 6 & is & is & is & I & I & 1 & is & is & क स \\
\hline Nikpouraghdam M (2020) & 3 & is & 1 & is & I & I & 1 & is & I & I \\
\hline Nowak B (2020) & 6 & is & is & is & , & I & 1 & is & is & is \\
\hline Qi X (2020) & 8 & is & is & is & I & is & is & कर & कर & is \\
\hline Renieris G (2020) & 7 & 虾 & 放 & 动 & 1 & 1 & 论 & 动 & 动 & 动 \\
\hline Shekerdemian L (2020) & 5 & is & 1 & 论 & I & I & 1 & 访 & is & 论 \\
\hline Sun H (2020) & 7 & is & is & is & 动 & I & 1 & is & w & is \\
\hline $\operatorname{Tan} \mathrm{N}(2020)$ & 8 & is & is & is & I & is & is & is & is & is \\
\hline Tang N (2020) & 7 & is & is & is & I & I & is & is & is & is \\
\hline Tian S (2020) & 6 & is & is & is & I & I & I & is & is & is \\
\hline Wan S (2020) & 7 & is & is & is & is & I & I & is & is & is \\
\hline Wang D (2020) & 6 & is & 论 & 动 & I & I & I & is & is & is \\
\hline Wang K (2020) & 6 & is & is & is & I & I & 1 & के & 许 & 虾 \\
\hline Wang Z (2020) & 6 & 虾 & 放 & 动 & 1 & 1 & 1 & 动 & 的 & 动 \\
\hline Wei J (2020) & 5 & is & 放 & के & 弥 & I & 1 & 弥 & I & I \\
\hline Wu J (2020) & 6 & 放 & is & is & I & I & 1 & is & 弥 & is \\
\hline Xie J (2020) & 6 & is & 放 & is & I & I & 1 & is & is & is \\
\hline Xu B (2020) & 4 & is & is & is & I & I & 1 & is & I & I \\
\hline Yang Q (2020) & 4 & is & is & is & I & I & 1 & is & I & I \\
\hline YuY (2020) & 6 & is & I & is & is & I & / & is & is & is \\
\hline Zhang H (2020) & 5 & is & I & is & I & I & 1 & is & is & is \\
\hline Zhang J (2020) & 4 & is & is & is & I & I & 1 & कर & I & I \\
\hline Zhang J (2020) & 6 & is & 虾 & 出 & I & 1 & 1 & is & 虾 & is \\
\hline Zhang L (2020) & 4 & 虾 & is & is & I & I & 1 & is & I & I \\
\hline Zhang Y (2020) & 7 & is & 动 & is & / & is & 1 & is & is & is \\
\hline Zhang Y (2020) & 6 & is & is & is & I & I & 1 & is & 的 & is \\
\hline Zhao X (2020) & 6 & is & 虾 & is & I & I & 1 & is & is & is \\
\hline Zhou F (2020) & 6 & is & is & is & I & I & I & is & is & is \\
\hline Zhou X (2020) & 4 & is & is & is & I & I & 1 & is & I & ' \\
\hline An W (2020) & 5 & के & is & is & I & I & is & is & I & / \\
\hline Chang Z (2020) & 7 & is & is & 1 & 论 & is & 1 & is & is & के \\
\hline Foy B (2020) & 6 & 虾 & is & 动 & I & I & 1 & 虾 & 的 & 许 \\
\hline Guo F (2020) & 7 & is & is & के & I & is & 弥 & is & I & is \\
\hline Li J (2020) & 6 & is & is & है & I & I & 1 & is & के & $\approx$ \\
\hline Luo M (2020) & 7 & is & is & is & I & is & 1 & is & is & is \\
\hline Fang X (2020) & 6 & is & is & is & I & I & 1 & is & is & 出 \\
\hline Yang H (2020) & 7 & is & is & is & / & is & I & 弥 & is & है \\
\hline Yang J (2020) & 6 & is & is & is & ' & 1 & 1 & is & 许 & 出 \\
\hline Zhang C (2020) & 7 & 虾 & कर & is & I & is & I & is & w & is \\
\hline Zhang F (2020) & 7 & is & is & is & ' & 1 & 1 & is & is & is \\
\hline Zhang G (2020) & 7 & 虾 & 虾 & 弥 & ' & is & 1 & is & is & is \\
\hline Zhang J (2020) & 6 & 弥 & is & 动 & 1 & S2 & 虾 & is & 1 & \\
\hline
\end{tabular}


Table S2 Results of meta-regression analyses

\begin{tabular}{lc}
\hline Covariates & P value \\
\hline Sample size $(\geq 100$ versus $<100)$ & 0.456 \\
Region (Asia versus Europe versus North America) & 0.0001 \\
Source of cases (single-center versus multiple-center) & 0.756 \\
NOS (>6 versus $\leq 6)$ & 0.956 \\
Study design (retrospective versus prospective) & 0.403 \\
Longest follow-up (>30 versus $\leq 30$ days) & 0.624 \\
Proportion of patients with severe disease $(>50 \%$ versus $\leq 50 \%)$ & $<0.001$ \\
\hline
\end{tabular}

NOS, Newcastle-Ottawa Scale. 
Table S3 Risk of factors in COVID-19 patients

\section{First author (year) \\ Risk factors of death in the univariate analysis}

Benussi A (2020)

Older age, hypertension, qSOFA score, thrombocytopenia, elevated C-reactive protein, and lactate dehydrogenase

(im

Age $\geq 75$, Male, CHD, CVD, COPD, diabetes, hypertension, malignancy, chronic renal diseases, abn

U/L, AST >40 U/L, ALT >40 U/L, TBIL >17.1, creatinine kinase $>200$, creatinine $>133$, D-dimer $\geq 0.5$

Andrea C (2020)

Older age, hypertension, heart failure, diabetes, COPD, cancer, CKD, ACEI/ARBs and B-blocker

Cummings M (2020) Older age, hypertension, chronic cardiac disease, chronic pulmonary disease, diabetes, higher concentrations of IL-6 and D-dimer

Du R (2020)

Age $\geq 65$ years, hypertension, cardiovascular or cerebrovascular diseases, dyspnea, fatigue, sputum production, headache, $W B C>10 \times 10^{\circ} /$ neutrop 作 $\mathrm{PaO}_{2} \geq 80$ or $<60 \mathrm{mmHg}$ Hg

Older age, male, hypertension, leukocytosis, lymphopenia, elevated NT-proBNP, Myoglobin, creatine kinase-MB, hs-Tnl, urea, creatinine, CRP and

Gao L (2020)

Giacomelli A (2020)

Huang J (2020)

Older age, comorbidity, obesity,

creatinine, and creatine kinase

Older age, any comorbidity, lymphopenia, hypoalbuminemia

Klang E cohort 1 (2020) $\quad B M I \geq 40 \mathrm{~kg} / \mathrm{m}^{2}$

Klang E cohort 2 (2020) Coronary artery disease, congestive heart failure, hypertension, diabetes mellitus, hyperlipidemia, chronic kidney disease

Mehta V (2020) Age >65 years, ICU admission, hypertension, chronic lung disease, CAD, CHF, reduced baseline hemoglobin and nadir hemoglobin, leukocytosis, lymphopenia, elevated D-dimer, lactate and LDH Renieris G (2020) Age $\geq 64$ years, Charlson's comorbidity index $\geq 3$, APACHE II score $\geq 10$, pneumonia severity index $\geq 11$, SOFA $\geq 4$, serum $\mathrm{H}_{2} \mathrm{~S}$ on day $1 \geq 150.44 \mu \mathrm{M}$, sever Older age, Male, $\mathrm{SpO}_{2}$, increased heart rate and respiratory rate, consciousness disorders, hypertension, previous respiratory diseases, leukocytosis

Sun $\mathrm{H}(2020)$

Older age, male, higher PT, lower platelet count, higher D-dimer, more sepsis-induced coagulopathy

Tang N (2020)

Wang D (2020)

Older age, male, hypertension, diabetes, cardiovascular disease, leukocytosis, thrombocytopenia, elevated neutrophil counts, CK-MB, lactate

dehydrogenase, ALT, AST, and creatinine

Wang K (2020)

Older age, hypertension, CHD, elevated neutrophil, hs-CRP, D-dimer, AST, and GFR, decreased $\mathrm{SpO}_{2}$, Iymphopenia

Xie J (2020)

Xu B (2020)

Age $\geq 60$ years, male, hypertension, dyspnea, $\mathrm{SpO}_{2} \leq 90 \%$, leukocytosis, thrombocytopenia, elevated CRP, D-dimer, and neutrophil count

cell $<50 / \mu L$, and B-cell $<50 / \mu L$ counts)

Older age, corran hert diserse d a

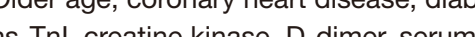

Zhou F (2020)

Foy B (2020)

Luo M (2020)

Older age, elevated RDW, Iymphopenia, D-dimer

Male, age $\geq 70$ years, use traditional Chinese medicine, clinical classification (severe/critical), hypertension, coronary heart disease, diabetes, tumors, uremia, nucleic acid test $(+)$

Older age, $\mathrm{SpO}_{2}$, lymphocyte, myocardial injury, LL-2R $>710 \mathrm{U} / \mathrm{mL}$, LL-6 $>35 \mathrm{ng} / \mathrm{L}$, LL-10 $>9.1 \mathrm{ng} / \mathrm{L}$

Yang $\mathrm{H}(2020)$

(

Yang $\mathrm{J}(2020)$

Decreased $\mathrm{SpO}_{2}$, elevated creatinine, D-dimer, and hs-Tnl

(andronenase

Zhang $\mathrm{F}(2020) \quad$ Decreased $\mathrm{SpO}_{2}$, elevect

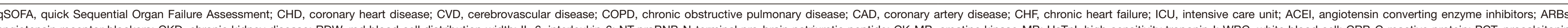
LDH, lactate dehydrogenase; BUN, blood urea nitrogen; AST, aspartate aminotransferase: TBIL, total bilirubin; Brixia score, chest X-ray scoring system; APACHE, acute physiology and chronic health evaluation; SOFA, sequential organ failure; SpO , peripheral capillary oxygen saturation.

Risk factors of death in the multivariate analysis

qSOFA score, thrombocytopenia, elevated lactate dehydrogenas

Older age, Brixia score, immunosuppressive conditions

Older age, heart failure and CKD

Older age, chronic cardiac disease, chronic pulmonary disease, higher concentrations of IL-6 and D-dimer

Age $\geq 65$ years, cardiovascular or cerebrovascular diseases, $\mathrm{CD}^{+} \mathrm{CD}^{+} \mathrm{T}$ cells $\leq 75 \mathrm{cell} / \mathrm{\mu L}$, cardiac troponin I $\mathrm{I} \geq 0.05 \mathrm{ng} / \mathrm{mL}$

Elevated NT-proBNP and procalcitonin, leukocytosis, lymphopen

Older age, obesity, critical disease, elevated CRP, creatine kinase

Any comorbidity, Iymphopenia, hypoalbuminemia

Age, BMl $\geq 40 \mathrm{~kg} / \mathrm{m}^{2}$, congestive heart failure, chronic kidney disease, intubation and mechanical ventilation

Older age, male sex, $\mathrm{BMI} \geq 40 \mathrm{~kg} / \mathrm{m}^{2}$, coronary artery disease, diabetes mellitus, chronic kidney disease, intubation and mechanical ventilation

Age >65 years, higher composite comorbidity score, ICU admission, elevated D-dimer, lactate and LDH

Serum H2S on day $1 \geq 150.44 \mu \mathrm{M}$, severe respiratory failure

Older age, leukocytosis, lymphopenia

Older age, higher PT, lower platelet count, higher D-dimer

Older age, male

Older age, decreased $\mathrm{SpO}_{2}$, elevated neutrophil, hs-CRP, and GFR

Dyspnea, $\mathrm{SpO}_{2} \leq 90 \%$, leukocytosis, elevated neutrophil count, and $\mathrm{CRP}$

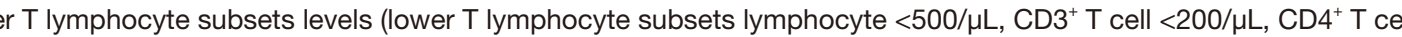
$<100 / \mathrm{LL}, \mathrm{CD} 8^{+} \mathrm{T}$ cell $<100 / \mathrm{ML}$, NK-cell $<50 / \mu \mathrm{L}$, and B-cell $<50 / \mathrm{HL}$ counts)

Elevated RDW $>14.5 \%$

Use traditional Chinese medicine, clinical classification (severe/critical), hypertension, coronary heart disease, diabetes, tumors, uremia

Older age, $\mathrm{SpO}_{2}, \mathrm{LL}-10>9.1 \mathrm{ng} / \mathrm{L}$

Fasting blood glucose $\geq 7 \mathrm{mmol} / \mathrm{L}$

Decreased $\mathrm{SpO}_{2}$, elevated D-dimer and hs-T

Annals of Palliative Medicine. All rights reserved. $\quad$ http://dx.doi.org/10.21037/apm-20-2557 

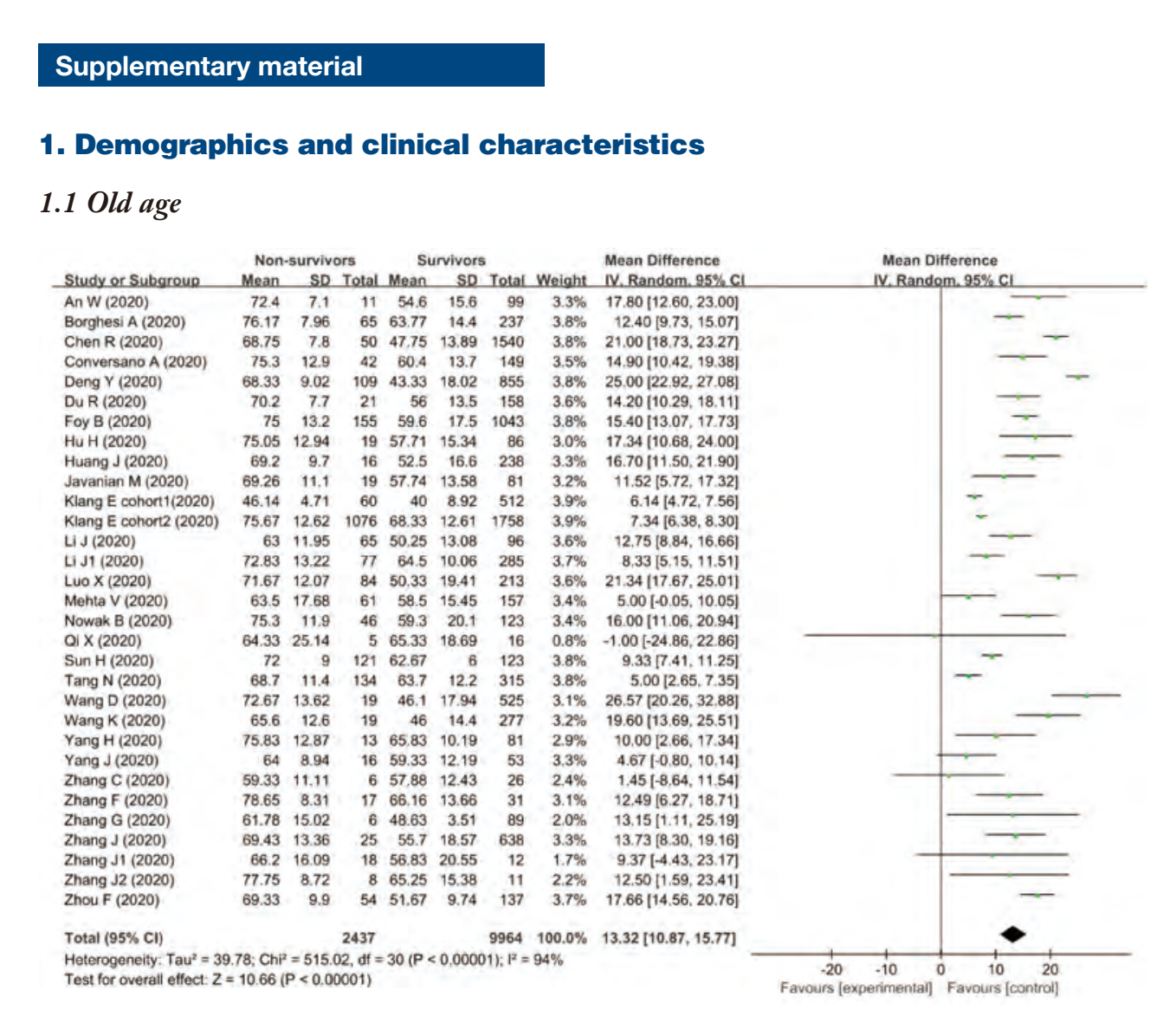

1.2 Male

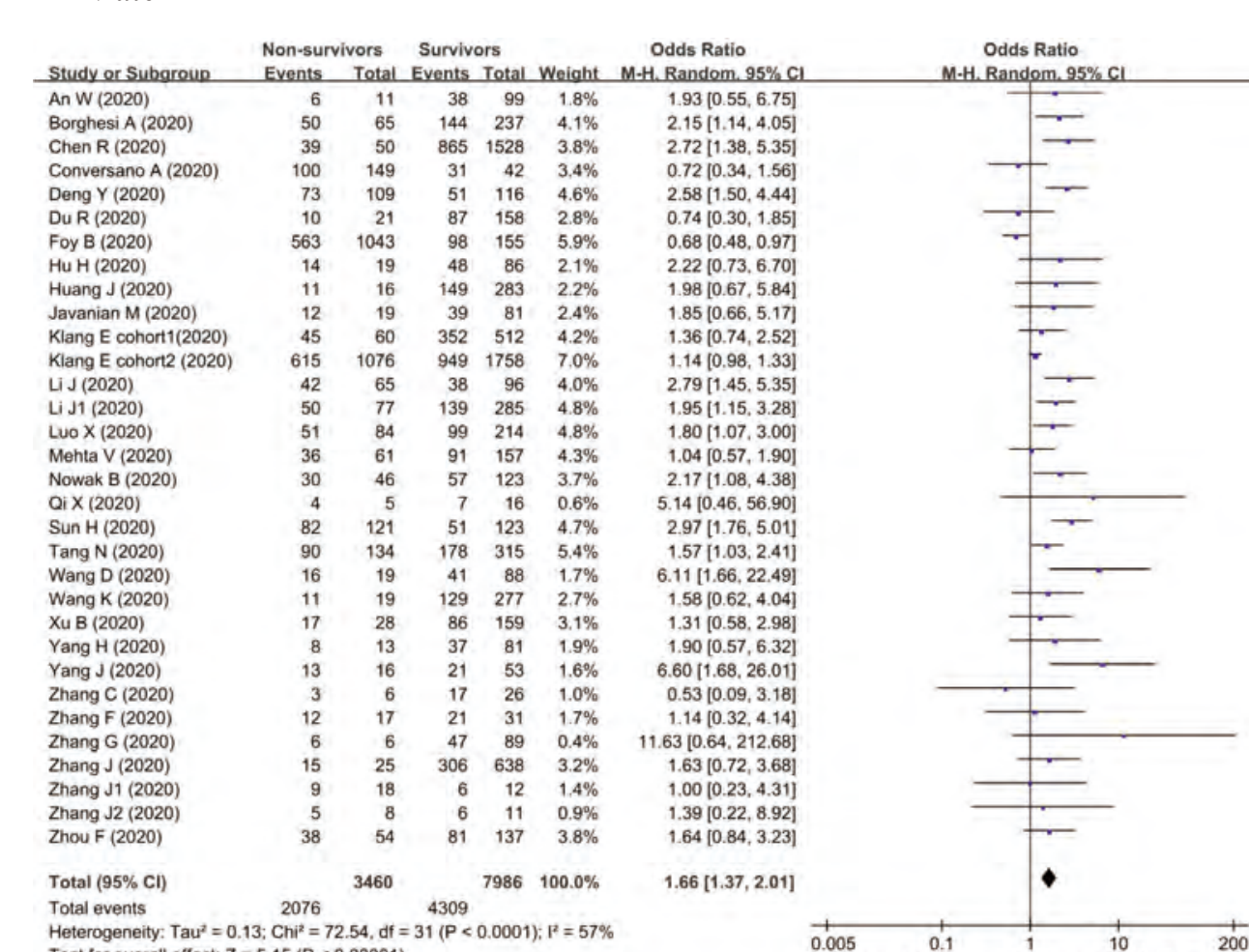

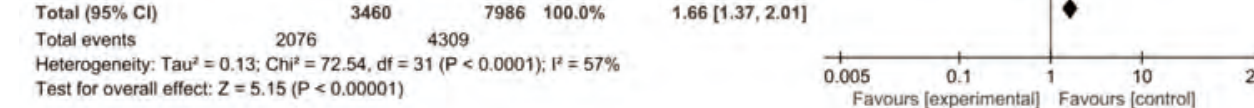

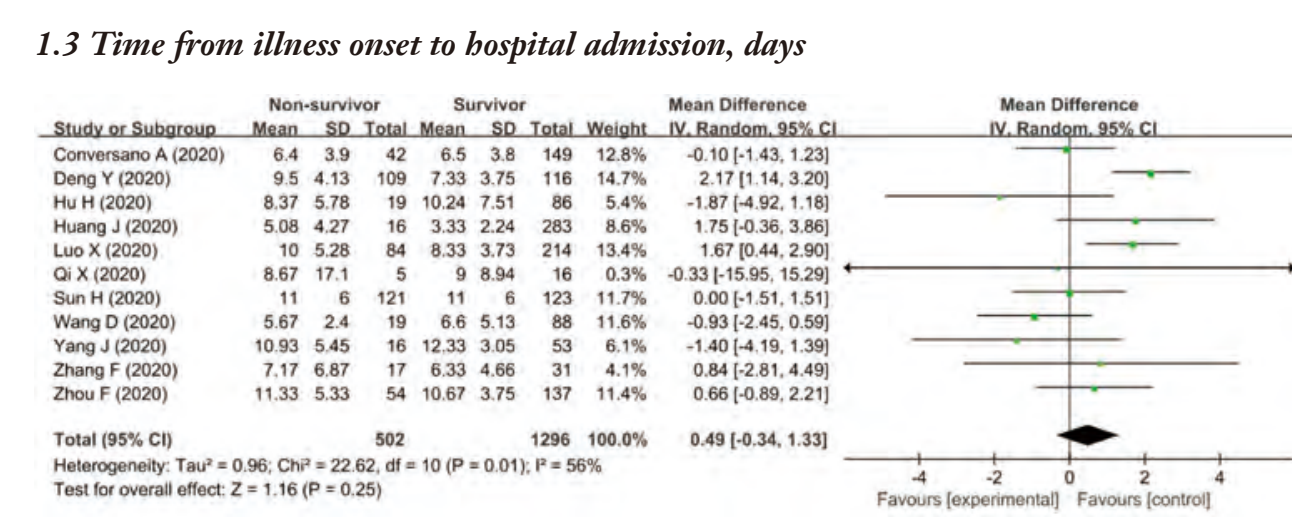

1.4 Comorbidities

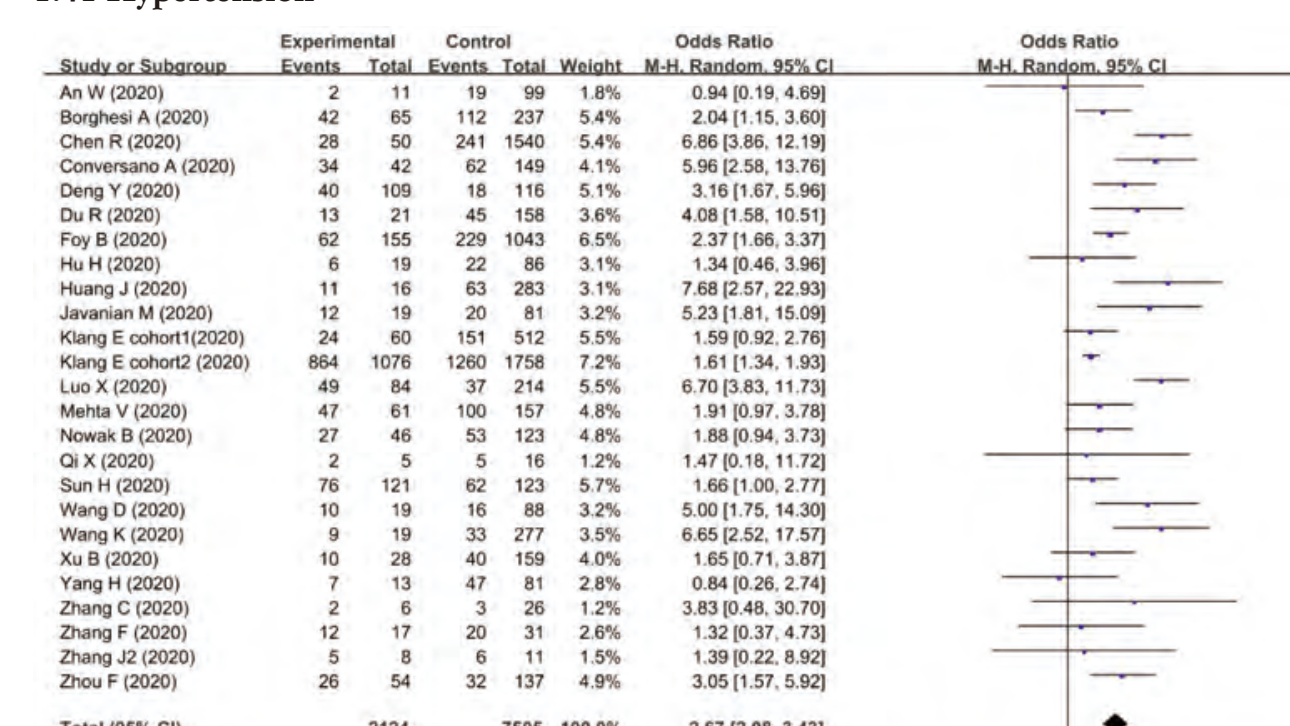

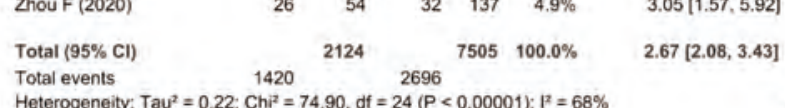

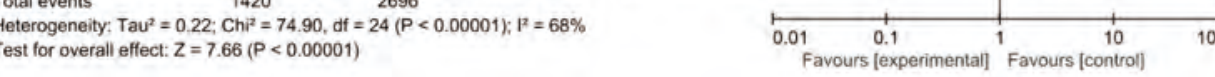
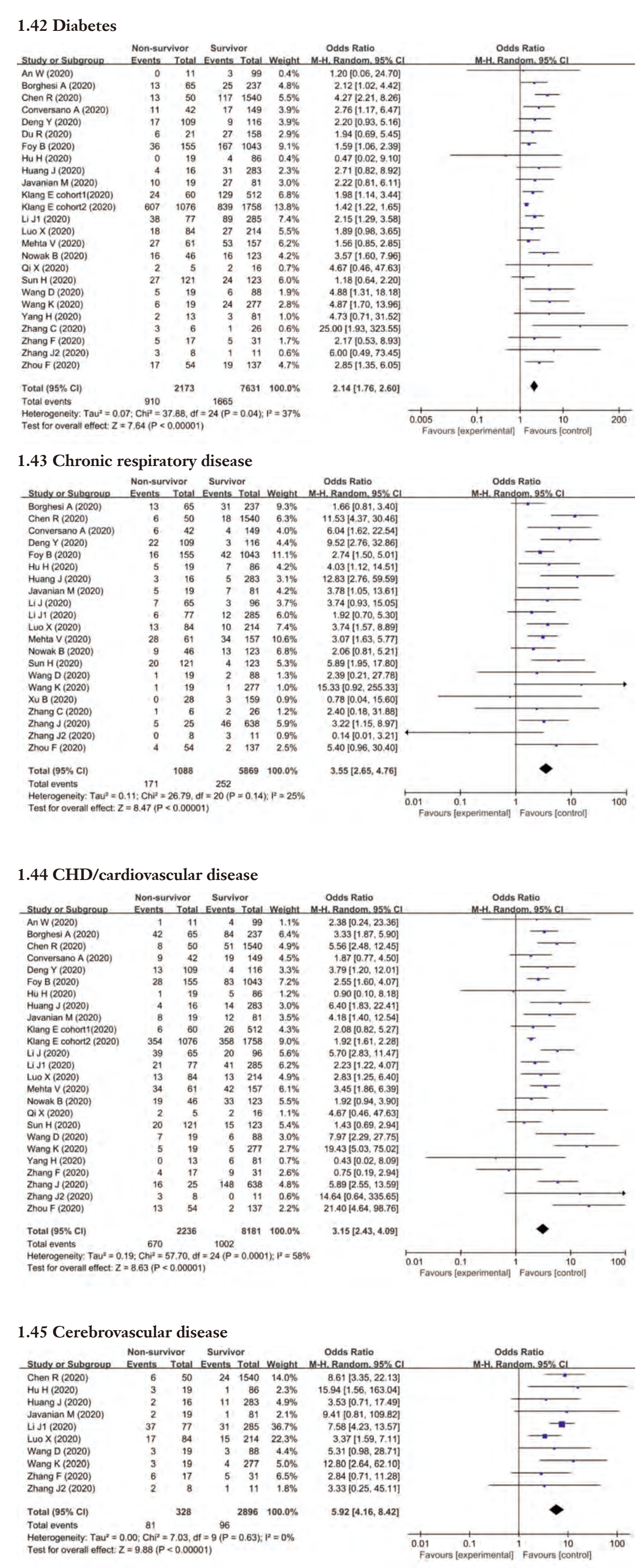


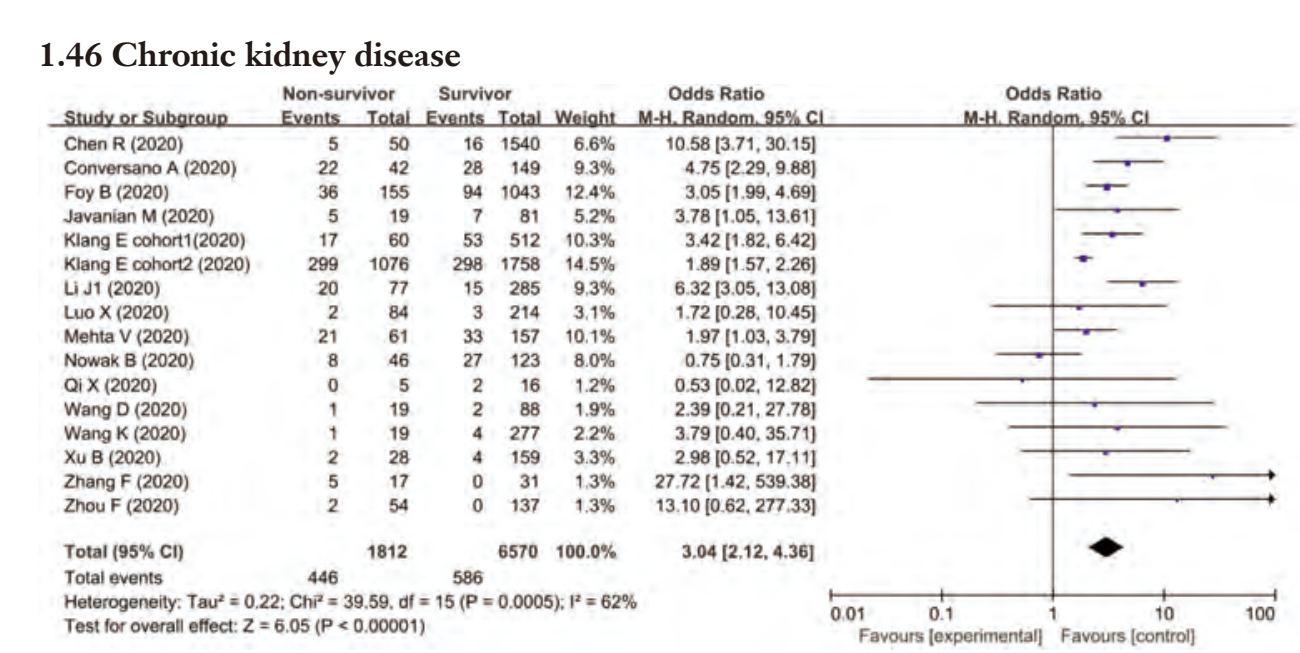

1.47 Smoking

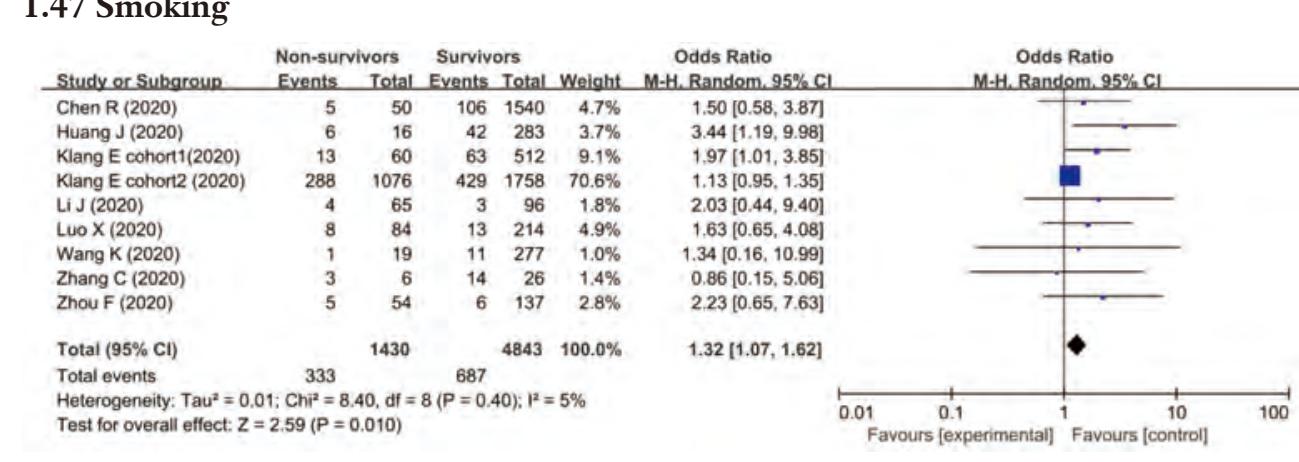

1.48 Cance

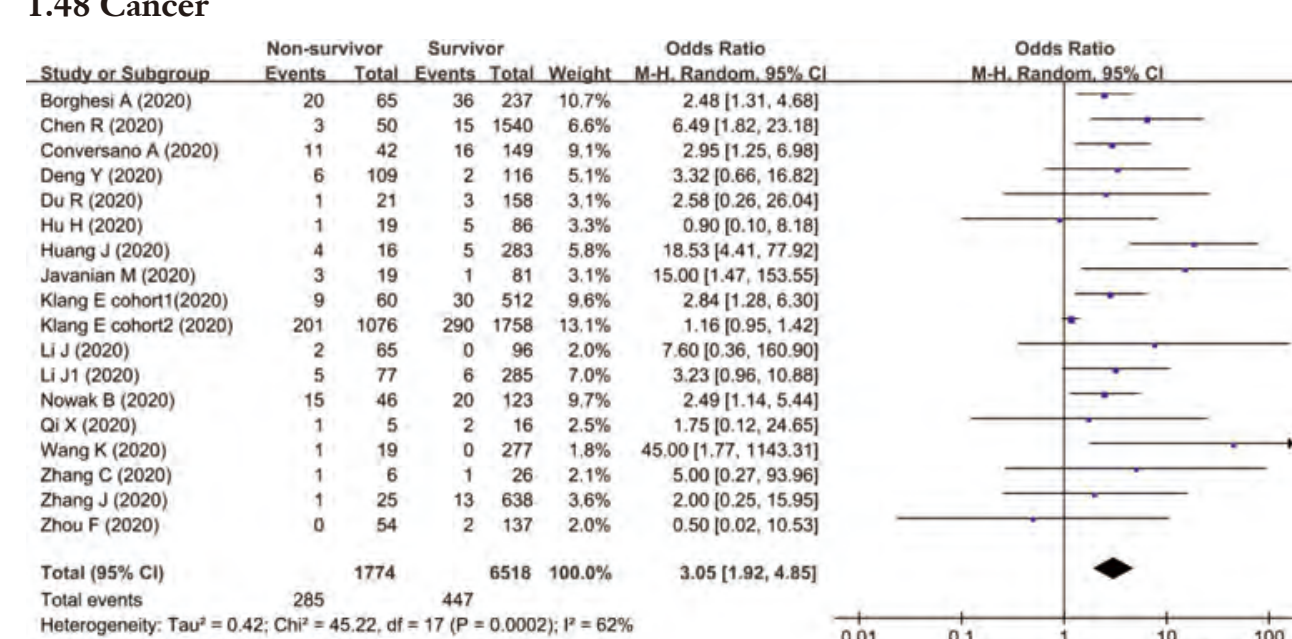

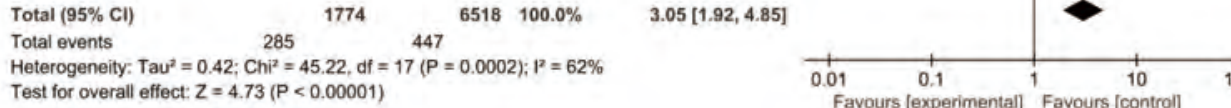

1.5 Clinical symptoms

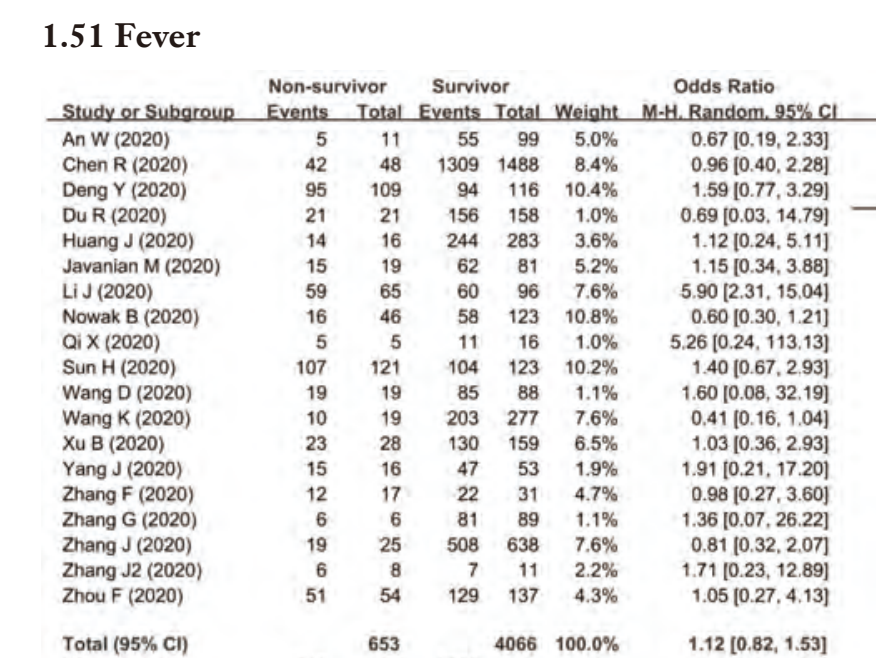

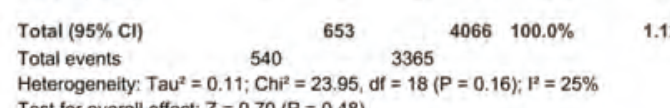
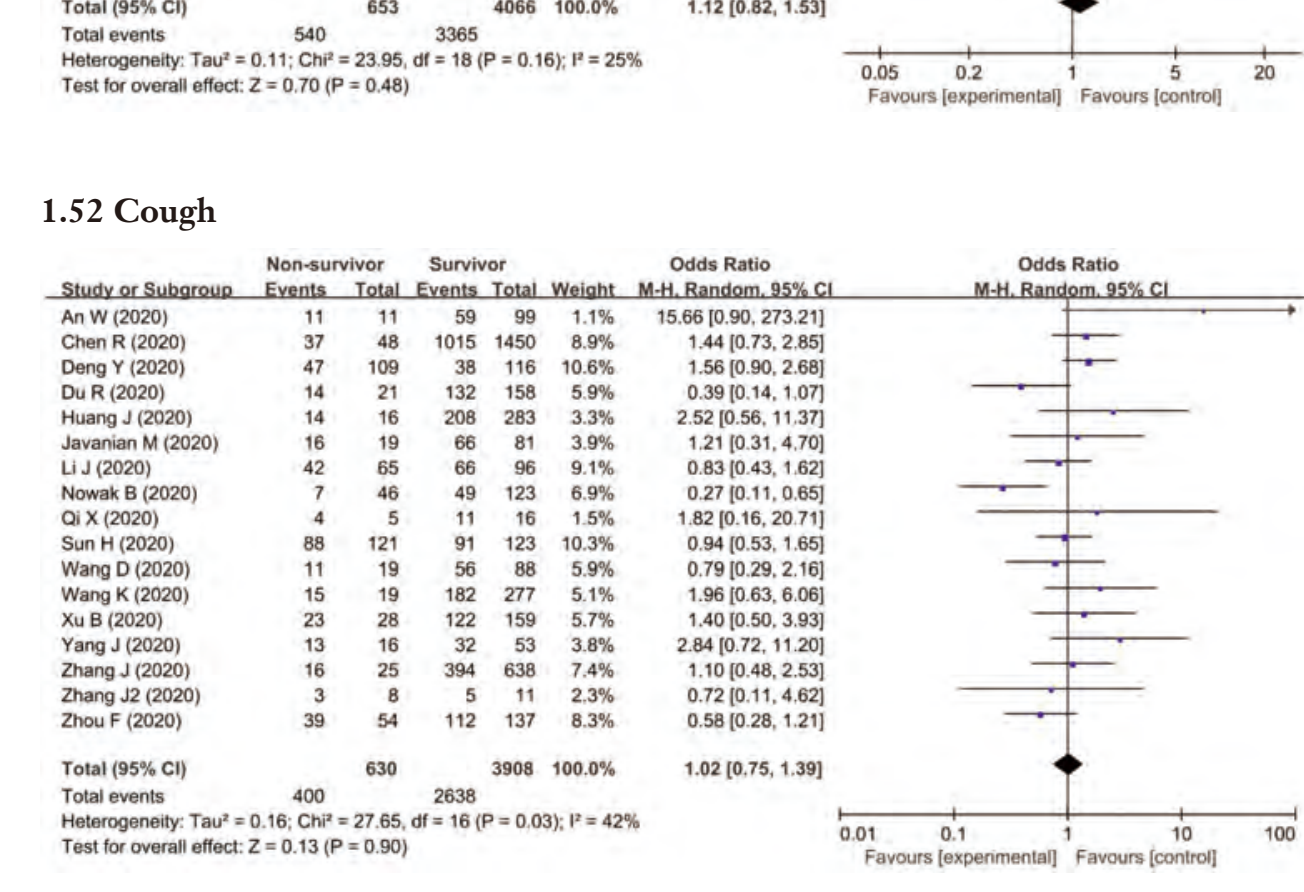

1.53 Dyspnea

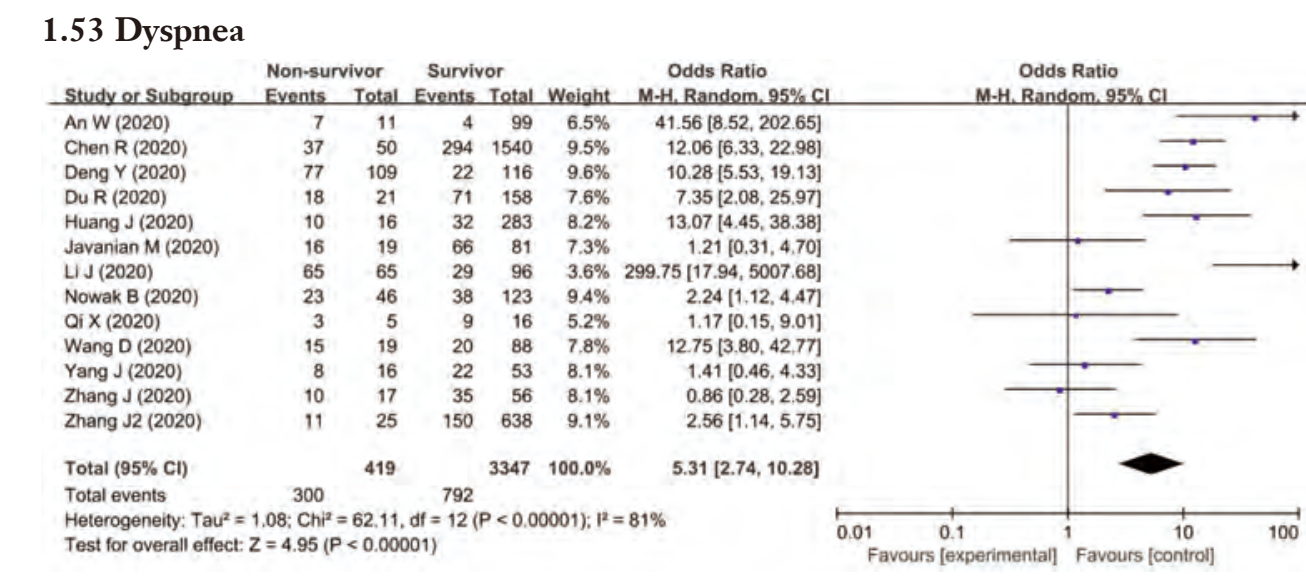

$1.54 \mathrm{Myal}$
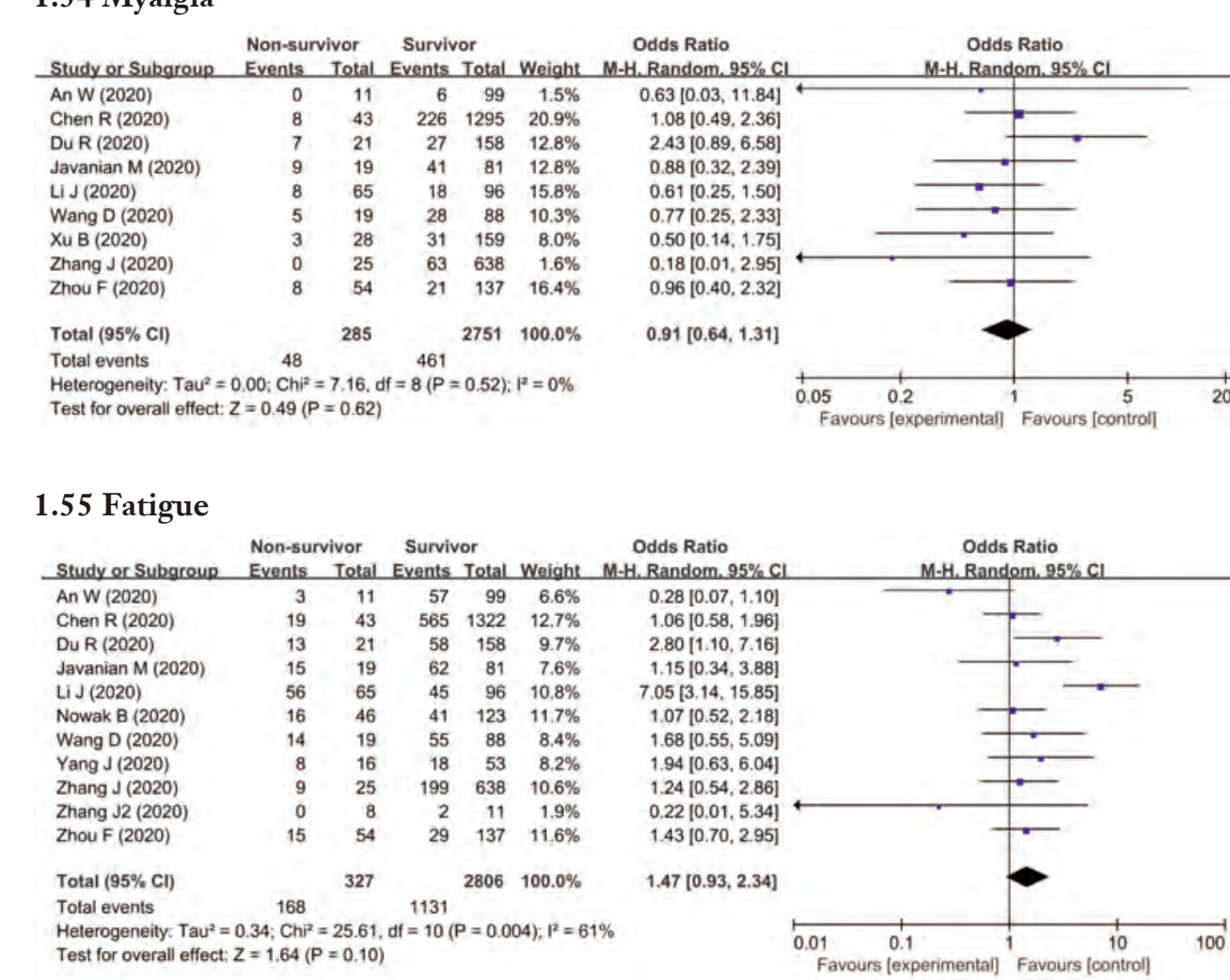

1.56 Expectoration
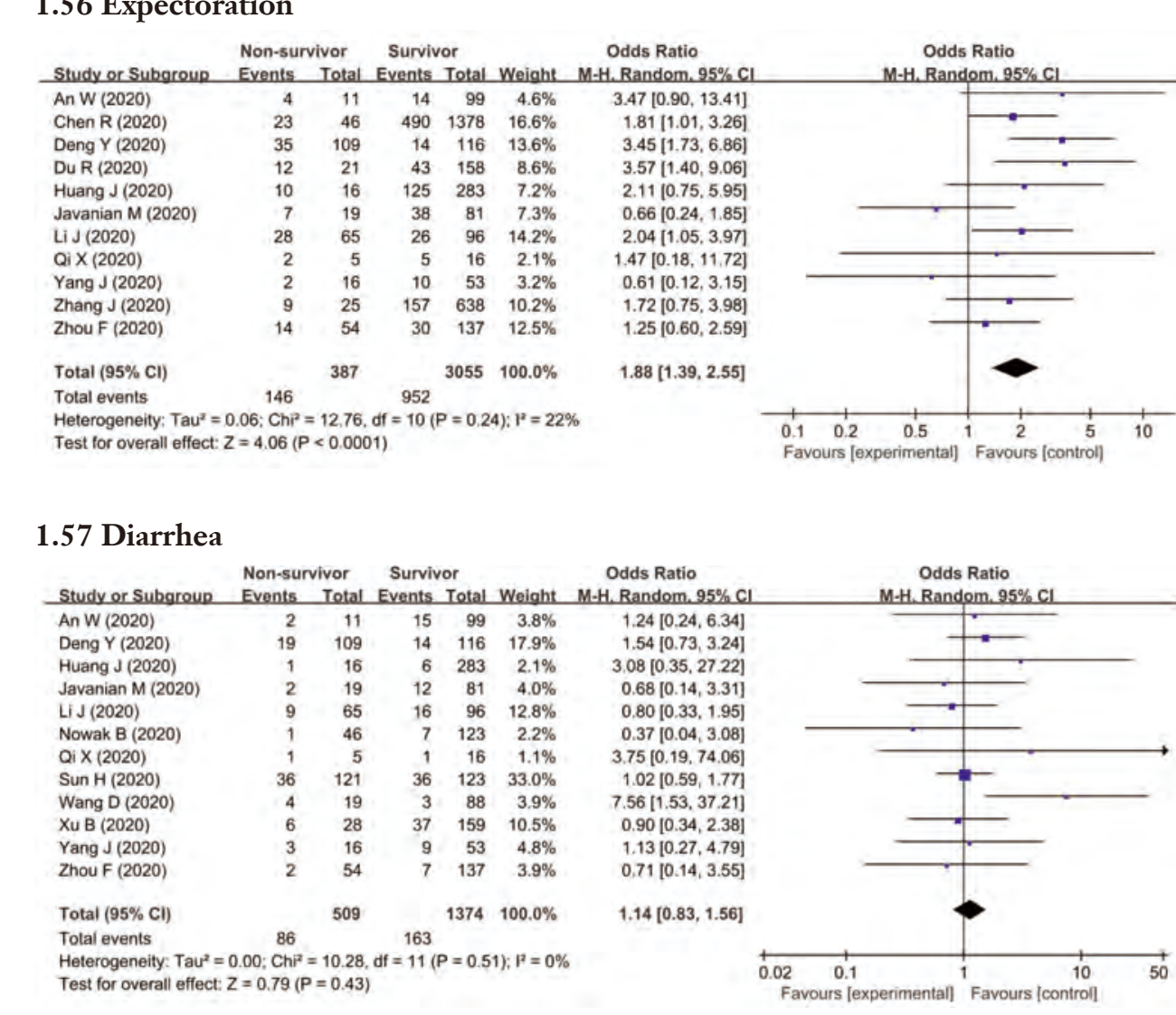

\section{Laboratory tests}

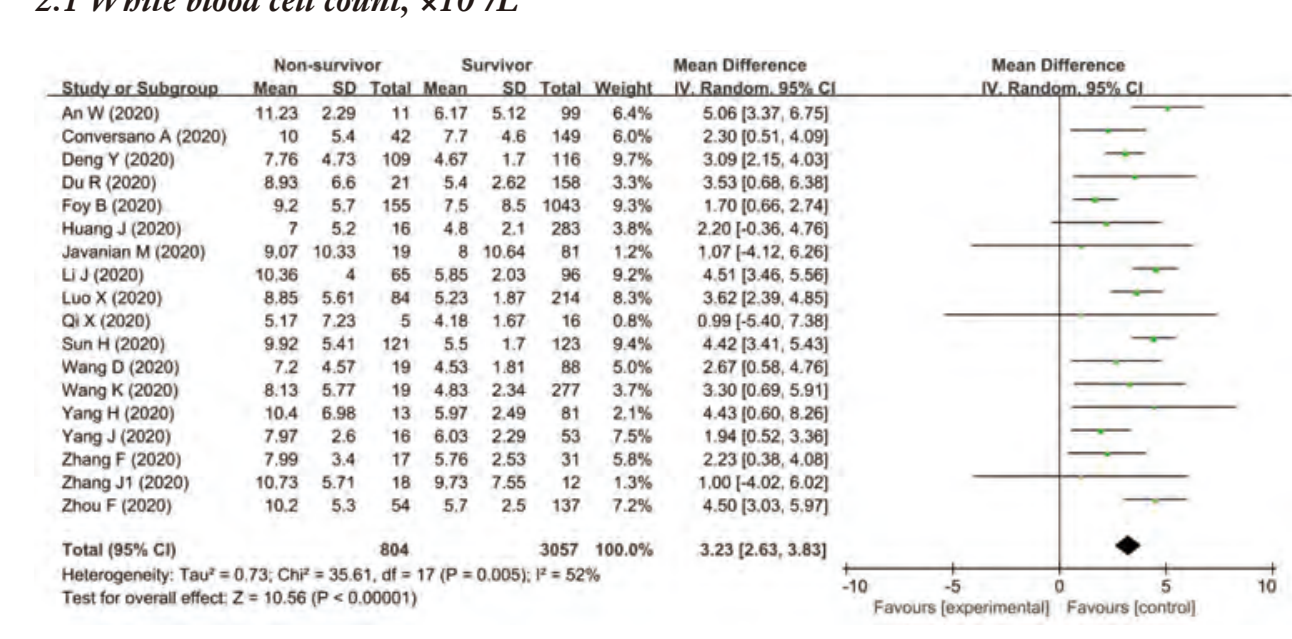




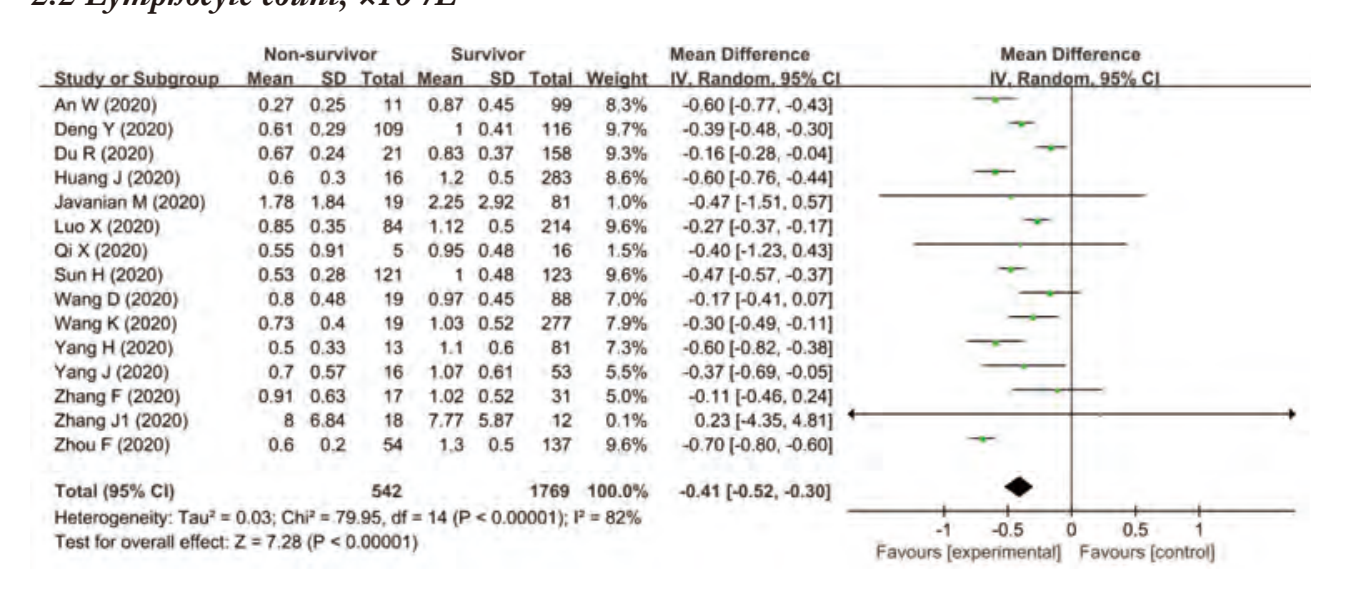

2.3 Neutrophil count, $\times 10^{\circ} \mathrm{L}$

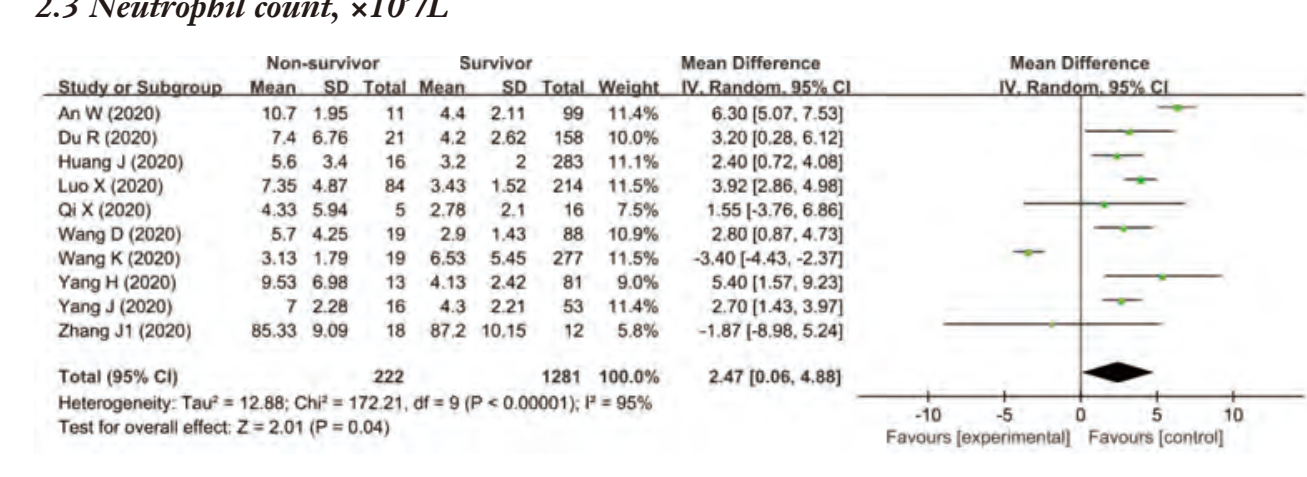

2.4 Platelet count, $\times 10^{\circ} \mathrm{L}$

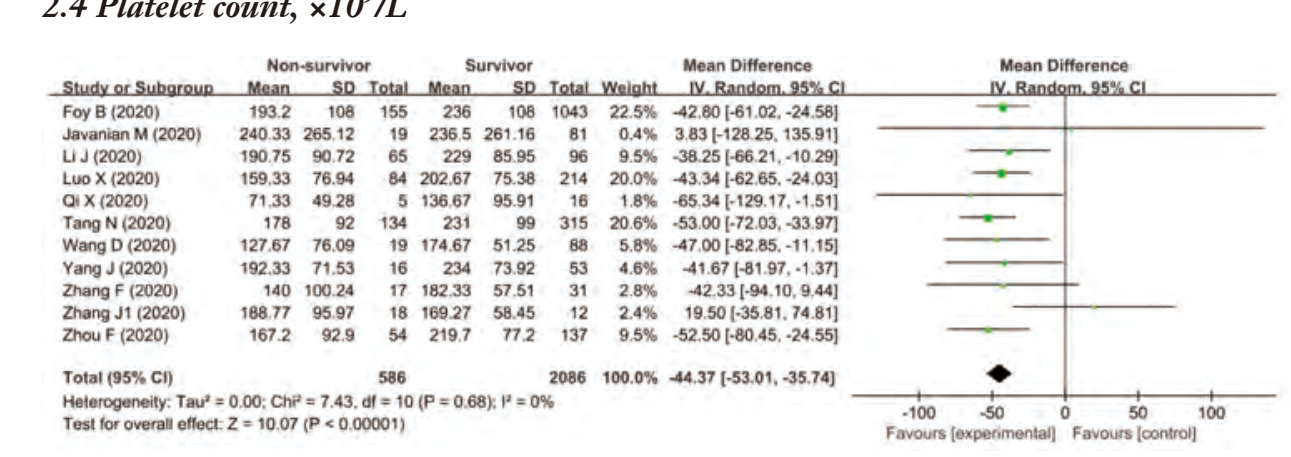

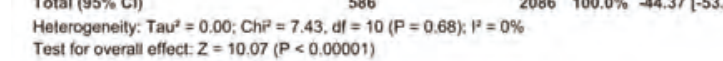

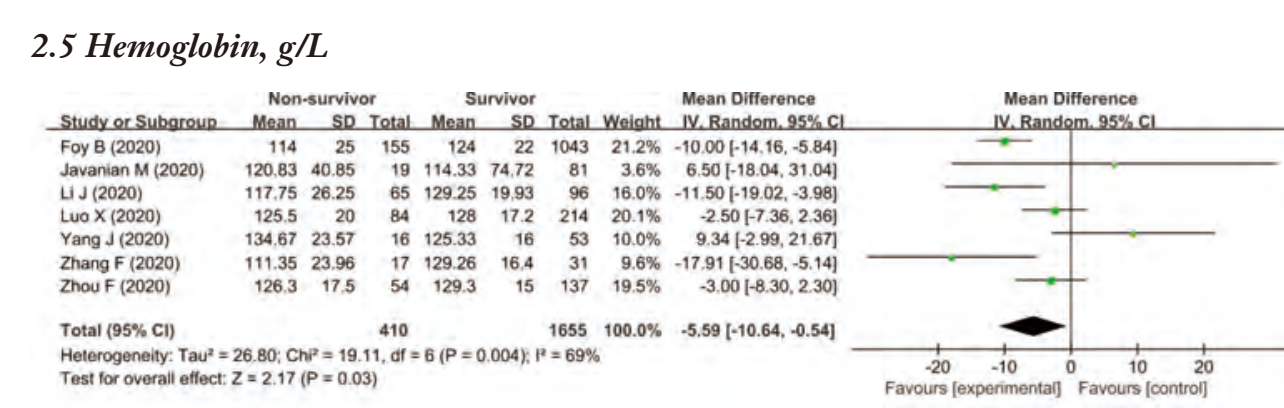

2.6 Albumin, $g / L$

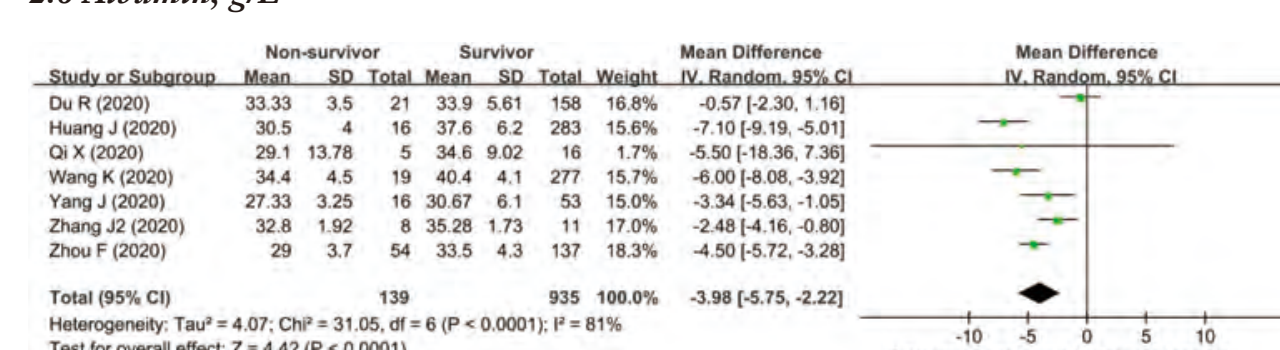

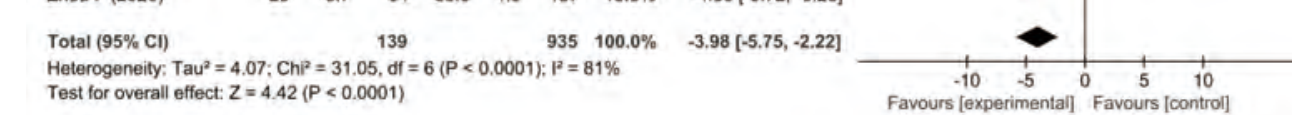

2.7 ALT, U

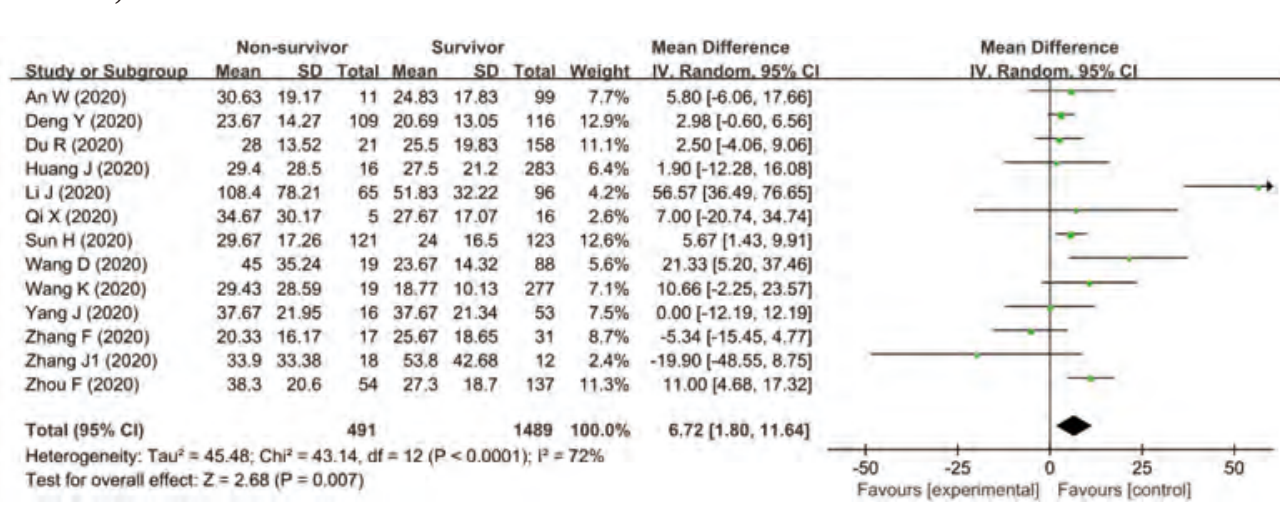

2.8 AST, ULL

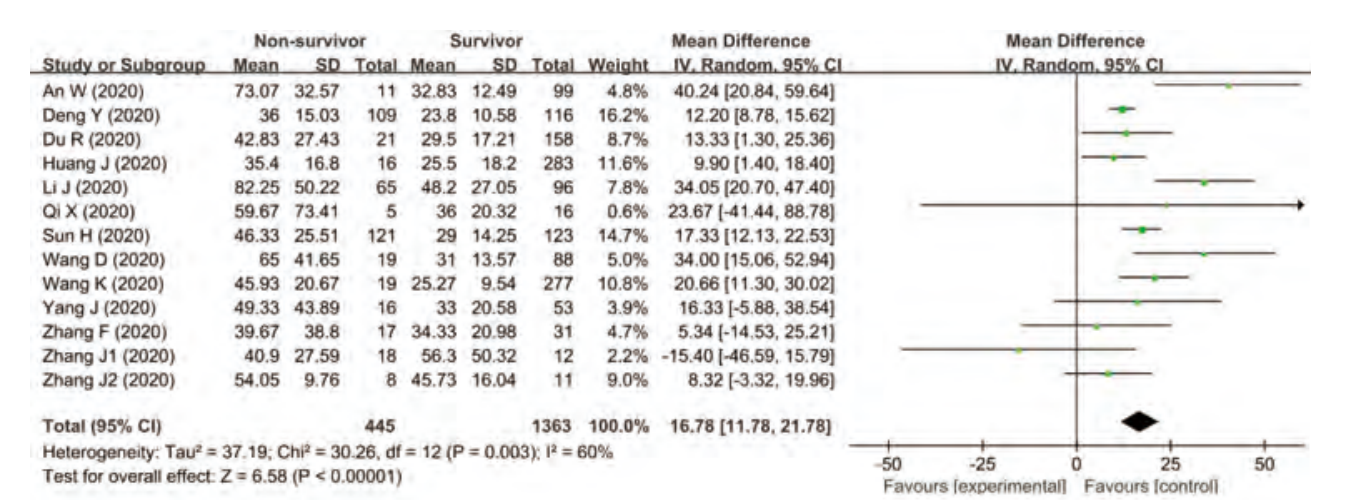

2.9 TBIL, umol/L

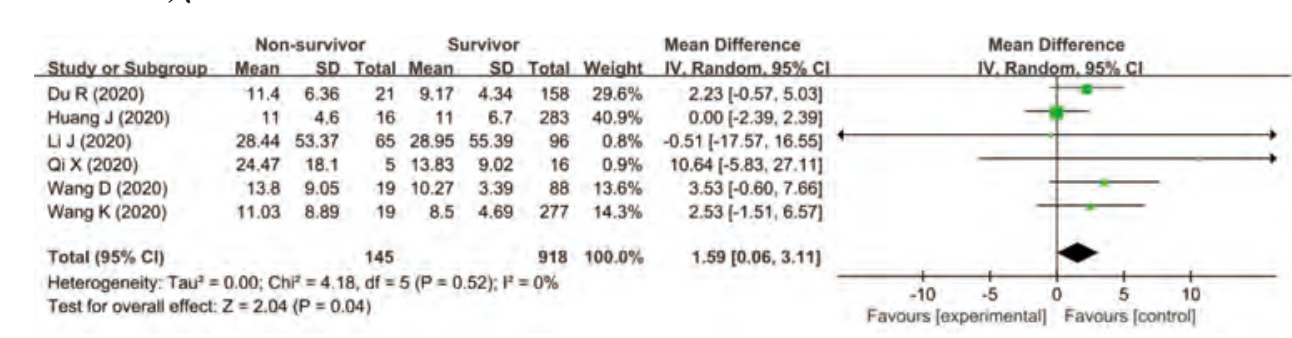

$2.10 \mathrm{LDH}, \mathrm{UL}$
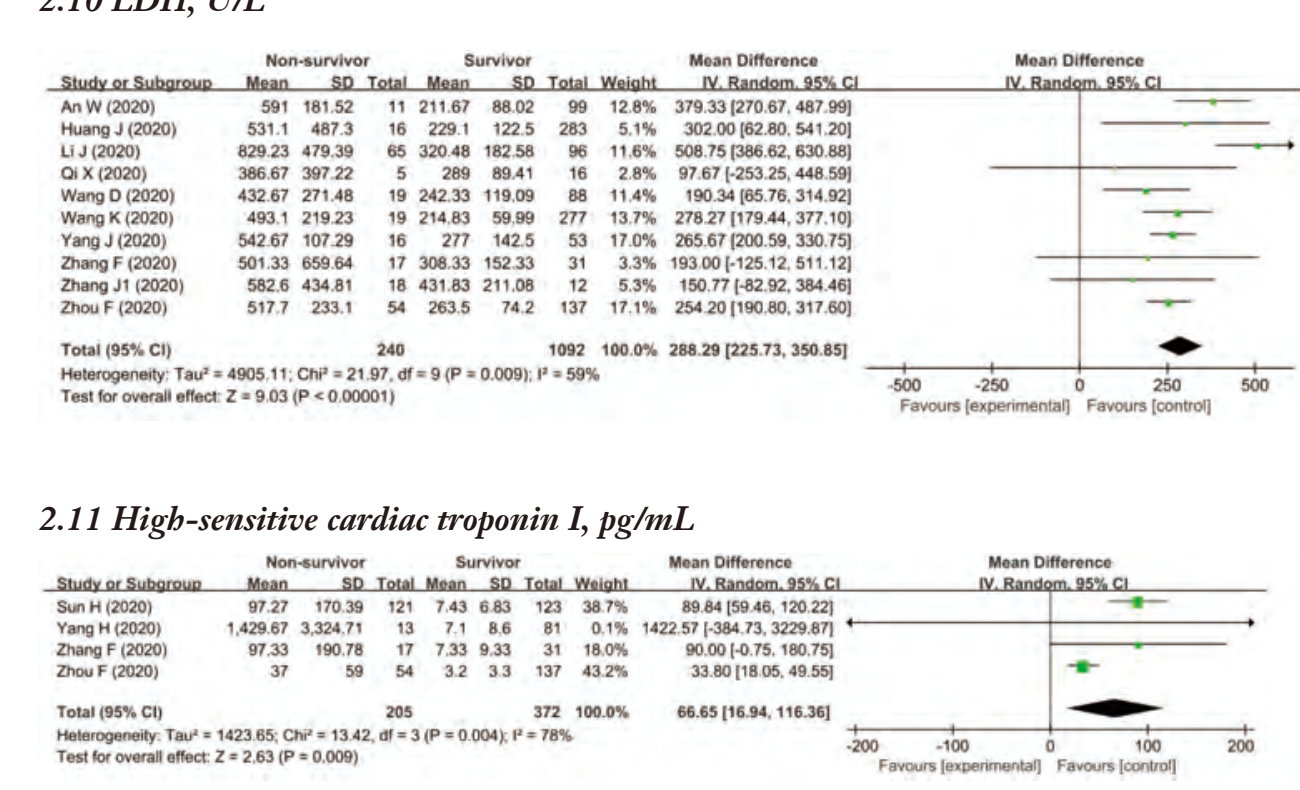

2.12 Hypersensitive troponin I, $>26.2 \mathrm{pg} / \mathrm{mL}$

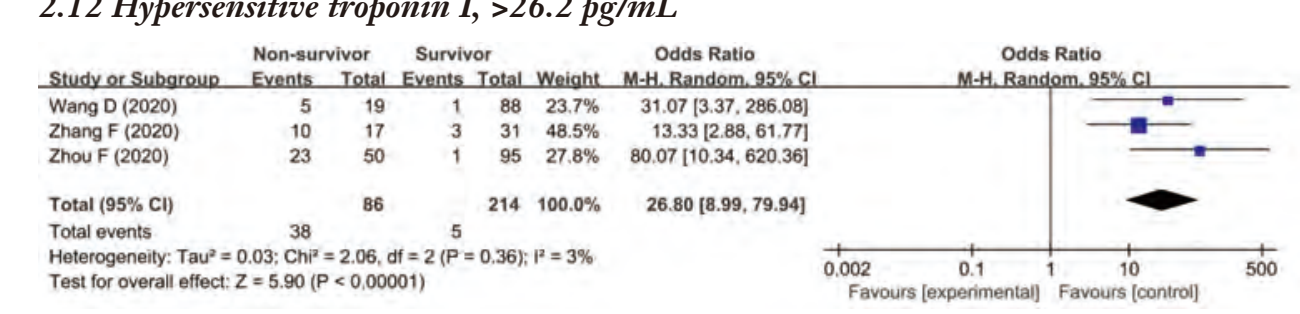

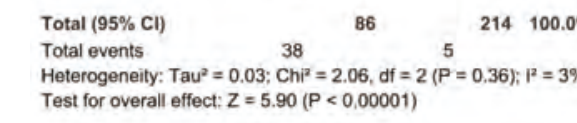
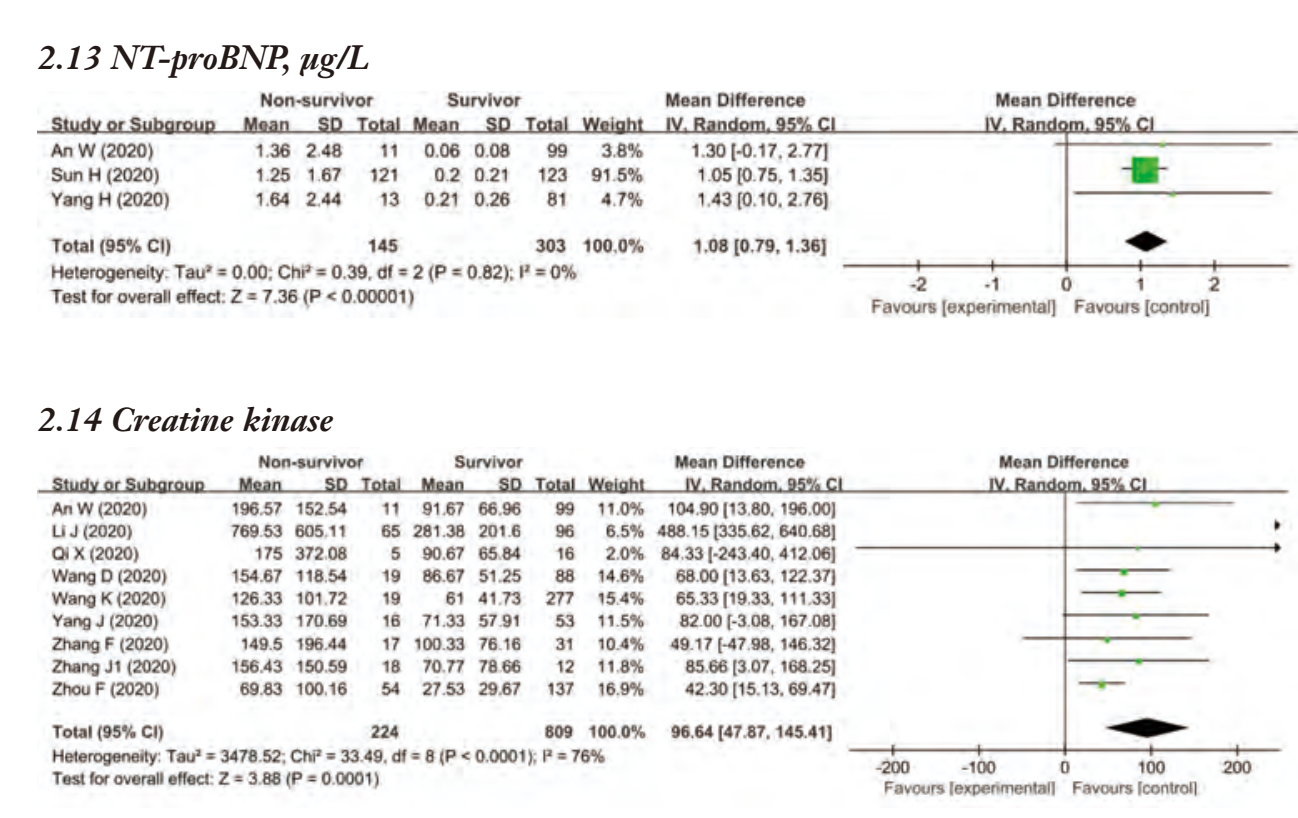

\subsection{5}

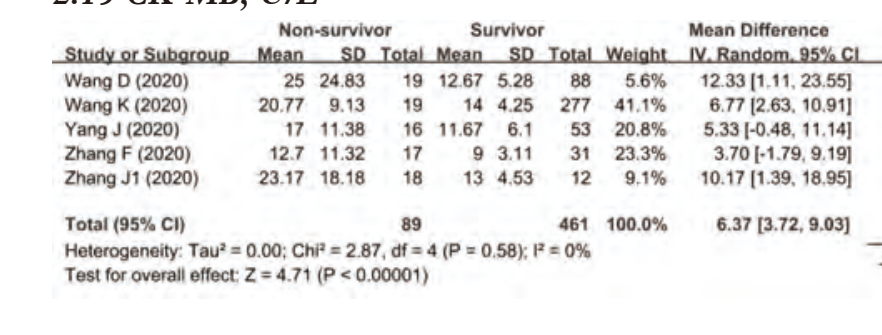

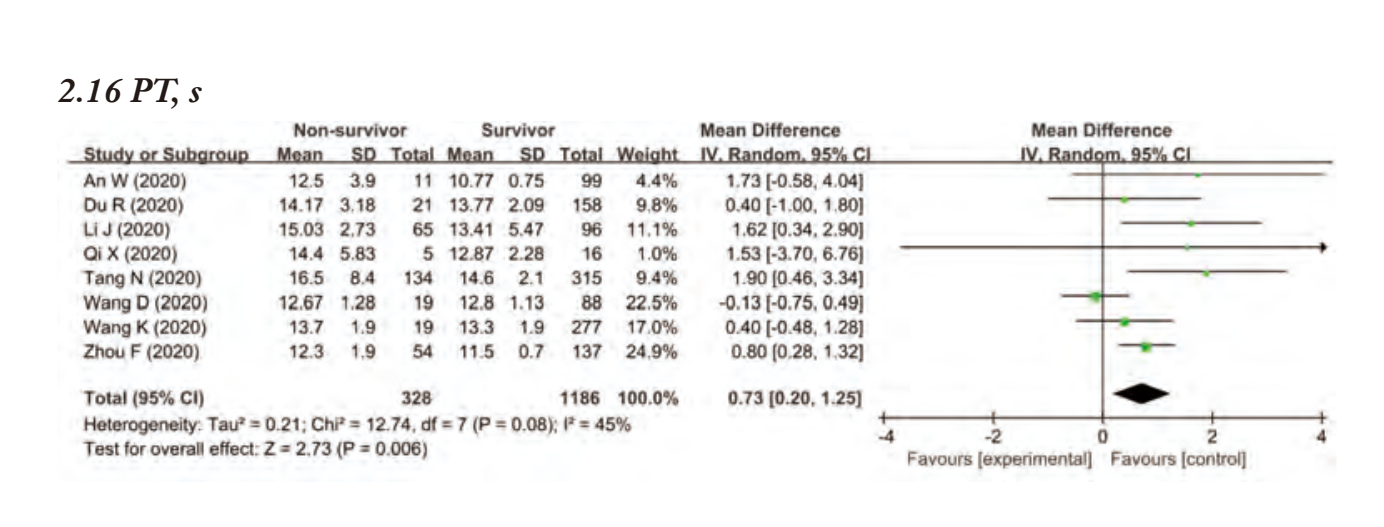



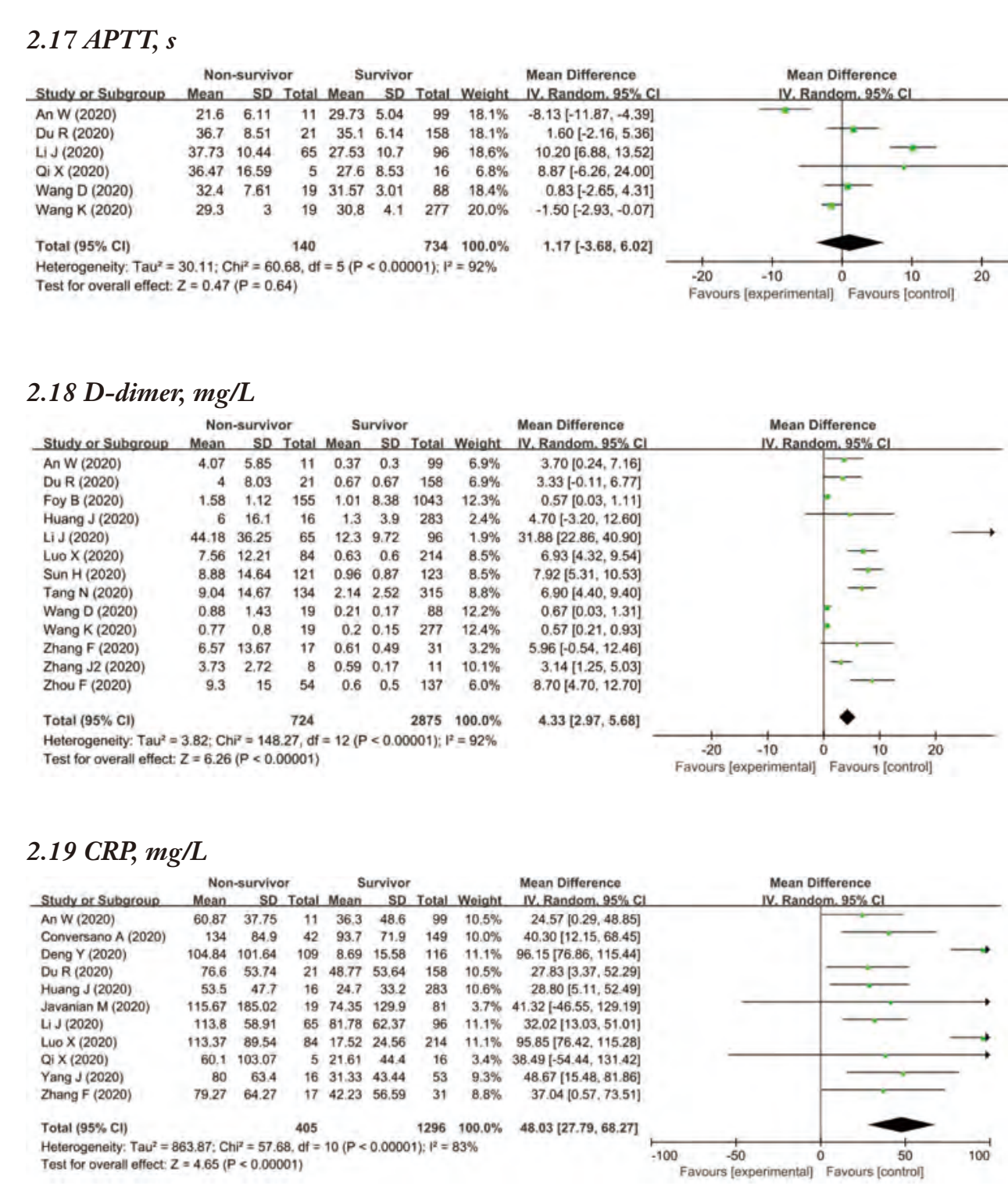

2.20 ESR, $\mathrm{mm} / \mathrm{h}$

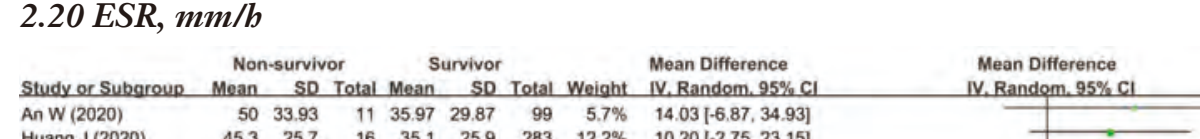

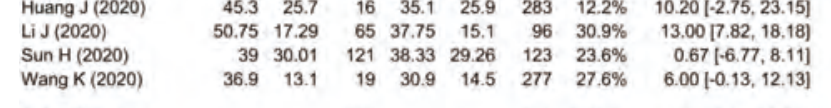

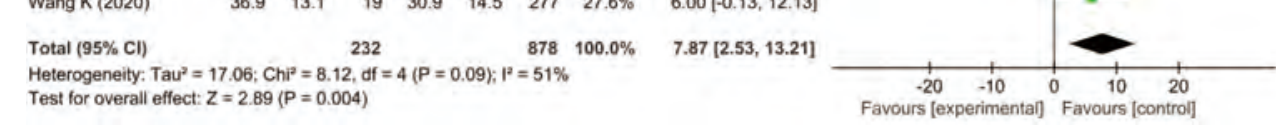

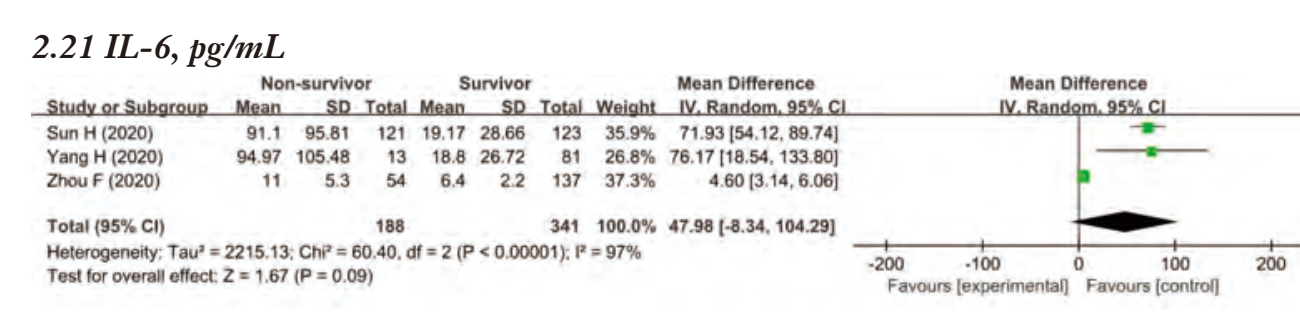

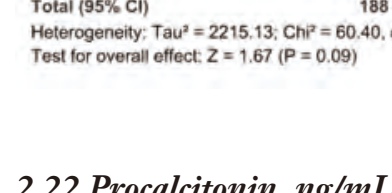

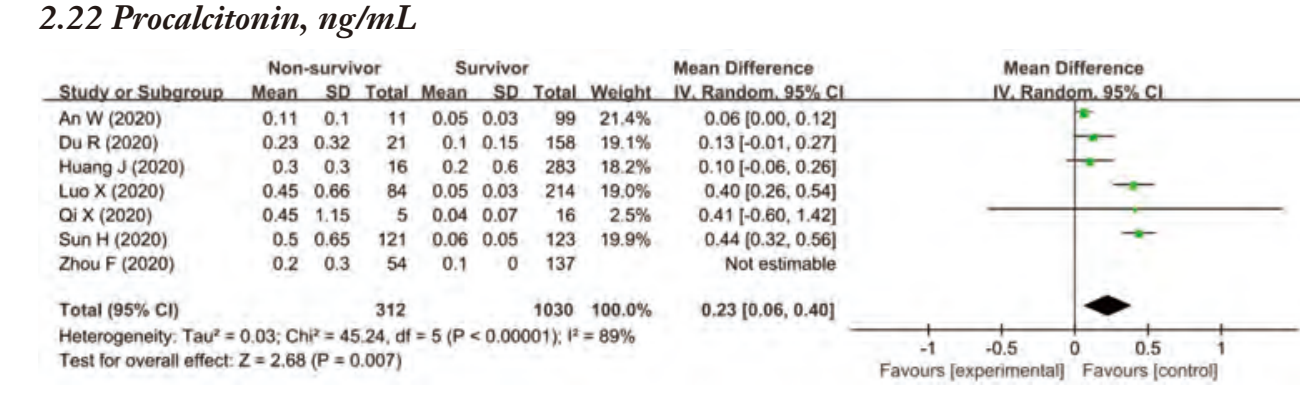

2.23 Serum ferritin, $m g / L$

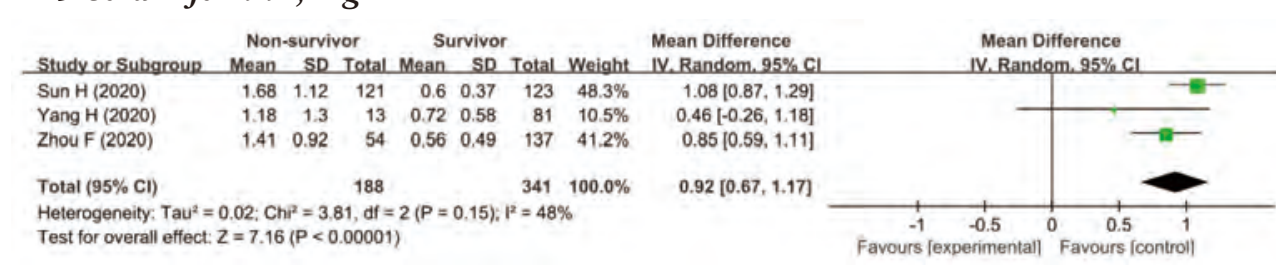

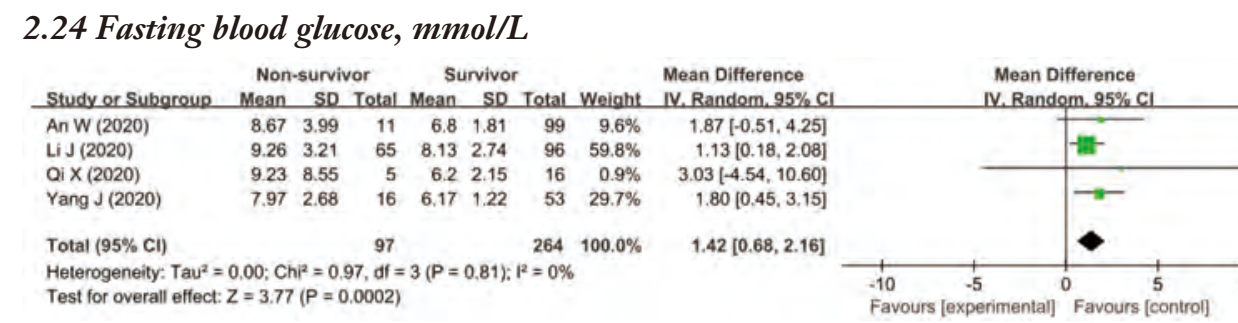

225 Sermun creatinine pum

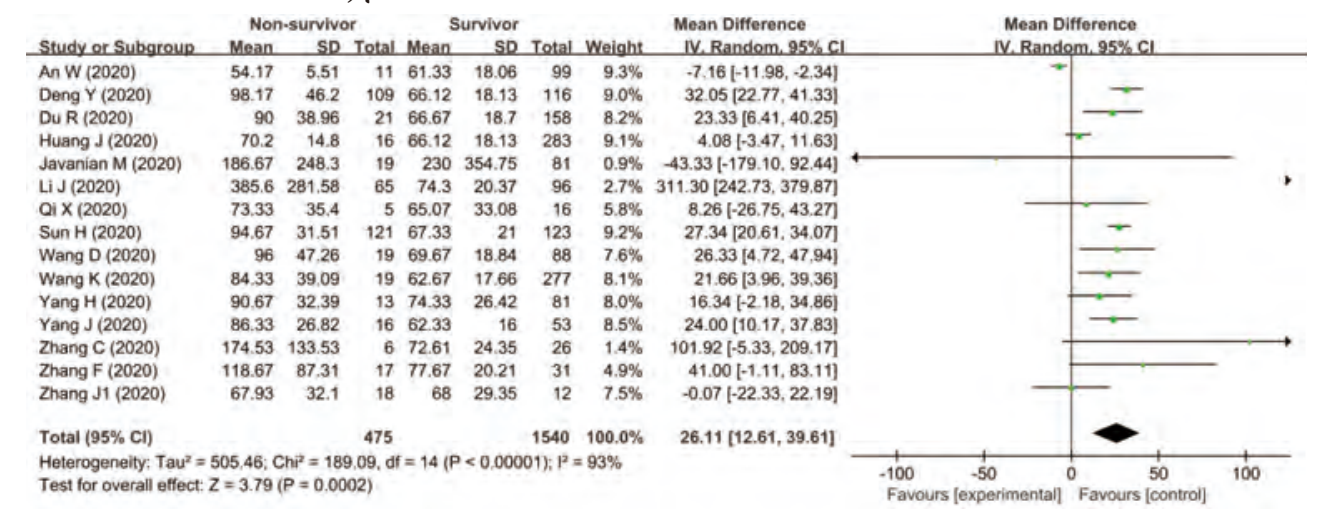

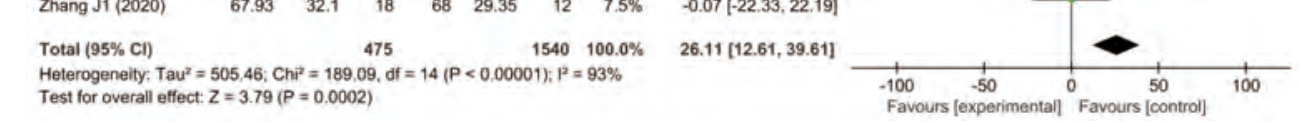

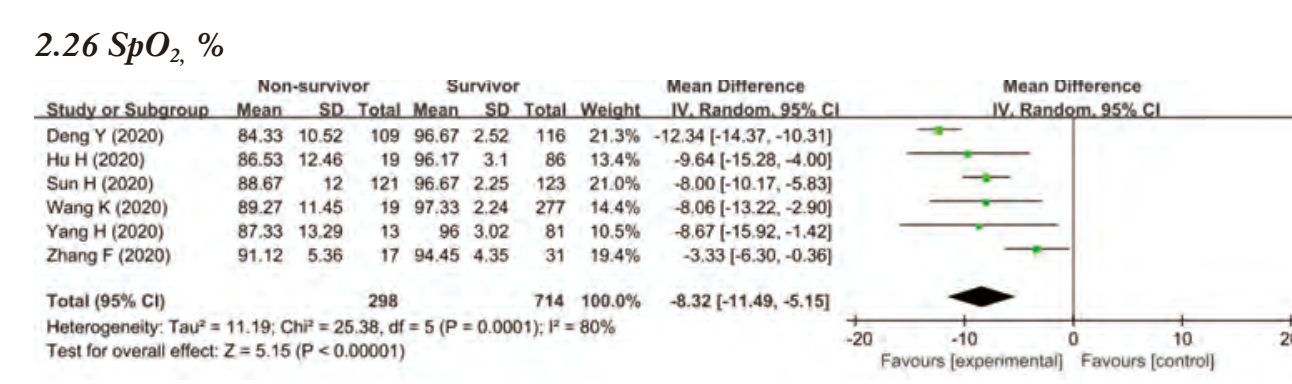

\section{Imaging features}

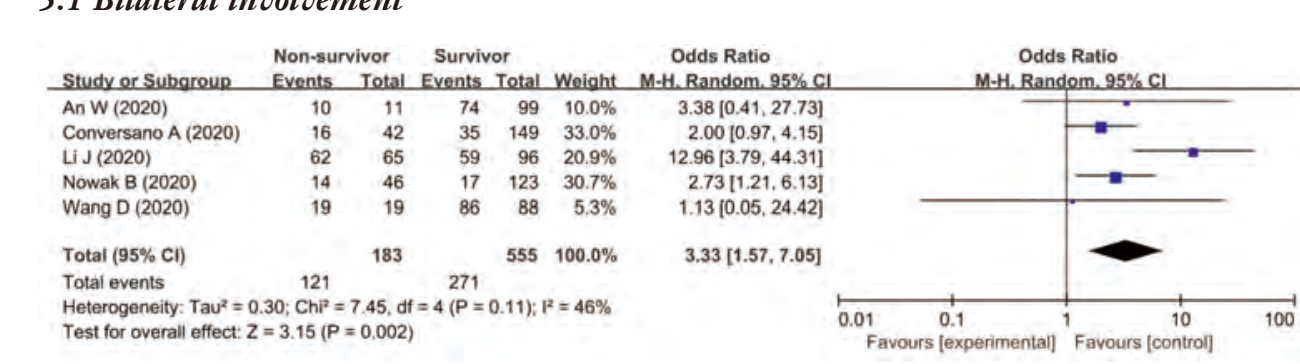

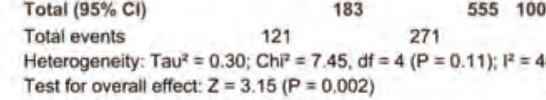

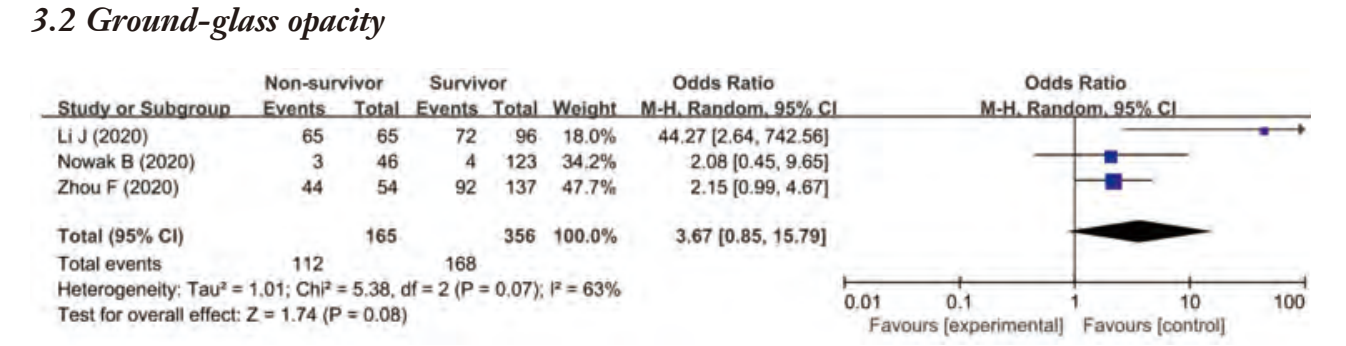

\section{Complication}

4.1 ARDS
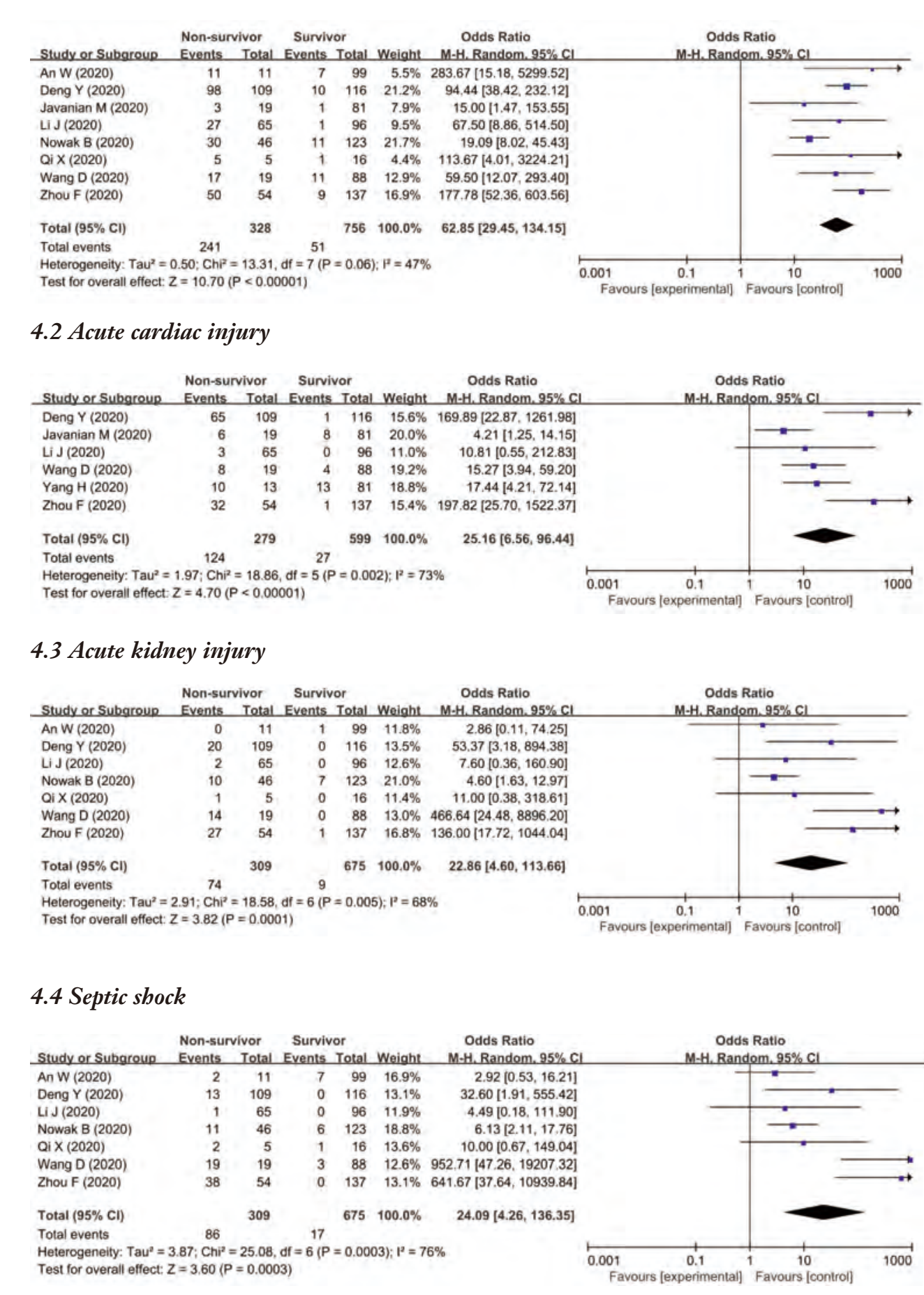